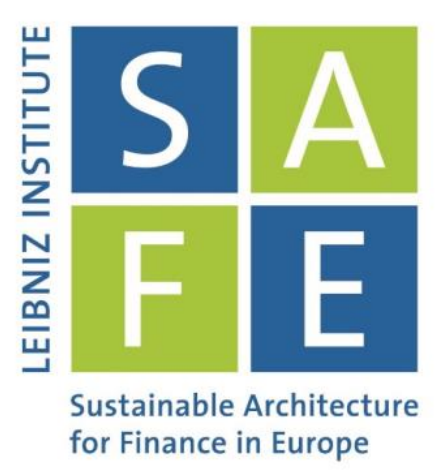

Volker Flögel | Christian Schlag | Claudia Zunft

\title{
Momentum-Managed Equity Factors
}

SAFE Working Paper No. 317

\section{Leibniz Institute for Financial Research SAFE}

\section{Sustainable Architecture for Finance in Europe}

info@safe-frankfurt.de | www.safe-frankfurt.de 


\title{
Momentum-Managed Equity Factors
}

\author{
Volker Flögel $\quad$ Christian Schlag $\quad$ Claudia Zunft周
}

This version: July 18, 2021

ABSTRACT: Managed portfolios that exploit positive first-order autocorrelation in monthly excess returns of equity factor portfolios produce large alphas and gains in Sharpe ratios. We document this finding for factor portfolios formed on the broad market, size, value, momentum, investment, profitability, and volatility. The value-added induced by factor management via short-term momentum is a robust empirical phenomenon that survives transaction costs and carries over to multi-factor portfolios. The novel strategy established in this work compares favorably to well-known timing strategies that employ e.g. factor volatility or factor valuation. For the majority of factors, our strategies appear successful especially in recessions and times of crisis.

KEYWORDS: factor timing, time series momentum, anomalies

JEL-ClASSIFICATION: G12, G17

* Quoniam Asset Management, Westhafen Tower, Westhafenplatz 1, 60327 Frankfurt am Main, Germany, phone: +4969 743840, email: volker.floegel@quoniam.com.

$\dagger$ Goethe University Frankfurt and Leibniz Institute for Financial Research SAFE, Theodor-W.-Adorno-Platz 3, 60323 Frankfurt am Main, Germany, phone: +49 69 79833699, email: schlag@finance.uni-frankfurt.de.

¥ Quoniam Asset Management, Westhafen Tower, Westhafenplatz 1, 60327 Frankfurt am Main, Germany, phone: +49 69 743840, email: claudia.zunft@quoniam.com.

Christian Schlag gratefully acknowledges research support from the Leibniz Institute for Financial Research SAFE. 


\section{Introduction}

The premiums associated with asset pricing anomalies like size, book-to-market equity, and momentum are sizable, persist across decades, and exist in various markets $1^{1}$ However, the remarkable performance of the associated factor portfolios goes along with sudden crashes and long periods of downturns. Examples are the enormous outperformance of large caps in the 1980's the 1990's and the momentum crash in 2009.2 Against the background that the distribution of excess returns of equity factors is strongly timevarying, it appears worthwhile to perform what is called "factor timing", i.e. to hold more of a factor portfolio when its excess return is expected to be high and, vice versa, to scale the factor exposure down when the expected excess return is low.

In this paper, we develop and implement a novel timing strategy for factor portfolios in equity markets. The higher the last-month excess return of the plain factor ${ }^{3}$ relative to past levels, the more the strategy invests in the plain factor, and vice versa. The resulting so-called managed factors outperform their plain counterparts in terms of average excess return and Sharpe ratio. $4^{4}$ The value-added induced by momentum-based timing is pervasive, survives transaction costs, is different from performance enhancements that are generated by traditional timing strategies, and carries over to multi-factor portfolios.

Using monthly data on US stocks from CRSP and Compustat, we calculate the excess

1 Evidence on the cross-sectional link between stock returns and size, book-to-market equity, and momentum is provided by a huge body of literature pioneered by Graham and Dodd (1934), Banz (1981), and Jegadeesh and Titman (1993).

2 Based on the market cap-weighted decile portfolios of US stocks taken from Kenneth R. French's homepage via http://mba.tuck.dartmouth.edu/pages/faculty/ken.french/ftp/Portfolios_Formed_ on_ME_CSV.zip and http://mba.tuck.dartmouth.edu/pages/faculty/ken.french/ftp/10_Portfo lios_Prior_12_2_CSV.zip, in Mar., Apr., and May 2009, the past-loser portfolio returned 155\% while the high-momentum decile delivered 7\% only. Further, from Aug. 1983 to Mar. 1999, large caps rose by $1,340 \%$ whereas small caps returned just $159 \%$.

3 The terms plain factor and managed factor used throughout this work follow Barroso and Santa-Clara (2015b). Plain factors refer to portfolios that exploit an anomaly. An example is a size factor that buys small caps against selling large caps. Managed factors aim to outperform plain factors via exploiting predictive patterns in their returns. An example is a size factor that takes neutral size exposure whenever large caps are predicted to outperform small caps according to a model.

4 Throughout this paper, we calculate the Sharpe ratio as the mean excess return divided by the volatility of excess returns as in Sharpe (1994) rather than using the original definition in Sharpe (1966). 
return of the market $5(\mathrm{MKT})$ as well as excess returns of factors formed on size (SMB), book-to-market equity (HML), momentum (WML), investment (CMA), operating profitability (RMW), and volatility (SMV). For each of these plain factors and at each month end, we compute a so-called timing signal that contains information on the expected next-month excess return of the given plain factor. In particular, we calculate the $z$-score of the last-month excess return of the plain factor, where standardization is performed with respect to an expanding window of past monthly excess returns of this factor. Then, we compute the associated value of the standard normal cumulative distribution function, so that the resulting timing signal approaches one when the last-month excess return of the plain factor is very high relative to past levels and is close to zero when it is relatively low. Making use of the timing signal, a managed factor then systematically scales the excess returns of the respective plain factor up or down over time. Momentum-based scaling yields increases in mean excess returns and Sharpe ratios. In our main sample with monthly rebalancing from July 31,1963 to Nov. 28, 2014, the annualized Sharpe ratios increase from 0.40 to 0.55 for the market factor, from 0.32 to 0.61 for size, from 0.43 to 0.60 for book-to-market equity, from 0.16 to 0.46 for operating profitability, and from 0.12 to 0.33 for volatility $\sqrt{6}$ These increases are significant at the $1 \%$ level in three out of five cases, and at the $5 \%$ level in the other two.

The benefits associated with momentum-based factor timing survive transaction costs, are not driven by excessive leverage, and carry over to multi-factor portfolios. We document the latter finding in a factor timing setup for multi-factor frontier portfolios as well as in a

\footnotetext{
${ }^{5}$ CRSP provides the return of a market index which is obtained as the value-weighted sum of the returns of all stocks in the CRSP universe. Due to minor differences between this set of stocks and the one used in our paper, the market index calculated here differs slightly from the market index provided by CRSP. In our main sample that includes monthly returns for the period from July 31, 1963 to Dec. 28, 2014, the correlation of the returns of the two indices exceeds 0.99 .

${ }^{6}$ Evidence on timing-induced performance improvements for momentum-managed momentum and investment is weak in the US. We find, however, significant increases in the Sharpe ratios of momentum and investment in broader international samples.
} 
factor rotation $]^{7}$ environment for equally weighted multi-factor portfolios. The performance enhancements induced by momentum-based factor management withstand a battery of robustness checks. For example, they exist in various sample periods including recessions as well as in many global developed markets including Europe. Importantly, momentummanaged factors are not spanned by well-known timing strategies that employ, e.g., factor volatility (Moreira and Muir (2017)) or factor valuation (Asness et al. (2017)).

In terms of a more fundamental economic interpretation of our findings, we obtain evidence, via a principal component analysis, in favor of a strong commonality in the excess return differentials between plain and managed factors. The first principal component explains close to $40 \%$ of variance and can be interpreted as a "level factor", since it loads on all factors with the same sign and in comparable magnitude. This principal component shows that all strategies tend to behave in an anticyclical fashion to a certain degree, although there are hardly any significant links to economic variables like investor sentiment, a set of equity factors, a collection of hedge fund factors, or macro factors.

Our paper is related to the literature on factor timing in equity markets $8^{8}$ Most papers investigate the timing ability of a specific predictor for the excess returns of a particular factor. Barroso and Santa-Clara (2015b), e.g., find that volatility of excess returns of momentum negatively predicts the excess return of momentum. A few papers identify variables that successively predict excess returns of various factors simultaneously. In

\footnotetext{
7 Timing of multi-factor portfolios refers to the construction of a plain multi-factor portfolio and the subsequent management of the exposure to that portfolio over time. Timing employs a single forecast for the performance of the plain multi-factor portfolio and does not change the relative weights of the single factors in the multi-factor portfolio compared to the plain portfolio. In contrast, we understand rotation in multi-factor portfolios as the construction of a managed portfolio. Here, we employ multiple forecasts referring to the performance of the single factors in the portfolio in order to alter the relative weights of the single factors. The term factor rotation is inspired by Asness et al. (2017) who refer to a timing strategy that employs multiple forecasts for the performance of various factors as style rotation.

8 Predictive patterns in the excess returns of a factor might be exploited by factor enhancement or factor timing. Factor enhancement refers to a modified construction of a plain factor itself. For example, Jacobs, Regele, and Weber (2015) construct a skewness-enhanced momentum factor via buying negatively-skewed winners against selling positively-skewed losers. In contrast to this, timing refers to the construction of the plain factor and the subsequent management of the exposure to the plain factor over time. For an overview about the literature on factor timing, we refer to Amenc, Coqueret, and Martellini (2015) and Peláez (2015).
} 
this context, Baker and Wurgler (2006) find that investor sentiment predicts excess returns of factors formed on size, age, volatility, profitability, dividends, growth, and distress. Stivers and Sun (2010) document that the cross-sectional dispersion of stock returns predicts excess returns of momentum and value, Asness et al. (2017) report that valuation has forecast power for HML and WML, and Moreira and Muir (2017) find that the volatility of the plain factor has predictive power for the market as well as for value, momentum, profitability, return on equity, investment, and a low-risk factor. Our paper adds to the literature that explores unified timing frameworks by showing that time series momentum pervasively predicts excess returns of equity factors. Even more, as our empirical results show, the predictive ability of past excess returns exceeds the pricing power of the predictors mentioned above.

Our work is also related to two strands within the momentum literature 9 In the literature on time series momentum, the studies by Moskowitz, Ooi, and Pedersen (2012), Baltas and Kosowski (2013), Tse (2015), and Hutchinson and O'Brien (2014) document time series momentum in currency, bond, and commodity markets. The authors also find time series momentum in sector equity ETFs, country equity ETFs, and equity index futures that mirror the performance of the market. Our contribution is to uncover that there is also time series momentum in equity factor portfolios.

Other papers focus on momentum in the cross-section of equity factor portfolios. In the model of Barberis and Shleifer (2003), so-called switchers buy factors that outperformed other factors in the past while selling underperforming factors. Lewellen (2002) and Teo and Woo (2004) provide empirical evidence on momentum and reversal in the cross-section of portfolios formed on size and book-to-market. Using an extensive data set that employs 51 factors, Arnott et al. (2018) find that the cross-section of factor returns is subject to

\footnotetext{
9 There is a huge body of literature documenting the momentum anomaly in the cross-section (exploiting that past winners tend to have higher average returns than past losers) and in the time series dimension (requiring that the past return of an asset is correlated with its future return), for individual assets and for portfolios, and within and across asset classes. For an overview on the momentum literature, we refer to footnote 2 in Barroso and Santa-Clara (2015b), footnote 1 in Daniel and Moskowitz (2016), and Menkhoff et al. (2012).
} 
return continuation and this finding holds for nearly all combinations and in small subsets of the 51 factors. Further evidence in this direction is provided by Avramov et al. (2017). With respect to these papers we extend the scope of the analysis and provide new insights by showing that there is not only cross-sectional but also time series momentum in equity factor portfolios.

The issue we are studying in this paper is currently at the center of an intense debate in the literature. For example, similar to us, Gupta and Kelly (2019) study the characteristics of a timing strategy that scales factor exposures up or down over time depending on the past factor performance, while Ehsani and Linnainmaa (2019) analyze the relation between standard single-stock price momentum (Jegadeesh and Titman (1993)) and a factor portfolio that exploits positive autocorrelations of excess returns of equity factors. Compared to these papers, we show in addition that momentum-based factor management outperforms traditional timing strategies based on factor valuation or volatility (by means of mean excess returns and Sharpe ratios). Further, our results go beyond existing studies by showing that the benefit associated with exploiting positive first-order autocorrelation of monthly excess returns of equity factors improves the performance of multi-factor portfolios employing factor timing (Moreira and Muir (2017)) and factor rotation (Asness et al. (2017)). We also directly compare our strategies to strategies building on time series factor momentum (TSFM) in the spirit of Gupta and Kelly (2019). Here, we find that, for five out of the seven factors considered in our paper, a regression of the excess returns of our strategies on those delivered by the corresponding TSFM strategies, yields a significantly positive intercept, while for the other two factors the intercept is not significant. Thus, the way of implementing factor timing based on past performance matters.

This paper proceeds as follows. Section 2 elaborates on the methodology behind the calculation of the plain and managed factors and presents our main empirical result. In Section 3, we provide more detailed studies on the empirical phenomenon documented in 
this work. In Section 4, we explore potential economic interpretations given that positive first-order autocorrelation can be turned into profits. Within Section 5, which comprises robustness checks, each section is self-contained, i.e. the reader can skip parts easily without loss. Section 6 concludes.

\section{Implementing Momentum Management}

\subsection{Plain Factors}

Motivated by the seminal three-, four-, and five-factor models by Fama and French (1992, 1993, 2015) and Carhart (1997), we consider the market portfolios (MKT) as well as longshort portfolios formed according to size (SMB), book-to-market equity (HML), momentum (WML), investment (CMA), and operating profitability (RMW). Due to the pronounced relevance of the low-risk anomaly, 10 we also examine a portfolio that buys stocks with stable returns against selling volatile equities (SMV). Particularly, the stock characteristic of interest is five-year volatility of the monthly stock returns which is inspired by Baker, Bradley, and Wurgler (2011). The seven factors under study are extremely relevant for practitioners. 11

\footnotetext{
${ }^{10} \mathrm{~A}$ huge literature shows that low-risk equities tend to outperform high-risk stocks. The so-called low-risk anomaly is not only established from an empirical point of view (see Fama and MacBeth (1973), Ang et al. (2006, 2009), Blitz and Vliet (2007), Baker, Bradley, and Wurgler (2011), and Baker and Haugen (2012)), but also supported from a model-based perspective (see Frazzini and Pedersen (2014)).

${ }^{11}$ As documented by a large number of studies including Grinblatt and Titman (1989, 1993), Chan, Chen, and Lakonishok (2002), Frazzini, Kabiller, and Pedersen (2013), and Jordan and Riley (2016), equity investors take substantial exposures to the market, size, value, momentum, quality, and investment, as well as factors formed on absolute risk (stock volatility) or relative risk (market beta of a stock). According to a study conducted by Morningstar, there were 673 strategic-beta exchange-traded products with collective assets under management of approximately USD 396 billion worldwide as of June 30, 2014. The study is restricted to exchange-traded products and, thus, excludes specialized funds. It can be accessed via http://www.morningstar.co.uk/static/UploadManager/Other/MorningstarMa nagerResearch-AGlobalGuidetostrategicBetaExchange-TradedProducts .pdf According to BlackRock, there were USD 1.9 trillion of assets under management in factor-based strategies in 2017. This number can be accessed via https://www.blackrock.com/institutions/en-axj/literature/whit epaper/factor-investing-landscape-2018-axj ·pdf
} 
At each month end and for each of the seven factor portfolios mentioned above, we track the associated one-month excess return given by

$$
f_{t}=r_{t}^{t}-r_{t}^{b}
$$

where $r_{t}^{t}$ and $r_{t}^{b}$ refer to the returns of the so-called top and bottom portfolio for the respective factor.

We now give a brief description of how the factors are constructed. We start with the monthly CRSP file and consider all common equity of US-based companies that is traded on NYSE, AMEX, and NASDAQ. For inclusion in the stock universe at a given month end, we require that a stock has the share price, the number of shares outstanding, and the next-month total return available.

For MKT, $r_{t}^{t}$ is given by the value-weighted return of all stocks, and $r_{t}^{b}$ equals the risk-free rate obtained from Kenneth R. French's homepage ${ }^{12}$ For the other factors, we calculate the respective characteristic for all stocks. The construction of the characteristics follows standard methodologies and is described in detail in Appendices $\mathrm{A}$ and $\mathrm{B}$. We require that at least 150 stocks have the characteristic available. Given this requirement, our basic sample of factors employs excess returns from July 1963 onwards as in numerous related papers including Fama and French $(1992,1993,2015)$. Based on the cross-sectional ranking of the characteristic, we allocate stocks into five portfolios each containing the same number of stocks. The fifth quintile (top portfolio) contains small caps, stocks with high book-to-market equity, low-investment firms, companies with robust profitability, high-momentum equities, or stocks with stable returns. Its value-weighted return is denoted by $r_{t}^{t}$. The first quintile (bottom portfolio) comprises stocks with the opposite characteristics, and $r_{t}^{b}$ is its value-weighted return.

Panel A of Table 1 reports statistics for the plain factors with monthly rebalancing. The

\footnotetext{
12 The data can be accessed via http://mba.tuck. dartmouth.edu/pages/faculty/ken.french/ftp/F-F _Research_Data_Factors_CSV.zip.
} 
seven factors deliver positive mean excess returns ranging between $2.29 \%$ p.a. and $13.34 \%$ p.a. The best-performing portfolio in terms of both mean excess return and Sharpe ratio is the portfolio formed on momentum. On the other hand, its excess returns are considerably negatively skewed and have a standard deviation and maximum 12-month drawdown that is second-largest 14 The worst-performing portfolio on the basis of average excess return is the one formed on operating profitability. ${ }^{15}$ Furthermore, SMV is the factor with both the highest maximum 12-month drawdown and the highest volatility of excess returns. This finding is driven by the bottom portfolio that contains, by construction, the most volatile stocks.

\subsection{Managed Factors}

In the cross-section of single stocks, it is well-documented that the last-month return is negatively related to the return in the upcoming month (Jegadeesh and Titman (1993)). In the cross-section of industry and factor portfolios, however, Moskowitz and Grinblatt (1999) and Arnott et al. (2018) observe strong evidence on the existence of last-month momentum rather than last-month reversal 16 Given that cross-sectional and time series momentum share common components $\sqrt{17}$ there might be time series momentum in the

\footnotetext{
${ }^{13}$ We obtain the maximum 12-month drawdown as the biggest loss in the product of the one-month excess gross returns over a period of one year.

${ }^{14}$ These characteristics of WML are consistent with Barroso and Santa-Clara (2015b) who report an average excess return of $14.46 \%$ p.a., a Sharpe ratio of 0.53 p.a., a skewness of -2.47 , and an excess kurtosis of 18.24 for decile-based WML constructed from US equities in a sample period from 1927 to 2011.

${ }^{15}$ This finding is likewise consistent with the literature. Depending on the construction methodology of US equity portfolios formed on operating profitability, Fama and French (2015) report an average excess return of $1.56 \%$ p.a. to $3.96 \%$ p.a. in a sample period from 1963 to 2013.

${ }^{16}$ Given the overwhelming evidence on stock-level last-month reversal, the portfolio-level last-month momentum is puzzling at first sight. However, short-term reversal of single stocks is consistent with theories of initial overreaction to firm-specific information as documented by Jegadeesh and Titman (1995) but these theories do not carry over to portfolios.

${ }^{17}$ Lewellen (2002) (p. 534) comprehensively explains the three sources of cross-sectional momentum identified by Lo and MacKinlay (1990): "Intuitively, a stock that outperformed other stocks in the past might continue to do so for three reasons: (1) the stock return is positively autocorrelated, so its own past return predicts high future returns; (2) the stock return is negatively correlated with the lagged returns on other stocks, so their poor performance predicts high future returns; and (3) the stock simply has a high unconditional mean [return] relative to other stocks."
} 
last-month returns of factor portfolios alike.

Given our particular interest in factor timing, we consider works on time series momentum. Using data from 1965 to 2009, Moskowitz, Ooi, and Pedersen (2012) document a positive link between last-month and coming-month excess returns of index futures that mirror the performance of developed equity markets. Likewise, Hutchinson and O'Brien (2014) find evidence on continuation of monthly excess returns of equity index futures which is strongest at the first lag and persists in both crisis and noncrisis periods. The study employs 21 equity index futures and an extended sample period reaching back to the early 1920's for some contracts. Next, Tse (2015) investigates monthly returns of sector and country ETFs in equity markets and reports positive excess returns of strategies that exploit their positive first-order autocorrelation. ${ }^{18}$ Against this background, we are motivated to investigate a strategy that relies on continuation of excess returns of plain factors and the formation period is one month.

We define the timing variable

$$
\pi_{t}=f_{t-},
$$

where $f_{t-}$ denotes the excess return of the respective plain factor over the previous month.

Next, consider the timing signal $\Pi_{t}$ with

$$
\Pi_{t}=\Phi\left(\frac{\pi_{t}-\mu\left(\pi_{t}\right)}{\sigma\left(\pi_{t}\right)}\right)
$$

Here, $\pi_{t}$ refers to the timing variable specified in (1), $\Phi(\cdot)$ denotes the standard normal

\footnotetext{
${ }^{18}$ The authors fail to establish statistical significance for most ETFs given the relatively short sample period ranging from the late 1990's to 2014 along with the deterioration of strategy performance in the period after the financial market crisis. Considering various asset classes and formation periods, Hutchinson and O'Brien (2014) document that trend-following strategies deliver a systematic underperformance in an extended period that follows global and regional financial crises.
} 
cumulative distribution function, and $\mu\left(\pi_{t}\right)$ and $\sigma\left(\pi_{t}\right)$ are estimates of the mean and the standard deviation of the timing variable that are calculated from all past data in the sample with equal weights for all past observations. To sum up, we evaluate the cumulative standard normal distribution function at the $z$-score of the timing variable. The resulting timing signal takes a value close to one whenever last month's return is high relative to the history, and approaches zero in the opposite case. In terms of prediction, we suggest in this paper that a high value for the timing signal also predicts high excess returns over the next month, and vice versa.

Finally, we employ a scaling approach as in Barroso and Santa-Clara (2015b), Daniel and Moskowitz (2016), and Moreira and Muir (2017). The one-month excess return of any managed factor then equals the scaled excess return of the respective plain factor. We compute

$$
\widetilde{f}_{t}=\Pi_{t} f_{t} c
$$

where $\Pi_{t}$ is the timing signal from (2), and $\widetilde{f}_{t}$ and $f_{t}$ denote the excess return of the managed and the plain factor with return start date $t$, respectively. The time-invariant parameter $c$ is introduced for the purpose of ex-post position sizing and is set such that the excess returns of any managed factor are exactly as volatile as the excess returns of the corresponding plain factor. Ex-post position sizing facilitates interpretation and is common practice in the literature on factor timing (Barroso and Santa-Clara (2015b)). Importantly, the choice of $c$ leaves Sharpe ratios unaffected and has, thus, no impact on our conclusions. We refer to the product $\Pi_{t} c$ as the exposure of the managed to the plain factor.

Panel B of Table 1 shows descriptive statistics for the managed factors. The managed portfolios deliver positive mean excess returns ranging between $3.91 \%$ p.a. and $13.10 \%$ p.a. For six out of seven managed factors, the mean excess return exceeds the respective 
number for the plain factor. Given that the volatilities of the excess returns are the same for the plain and the corresponding managed factors, Sharpe ratios are also higher for the managed factors in these cases. Furthermore, the managed factors have almost exclusively lower maximum 12-month drawdowns and excess returns with higher skewness values compared to their plain counterparts. Overall, the descriptive statistics suggest that managed factors outperform their plain counterparts in terms of return, risk, and consequently risk-adjusted return.

We now investigate this point more formally. In particular, we are interested in the alpha delivered by a managed factor that is given by

$$
\alpha_{t}=\widetilde{f}_{t}-f_{t}
$$

where $\widetilde{f}_{t}$ and $f_{t}$ denote the excess returns of the managed and the plain factor portfolio, respectively. We compute $p$-values for the null that the average alpha is smaller than or equal to zero. We also check the risk-adjusted performance of the managed and plain factors against each other and calculate $p$-values for the null that the Sharpe ratio of the managed factor is smaller than or equal to the Sharpe ratio of the respective plain factor. Our statistical tests are based on the stationary bootstrap suggested by Politis and Romano (1994) with 10,000 bootstrap samples and a block length parameter of 12.19 We refer to the bootstrapped $p$-values as $\widetilde{p}$ throughout our paper. For robustness, we also compute $p$-values that follow the methodology developed by Newey and West (1987) for the tests on means and $p$-values based on the HAC-approach of Ledoit and Wolf (2008) for the tests on Sharpe ratios. The lag length is computed as in Newey and West (1994) and we label the $p$-values with $\widehat{p}$. Compared to related studies on factor timing, including Barroso and Santa-Clara (2015b) and Asness et al. (2017), our statistical tests are extensive including tests on both mean alphas and Sharpe ratios as well as providing two types of $p$-values.

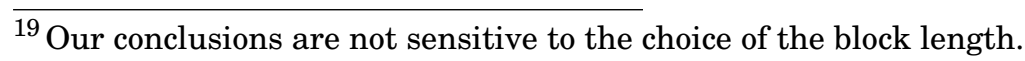


Panel C of Table 1 shows that the mean excess returns and Sharpe ratios grow considerably for five out of seven factors when timing is employed. In particular, the mean alphas for MKT, SMB, HML, RMW, and SMV take values as high as $2.41 \%$ p.a., $5.57 \%$ p.a., $2.23 \%$ p.a., $4.33 \%$ p.a., and $5.52 \%$ p.a., in that order, with $p$-values less than $1 \%$ Annualized Sharpe ratios for MKT, SMB, HML, RMW, and SMV grow by 0.16, 0.29, 0.17, 0.30, and 0.22 in absolute terms, respectively, and the corresponding $p$-values are less than $5 \%$ or even less than $1 \%$ in some cases. They translate into relative gains in Sharpe ratios of $39 \%, 90 \%, 38 \%, 189 \%$, and $185 \%$, in that order. To conclude, momentum management adds value in terms of both increased mean alphas and Sharpe ratios. We investigate this main finding from various angles in Section 3 and conduct a number of robustness checks in Section 5 .

Information on the exposures of managed to plain factors is provided in Panel D of Table 1 . The minimum exposure of each managed factor is basically zero (the numbers are smaller than represented by the format used in the table, so they show up as zeroes). Furthermore, we see that, on average, the exposure of managed to plain factors is around or even less than 1. Exposures are basically not skewed, and means are very similar to medians. With respect to the higher quantiles, we find that across the seven factors the ninth decile of the respective exposure is around 1.5. The maximum exposure ranges from 1.53 for CMA to 2.03 for MKT. We take these properties of the exposures as a first piece of evidence that the performance of our managed factors is not due to excessive leverage, an issue we will discuss in more detail below.

Note that it is essential for our managed factor strategy to exploit the information contained in the excess return of the previous month. Table 2 shows the autocorrelation coefficients for the excess returns on the seven plain factors for orders 1 to 10. Except for CMA, we observe significant coefficients at lag 1 for our plain factor excess returns, while for any other lag order there are at best randomly scattered cases of significant

\footnotetext{
${ }^{20}$ The weak performance of managed CMA and WML is in line with the first-order autocorrelations of the monthly excess returns of plain CMA and WML as discussed below.
} 
autocorrelations. This in turn means that the excess return $n$ months past (with $n>1$ ) does not provide any useful information for the next excess return 21

Figure 1 provides information on the drawdown in the relative performance of the managed compared to the plain factor strategy, i.e., the graphs show the percentage loss from the peak in the quantity $\prod_{t}\left(1+\widetilde{f}_{t}\right) /\left(1+f_{t}\right)$. There are a couple of interesting facts to observe. First, drawdowns are somewhat high in the early 2000s for pretty much all of the strategies. The difference between those managed factors strategies, which ultimately remain successful over the whole sample, and CMA and WML comes to a large part from the later part of the sample. Here, drawdowns remain especially high for those two factors, whereas for the others, drawdowns go down in a substantial fashion during the financial crisis and afterwards. These similarities in the drawdowns across strategies provides a first indication that there might be a common component shared by the excess return differentials between managed and plain strategies across factors. We will discuss this issue in more detail below.

\section{Analyzing Momentum Management in Detail}

\subsection{Transaction Costs}

Managing factors based on last month's momentum increases turnover considerably. In more detail, the average monthly one-way turnover of plain MKT, SMB, HML, WML, CMA, RMW, and SMV amounts to $0.77 \%, 12.66 \%, 9.83 \%, 68.64 \%, 17.87 \%, 7.40 \%$, and $8.51 \%$, in that order, whereas the respective numbers for the managed factors are as high

\footnotetext{
${ }^{21}$ This pattern in autocorrelation coefficients is also exactly mirrored in the performance of managed factor strategies based on excess returns further back than one month. None of the manged factor strategies generates significant improvements over the plain factor when the lag in the computation of the signal is greater than 1.
} 
as $32.96 \%, 54.40 \%, 51.80 \%, 77.78 \%, 52.94 \%, 50.95 \%$, and $46.62 \%$, respectively. ${ }^{22}{ }^{23}$ In this section, we show that the increase in turnover induced by timing does not outweigh the benefits of timing.

Following Moreira and Muir (2017), we consider strategies that implement timing but do so with reduced trading activity. In particular, we replace the timing signal $\Pi_{t}$ in (3) by a smoothed version given by

$$
\bar{\Pi}_{t}=\left\{\begin{array}{ll}
\Pi_{t} & t=0 \\
\phi \Pi_{t}+(1-\phi) \bar{\Pi}_{t-} & \text { otherwise }
\end{array},\right.
$$

where $\phi$ is the half life parameter, and $\bar{\Pi}_{t-}$ denotes the smoothed timing signal calculated one month ago. The benchmark strategy we employ in this paper thus corresponds to the special case $\phi=1$. Alternatively, we consider strategies where the half life of our timing signal $\Pi_{t}$ is one month and three months which implies $\phi=0.5$ and $\phi=0.2063$, respectively. Statistics for these strategies are shown in the middle and right part of Table 3. while the left part presents the results for our benchmark case.

Panel A shows that the turnover of the alternatively managed factors is reduced considerably compared to the benchmark strategy. To give an example, managed HML has an average one-way turnover of $51.80 \%$ each month, which is reduced to $29.26 \%$ or $17.38 \%$ when the half life of the timing signal equals one month and three months, respectively. At the same time, the average alphas as well as the differences in Sharpe ratios before transaction costs remain significantly positive for the turnover-reduced strategies as shown in Panel B. As an example, consider again HML. In the benchmark case, managed HML delivers a gain in Sharpe ratio as high as 0.17 annualized, which is significant at the 5\% level. Turnover-reduced managed HML delivers increases in annualized Sharpe

\footnotetext{
${ }^{22}$ Managed MKT has a time-varying weight in the risk-free asset. Given that the volatility of the returns of the risk-free asset is tiny compared to the respective numbers for the positions taken in stocks, we neglect the transaction costs associated with trading the risk-free asset.

${ }^{23}$ Barroso and Santa-Clara (2015b) comprehensively explain the calculation of turnover of scaled portfolios in their Appendix B. The quantity denoted by $L$ in their paper corresponds to our exposure $\Pi_{t} c$.
} 
ratios of 0.13 and 0.08 , when the half life of the timing signal equals one month and three months, respectively. These gains are significant at the $1 \%$ level. Put differently, even when we employ the smoothed version of the signal, timing still yields significant increases in average excess returns and Sharpe ratios.

Following Grundy and Martin (2001) and Moreira and Muir (2017), we back out the breakeven transaction costs that would result in a mean alpha equal to zero and show results in Panel C of Table $3^{24}$ There, we also detail the implied trading costs that would offset Sharpe ratios of the managed and plain factors. Going one step further, in Panel $\mathrm{D}$ of Table 3 we report the transaction costs that would yield a $p$-value of $10 \%$ for the average alpha induced by timing, an approach inspired by Grundy and Martin (2001) and Barroso and Santa-Clara (2015b). Likewise, we show breakeven transaction costs that would remove the significance of the increases in Sharpe ratios at the level of $10 \%$.

Neglecting CMA and WML (for which we did not find significant timing-induced enhancements in mean alphas and Sharpe ratios in Table 1), the positive average alphas of our benchmark strategy survive as long as trading costs do not exceed values ranging from 21 bps (HML) to 59 bps (SMV), as indicated by the entries in the left part of Panel C of Table 3. The positive average alphas of the corresponding turnover-reduced managed strategies in the right part of Panel $\mathrm{C}$ of Table 3 do not vanish as long as transaction costs are less than 59 bps (HML) or even 136 bps (SMB), with similar results for Sharpe ratios. Turning to the breakeven transaction costs that would remove significance of the positive average alphas at the $10 \%$ level, we find numbers between 9 bps (HML) and 38 bps (SMV) for our benchmark strategy and from 24 bps (RMW) to 83 bps (SMB) for the turnover-reduced strategies in the right part of Panel D of Table 3. Again, we obtain similar numbers for Sharpe ratios. Given these results and considering that papers similar to ours make assumptions about empirically realistic transaction costs ranging between 10 and 50

\footnotetext{
${ }^{24}$ Whenever we compute breakeven transaction costs, we make use of excess returns net of transaction costs for both plain and managed factors. Note that the standard deviations of the excess returns net of transactions costs of the plain and managed factors are not equal anymore because ex-post position sizing is carried out prior to the subtraction of transaction costs from excess returns gross of transaction costs.
} 
bps, ${ }^{25}$ we conclude that the merits associated with momentum-based factor timing survive transaction costs.

\subsection{Momentum Versus Other Timing Signals}

Conceptionally, momentum-based timing is different from other timing strategies established by academics and practitioners. In this section, we confirm empirically that momentum has a different information content than well-known timing signals including the variance of the excess returns of the plain factor (Moreira and Muir (2017)), valuation spreads (Asness et al. (2017)), investor sentiment (Baker and Wurgler (2006)), and return dispersion (Stivers and Sun (2010) and Angelidis, Sakkas, and Tessaromatis (2015)).

Methodologically, we stay within the framework presented above, but replace the timing variable $\pi_{t}$ in (2) by, respectively,

$$
\begin{aligned}
& \pi_{t}^{a}=\frac{1}{\sigma_{t-}^{2}}, \\
& \pi_{t}^{b}=v_{t}^{t}-v_{t}^{b}, \\
& \pi_{t}^{c}= \pm s_{t}, \\
& \pi_{t}^{d}= \pm d_{t},
\end{aligned}
$$

where $\sigma_{t-}^{2}$ denotes the variance of previous month's excess return of the plain factor, measured using daily excess returns ${ }^{26}$ Further, $v_{t}^{t}$ and $v_{t}^{b}$ refer to the time- $t$ valuation of

\footnotetext{
${ }^{25}$ Plyakha, Uppal, and Vilkov (2014) assume that trading costs amount to 50 bps which is based on French (2008). For stocks traded at NYSE, AMEX, and NASDAQ, French (2008) reports that transaction costs decline from $146 \mathrm{bps}$ in 1980 to $11 \mathrm{bps}$ in 2006 and amount to $59 \mathrm{bps}$ in an average year. Jegadeesh (1990) suppose that trading costs are as high as 25 bps. This assumption is inspired by Berkowitz, Logue, and Eugene A. Noser, Jr. (1988) who report trading costs of 23 bps for equities traded at NYSE in the first quarter of 1985. Moreira and Muir (2017) assume costs of $10 \mathrm{bps}$ for trading the market portfolio. They rely on Frazzini, Israel, and Moskowitz (2015) who analyze trading costs for different equity markets from Aug. 1998 to Sept. 2013. For stocks traded on NYSE and NASDAQ, they report costs of 9 and 11 bps, respectively.

${ }^{26}$ Replacing the timing signal $\Pi_{t}$ in $(3)$ with $1 / \sigma_{t-}^{2}$ as in Moreira and Muir (2017) (rather than substituting $1 / \sigma_{t-}^{2}$ for the timing variable $\pi_{t}$ in (2) does not change our conclusions.
} 
the top and bottom portfolio. We measure portfolio valuation based on the cap-weighted book-to-market equity of the stocks in the portfolio ${ }^{27}$ Next, $s_{t}$ is a proxy for investor sentiment which is an updated version of (3) in Baker and Wurgler (2006), obtained from Jeffrey Wurgler's homepage ${ }^{28}$ and given by the first principal component of five standardized sentiment proxies, where each of the proxies has first been orthogonalized with respect to a set of six macroeconomic indicators ${ }^{29}$ The symbol \pm in $(8)$ denotes that we employ different signs for different factors. Baker and Wurgler (2006) (p. 1645) find that, “[...] when beginning-of-period proxies for sentiment are low, subsequent returns are relatively high for small stocks, [...], high volatility stocks, unprofitable stocks, nondividend-paying stocks, extreme growth stocks, [...]." Thus, sentiment enters our timing variable negatively for SMB and positively for the other factors ${ }^{30}$ Finally, $d_{t}$ denotes an estimate of return dispersion that we obtain as follows. Using the cross-section of stock returns, we calculate the market cap-weighted standard deviation of the difference of the stock return and the market return at each month end. At each month end, $d_{t}$ is then given by the average of the three most recent cross-sectional standard deviations, as in Angelidis, Sakkas, and Tessaromatis (2015) and Stivers and Sun (2010). The symbol \pm in (9) denotes a negative sign for WML and MKT and a positive sign for the other factors. Angelidis, Sakkas, and Tessaromatis (2015) (p. 272) discover that “[...] a higher [...] return dispersion is followed by lower market returns, a smaller momentum premium and a higher value premium" and Stivers and Sun (2010) obtain the same relation for WML and HML 31

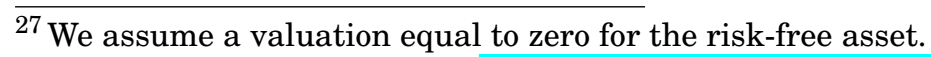

${ }^{28}$ The data can be accessed via http://people.stern.nyu.edu/jwurgler/data/Copy\%20of\%20Investo r_Sentiment_Data_20160331_POST.xlsx.

${ }^{29}$ Jeffrey Wurgler provides another sentiment index where the sentiment proxies are not orthogonalized. Employing that sentiment index does not change our major results.

${ }^{30}$ Baker and Wurgler (2006) do not examine the relation between investor sentiment and CMA and MKT, respectively. Further, they argue that investor sentiment does not have predictive power for WML. No matter whether we hypothesize a positive or negative relation between investor sentiment and the factors just mentioned, our main result is unaltered.

${ }^{31}$ Angelidis, Sakkas, and Tessaromatis (2015) study the relation between dispersion and SMB and obtain mixed results. The authors do not examine the relation between dispersion and CMA, RMW, and SMV, respectively. No matter which sign we employ, correspondingly, our conclusions are unaffected.
} 
Table 4 presents performance statistics for the managed factors mentioned before. Panels $\mathrm{B}$ and $\mathrm{E}$ reveal that the predictors specific to factor risk do a great job in forecasting WML, yielding mean alphas of up to $9.37 \%$ per year and increases in annualized Sharpe ratios of up to 0.40 and the corresponding $p$-values are less than $1 \%$. Altogether, however, variance- and dispersion-based timing as well as valuation- and sentiment-induced factor management deliver significantly positive mean alphas and increases in Sharpe ratios for one to three factors only, respectively, which is largely consistent with the literature on factor timing. 32

We put these findings into the context of the timing strategy established in this paper with results in Panel A of Table 4. For five out of seven factors, momentum-based factor management is superior to existing timing strategies with respect to economic and statistical gains in both average excess returns and Sharpe ratios. In Table 4 , it is striking to see that factor momentum is the only timing variable with predictive power for HML.

We assess the superior forecasting power of factor momentum relative to predictors previously suggested in the literature more formally in Table 5 . Here, we report the difference of the mean excess returns of the momentum-managed and the corresponding variance-, valuation-, sentiment-, or dispersion-managed factors together with $p$-values for the null that the mean excess return of the momentum-managed factor is less than or equal to the mean excess return of the respective other managed factor. The panels show

\footnotetext{
$\overline{32}$ The timing ability of variance for MKT, WML, and SMV is in line with Moreira and Muir (2017) and so is the weak predictive power of variance for SMB and CMA. However, the authors just mentioned report significant merits induced by variance-based timing of RMW and HML, which we cannot confirm in our sample. Asness et al. (2017) report excess returns and Sharpe ratios of valuation-managed HML, WML, and SMV. We find consistency with their enhanced performance metrics for managed HML and WML. For SMV, the authors do not find a value-added induced by timing which contradicts our findings and is possibly due to the different construction of the plain factor. In contrast to our sorting based on five-year volatility, Asness et al. (2017) employ the betting-against-beta factor of Frazzini and Pedersen (2014). Baker and Wurgler (2006) study sentiment-based timing of RMW, SMV, SMB, and HML. For SMB, SMV, and RMW, they report increases in average excess returns induced by timing as we do. Our mean excess returns of sentiment-managed and plain HML are fairly similar, which is likewise consistent with the results of the authors. Furthermore, Angelidis, Sakkas, and Tessaromatis (2015) investigate dispersion-based timing of MKT, HML, SMB, and WML. We confirm their timing-induced performance impact except for HML, which is probably due to the discrepancy of the forecast horizons. The authors report results for yearly excess returns. In contrast, we predict monthly excess returns.
} 
the analogous statistics for Sharpe ratios.

Except for five out of 28 cases, momentum-based timing yields economically larger mean excess returns and Sharpe ratios than conventional timing strategies. Statistical significance of the increased mean excess returns and Sharpe ratios can be established in about half of the cases. We conclude that momentum-based factor management picks up a different empirical phenomenon than well-known timing strategies. In Section 5.4, we establish robustness of this finding in a regression framework.

The reason for the superior performance of the momentum-managed factors relative to existing timing strategies is the substantial informational content of the novel timing signal we propose in this paper. Besides, valuation-based timing suffers from an important drawback outlined by Asness et al. (2017), namely that the alpha associated with valuationmanaged HML has, by construction, a huge and positive time series correlation with the excess returns of the plain HML factor. 33 Put differently, in times of low performance of plain HML, valuation-managed HML performs similarly poorly. The same applies to dispersion- and volatility-managed SMV as well as to all valuation-, dispersion-, and volatility-managed multi-factor portfolios loading on SMV or HML. Coming back to the novel momentum-managed factors we propose in this paper, there is no hard-wired correlation of the timing signal with the stock characteristics employed in the creation of the plain portfolios. If anything, the information about last month's performance enters the construction of the plain and managed factors in opposite directions: A very strong performance of an individual stock over the previous month predicts a belowaverage performance of that stock (which is considered in the construction of WML) as mentioned above, whereas a large observation of the last-month performance of a plain factor forecasts an above-average performance next month.

\footnotetext{
${ }^{33}$ Asness et al. (2017) look into rotation in multi-factor portfolios and find less compelling evidence on the predictive power of valuation. They assign this result to, among others things, the correlation of the timing signal with the informational content of the plain portfolio. Asness et al. (2017) (p. 78) claim that “[...] the greater the correlation of a [...] timing signal to the existing signals in the [plain] portfolio, the harder it is for [...] timing to improve risk-adjusted returns."
} 


\subsection{Multi-Factor Portfolios}

Inspired by Moreira and Muir (2017), we implement timing in multi-factor portfolios as follows. Consider five different sets of plain factors that are included in the models of Fama and French $(1992,1993)$ (FF3), Carhart (1997) (CAR), Fama and French (2015) (FF5), Hou, Xue, and Zhang (2015) (HXZ), or comprise the factors MKT, SMB, HML, CMA, RMW, WML, and SMV (ALL). For each set of plain factors, we construct the portfolio frontier. The vector of mean returns of the plain factors as well as the corresponding covariance matrix are estimated only once from the whole sample such that the weights of the single factors are constant across time, ${ }^{34}$ which follows, e.g., Moreira and Muir (2017) and Della Corte, Ramadorai, and Sarno (2016). We drop all inefficient portfolios and then consider three special portfolios. The first one is the one where the excess return is as volatile as that of the market factor. The second one is the one with the highest Sharpe ratio, and the third one is the one with the smallest variance of excess returns.

Having constructed our 15 plain multi-factor portfolio of interest, we obtain the corresponding managed portfolio via scaling excess returns as usual. Formally, (3) applies, where $f_{t}$ now is the excess return of the respective plain frontier portfolio. Note that the managed portfolios are efficient, since we do not change the relative weights of the single factors in our efficient plain portfolios.

Consider the portfolios in Panel A of Table 6, where the volatility of excess returns is the same as the respective number for MKT. No matter which set of factors is employed, timing yields positive alphas on average and increases in Sharpe ratios. Statistical significance of the performance enhancements can be established for the three portfolios that exclude WML from their factor set. In a similar fashion, timing-induced performance enhancements are generally higher for the plain portfolios with the lowest variance of excess returns in Panel B and plain portfolios with the largest possible Sharpe ratios in

\footnotetext{
${ }^{34}$ Of course, the creation of the plain single-factor portfolios is subject to a monthly rebalancing and out-of-sample, as it is throughout the whole paper.
} 
Panel $\mathrm{C}$ that refrain from taking positions in WML Altogether, when timing is employed, mean excess returns and Sharpe ratios increase for 12 out of 15 portfolios with $p$-values less than $1 \%$ for five portfolios. We conclude that momentum-based timing adds value to frontier portfolios.

We verify the added value of our signals in multi-factor portfolios in the rotation framework of Asness et al. (2017). Here, we construct our plain multi-factor portfolio as a static and equally weighted long-only portfolio of a set of single factors. We then obtain the managed weights as follows: We multiply the plain weights by a factor given by the quantity $g_{t}^{i} \equiv a+b \Pi_{t}^{i}$, where $\Pi_{t}^{i}$ denotes the time- $t$ signal of the $i$-th factor defined in (2). We consider a conservative factor rotation with $a=0.9$ and $b=0.2$ such that $g_{t}^{i} \in(0.9,1.1)$, a moderate implementation of our signal where $a=2 / 3$ and $b=2 / 3$ ( $\operatorname{such}$ that $g_{t}^{i} \in(2 / 3,1+1 / 3)$ ), as well as a case with aggressive factor rotation where $a=0.5$ and $b=1$ ( $\operatorname{such}$ that $g_{t}^{i} \in(0.5,1.5)$ ). We rescale the weights of the factors in the managed portfolio such that they sum up to one and rebalance portfolios at each month end as usual.

Panels D, E, and F of Table 6 report the associated results. 6 For all combinations of factor sets (FF3, CAR, FF5, HXZ, and ALL) and ways of implementation $\left(g_{t}^{i} \in(0.9,1.1)\right.$, $g_{t}^{i} \in(2 / 3,1+1 / 3)$, and $\left.g_{t}^{i} \in(0.5,1.5)\right)$, we find significant increases in average excess returns and Sharpe ratios induced by factor rotation. Even more, we observe $p$-values less than $1 \%$ for gains in mean excess returns and Sharpe ratios of nine managed portfolios. These results clearly demonstrate the power of the new timing signals that we propose in this paper.

Note that the significantly positive mean alphas and significant increases in Sharpe ratios

\footnotetext{
${ }^{35}$ The moderate performance of the managed portfolios that hold WML is in line with the first-order autocorrelations of the respective plain portfolios. As an example, consider the plain portfolio formed from MKT, SMB, and HML with the largest possible Sharpe ratio. Here, timing delivers a mean alpha equal to $2.48 \%$ p.a. together with an increase in Sharpe ratio of 0.27 p.a. with $p$-values less than $1 \%$. The plain portfolio has a first-order autocorrelation coefficient of 0.21. As soon as WML is added to the plain portfolio, the autocorrelation takes a value of 0.12 and timing yields an insignificant change in average excess return and Sharpe ratio.

${ }^{36}$ For the rotation-based strategies, the volatilities of the excess returns of the respective plain and managed factors are not equal anymore.
} 
are not only existent in the less diversified plain portfolios (like FF3) but also in the portfolios with the broader factor sets (like ALL). The strong results for the diversified plain portfolios substantiate the forecasting power of our signals, since timing-induced performance enhancements are, ceteris paribus, particularly hard to achieve in welldiversified portfolios. 37

\section{Economic Interpretation}

\subsection{Commonalities in Performance and Link to Economic Variables}

We had already mentioned above that there is reason to assume a certain commonality among the managed factor portfolios with respect to their outperformance relative to the plain factors. In this section, we are going to explore this matter in more detail and will use the results of our analysis to discuss an economic interpretation of our findings.

As a first step, we simply look at correlations. Panel A of Table 7 shows the correlations between alphas (i.e., excess returns differentials) for all pairs of factors. Then, we perform, for each factor separately, a regression of the excess return of the managed factor on the excess return of the plain factor. Panel B presents the pairwise correlations between the residuals of these regressions.

Looking at the excess return differentials first, we find that, with only two exceptions (WML-SMB and WML-HML), the correlation is positive and almost always highly significant. The same is true for the regression residuals, where the numerical values for

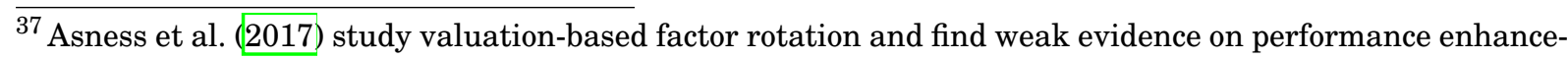
ments in multi-factor portfolios. The authors attribute the weak performance of the valuation-managed portfolios to, among other things, the high degree of diversification in the plain multi-factor portfolios. Asness et al. (2017) (p. 78) claim that "[...] the greater the existing diversification in the [plain] portfolio [...], the harder it is for [...] [factor rotation] to improve risk-adjusted [excess] returns" which is intuitive.
} 
the correlations tend to be even higher with very strong significance throughout. We find correlations of up to almost $60 \%$. Overall, we take this as strong evidence for a common source that drives the alphas of our managed factors as well as the regression residuals.

As a next step, we thus perform a principal components analysis (PCA) to extract this common component. The results are shown in Table $8{ }^{38}$ The first principal component for alphas (returns differentials) and regression residuals explains close to $40 \%$ of variance, and it loads on all the seven strategies positively and in roughly comparable magnitudes. This means that there is a "level factor" that impacts all strategies in a similar way. We thus focus on this first principal component in our further discussion.

Figure 2 shows the cumulative sums of the first principal components of alphas and regression residuals. The main take-away from this figure is that, with respect to the overall level of performance, the strategies do not seem to work well during the dot com bubble around 2000, but they perform very strongly during the financial crisis from around 2008 to 2010 .

Given the results so far, a natural thing to do is to investigate the link of the first principal component to different types of economic variables. We focus here on the return differentials (alphas), since the results for regression residuals are qualitatively very similar. Details on the economic variables are provided in Appendix C.

The results are shown in Table 9. Since it has been popular in the literature on anomalies (see, e.g., Stambaugh, Yu, and Yuan (2012)), we first look at whether investor sentiment has explanatory power for the first principal component. Panel A of Table 9 shows, however, that there is basically no link between the two variables. When we look at the regression with equity factors in Panel B, we find two variables with very strong explanatory power, namely MKT and and SMV, both with a negative sign. This means that the common

\footnotetext{
${ }^{38}$ Given that the input series of the PCA are all measured in the same unit, one can choose to either standardize or simply demean the data before performing a PCA. We report results for the case with standardized data. This choice has no impact on our conclusions.
} 
component in the seven strategy excess returns tends to be high when the excess returns on the market and on the volatility factor are low. The first result is in line with the analysis of the overall performance of the strategies, many of which end to perform well in crisis times ${ }^{39}$ The second result means that our strategies tend to perform well when (holding all other variables fixed) the return on volatile stocks is higher than the one on stable stocks. The regression in Panel C using hedge fund factors as right-hand side variables, on the other hand, does not indicate any link between the level factor in our managed factor alphas and these variables. This indicates to us that the performance of our strategies is not related to any category of risk represented here. A similar conclusion has to be drawn from the results in Panel D, where we use a set of macro factors as regressors. The only significant coefficient is observed for employment (growth), again with a negative sign. This again reflects the notion of a somewhat countercyclical behavior of the strategy returns.

Overall, the conclusion from this exercise is that there is not a whole lot of strong evidence in favor of a risk-based explanation for the performance of our strategies. The main characteristic of the common component is some sort of anticyclical behavior with a good performance when the overall stock market exhibits negative returns. The link to investor sentiment, hedge fund strategies, and macro factors is weak with the exception of a negative link to employment.

\subsection{An Alternative Momentum Strategy}

Our way of setting up the managed factor strategy is, of course, not the only possible one. A potential alternative is a time series momentum strategy in the spirit of Gupta and Kelly (2019), Equation (1), for the case of a one-month formation period ${ }^{40}$ Essentially, this strategy determines the exposure to the plain factor via computing a $z$-score (capped at

\footnotetext{
${ }^{39}$ See also Table 12 in Section 5 below.

${ }^{40} \mathrm{We}$ would like to thank an anonymous referee for suggesting this analysis.
} 
\pm 2 ) for the previous month's excess return of the plain factor. Following Gupta and Kelly (2019), we refrain from carrying out ex-post position sizing and compute the mean and the standard deviation employed in the calculation of the $z$-score over a rolling window of 36 months. We refer to the timing strategy as time series factor momentum (TSFM).

Table 10 shows summary statistics for the plain factors in Panel A (repeated from Panel A in Table 1), statistics on the TSFM strategies in Panel B, and the average alphas of TSFM relative to the corresponding plain factors along with the differences in Sharpe ratios in Panel C.

For RMW and SMV, we find sizeable and significant performance improvements of TSFM relative to the respective plain factors. We also observe that the TSFM strategy has the same problem as ours to generate performance improvements for WML and CMA, but there is also no evidence for additional value in running this type of strategy for MKT, HML, and SMB. This first analysis already provides evidence for the claim that our strategy seems to perform at least as well as the TSFM factors.

We now compare our benchmark strategies directly to the TSFM factors. Table 11 presents the results of two types of regressions with our respective benchmark strategy on the left-hand side. In Panel A, the explanatory variable is just the TSFM strategy, while in Panel B, the regressors are the excess returns on the plain and the TSFM factor. The results in Panel A give strong evidence in favor of our strategies. In five out of seven cases, the intercept is significantly and substantially positive, and for the other two factors (RMW and SMV), the intercept is still positive, albeit not statistically different from zero. This means that there is no factor for which at least this simple regression would indicate a superior performance of the TSFM factor relative to our benchmark strategy.

When we add the plain factor as an explanatory variable on the right-hand side of the regression, we find high $R^{2}$ values together with either insignificant or still positive 
intercepts, except for WML, where the intercept is negative, but only borderline significant. The high $R^{2}$ values mean that our benchmark strategies basically represent linear combinations of the plain and the TSFM factors, which means that, given their mostly superior performance, our strategies somehow seem to combine the advantages of the plain and the TSFM factors.

In addition, we also investigate the turnover as an implicit measure for transaction costs associated with the different types of strategies. The results are shown in Panel $\mathrm{D}$ of Table 10. When comparing the turnover numbers in this panel to those in Table 3 for the case of $\phi=1$, we find that the mean turnover is uniformly and substantially higher for the TSFM strategies than for our benchmark strategies ${ }^{41}$ The average TSFM turnover is in some cases about twice as high as for our strategies, and always at least $40 \%$ higher. This would, obviously, make it even harder for the TSFM strategies to generate a better performance than our benchmark strategies when transaction costs are taken into account.

\section{Robustness Analysis}

\subsection{Sample Period}

We document the robustness of the performance enhancements generated by momentumbased timing across different sample periods ${ }^{42}$ As a simple first check, we split the sample into two parts, Aug. 1963 to Apr. 1989 (309 observations) and May 1989 to Dec. 2014 (308

\footnotetext{
${ }^{41}$ One might wonder how an average one-way portfolio turnover exceeding 100\%, like in Panel D of Table 11 is possible in the first place. Following Barroso and Santa-Clara (2015a), we compute the turnover of the long-short portfolio as the sum of the turnovers of the long and the short leg. Given a maximum one-way turnover of the long leg of $100 \%$ and a maximum one-way turnover of the short leg of $100 \%$, the maximum one-way turnover of the long-short portfolio is $200 \%$.

42 Throughout this section, we do not carry out within-subsample ex-post position sizing such that the volatilities of the excess returns of the managed and correspondent plain factors are not equal anymore within any subsample.
} 
observations). As one can see from Panels A and B of Table 12 , the positive mean alphas and increases in Sharpe ratios induced by timing are statistically significant for four and sometimes even five factors in both subsamples. Thus, the merits of timing are observable universally and are not due to the particular structure of either subsample.

We next investigate the timing ability of momentum along the business cycle. To do so, we split the sample into 83 months that are classified as recession period by NBER and 534 months which are not 43 Panels $\mathrm{C}$ and D of Table 12 show the results. During non-recession periods in Panel C, we obtain positive mean alphas and gains in Sharpe ratios with $p$-values less than $1 \%$ for four factors which substantiates our main result. Turning to recessions, we find simultaneous increases in mean excess returns and Sharpe ratios for six managed factors. Average alphas of these factors are very large, reaching values between $3.75 \%$ (CMA) and $16.41 \%$ (MKT) per year. Increases in annualized Sharpe ratios range from 0.17 (CMA) to 0.79 (MKT) ${ }_{4}^{44}$ The increases in mean excess returns and Sharpe ratios are simultaneously significant for three factors which is a respectable result given that the sample consists of 83 observations only. Overall, the results confirm a certain anticyclical behaviour of the timing alphas as discussed before.

Finally, we no longer employ a common sample period for all seven factors, but instead consider excess returns reaching back as long as possible. For price-based MKT, SMB, WML, and SMV, rebalancing begins in the 20's whereas the samples for CMA, RMW, and HML do not start prior to the 50's or 60's. In five cases, Panel E of Table 12 reports significantly higher mean excess returns and Sharpe ratios for the managed than for the equivalent plain factors. The findings again show that our main result is not driven by the sample period used in our benchmark analysis.

\footnotetext{
${ }^{43}$ The NBER recession dates are available via https://www.nber.org/cycles.html.

${ }^{44}$ The large mean alpha and gain in Sharpe ratio for managed MKT is virtually tautological. According to the recession dating methodology of NBER that can be accessed via https://www.nber.org/cycle $\mathrm{s} / \mathrm{jan} 2003 . \mathrm{html}$, "[a] recession is [defined as] a significant decline in economic activity spread across the economy, lasting more than a few months, normally visible in real GDP, real income, employment, industrial production, and wholesale-retail sales" and these symptoms, ceteris paribus, go along with continuing negative market returns that, in turn, favor momentum-based market timing.
} 


\subsection{Alternative Construction of Plain Factors}

We analyze the performance of the plain and momentum-managed factors when the plain factors are constructed differently than described in Section 2.1. We start with a restricted universe of more liquid stocks. In a first step, we filter out stocks with prices less than USD 1. In a second step, we filter out the smallest stocks up to the point where we drop $10 \%$ of the market equity that remains after the first step. Asness, Moskowitz, and Pedersen (2013) (p. 933) convincingly explain that "[this] universe corresponds to an extremely liquid and tradeable set of securities." Panel A of Table 13 shows the results. Increases in mean excess returns are significant for six out of seven factors. Given that gains in Sharpe ratios are significant for five factors, we conclude that the benefits of momentum-based factor timing are present also in the universe of more liquid stocks, i.e., our results are not generated by latent liquidity premiums.

In our benchmark analysis, we employ all stocks in our universe (which includes equities traded at NYSE, AMEX, and NASDAQ) to determine the break points of the quintile portfolios. Now, we use stocks traded at NYSE exclusively in order to determine the break points which follows Fama and French $(1992,1993,2015)$. Panel B of Table 13 shows that our findings are robust to a variation of the break points of the quintiles.

We employ equally weighted factor portfolios and report results in Panel C of Table 13 . Here, factor timing yields significantly positive mean alphas and significant increases in Sharpe ratios for four factors. Thus, performance enhancements induced by momentumbased timing are robust to a variation of the weighting scheme of the factor portfolios.

Next, we consider double-sorted factors. In particular, we use SMB-orthogonal HML, WML, CMA, RMW, and SMV as well as HML-, CMA-, and RMW-orthogonal SMB from 
Kenneth R. French's homepage 45 Panel D of Table 13 shows that momentum-based factor timing yields significant increases in mean excess returns and Sharpe ratios for the double-sorted portfolios.

For some of the plain factors, there is more or less a consensus about the definition of the stock characteristic used in the sort-based factor construction $\sqrt{66}$ However, the gradual categorization from value to growth stocks might be based on characteristics other than book-to-market equity, like, e.g., earnings yield (EAY), cash flow yield (CFY), or dividend yield (DIY). Similarly, the distinction between stable and volatile stocks might be based on metrics other than the five-year volatility of stock returns, like, e.g., one-month volatility (OMV) as in Ang et al. (2006) or five-year beta (FYB) as in Baker, Bradley, and Wurgler (2011). We redo the computation of the plain and managed factors, employing the five alternative stock characteristics just mentioned when constructing the plain factors. ${ }^{47}$ Panel E of Table 13 documents that factor timing yields positive mean alphas and increases in Sharpe ratios also when alternative sort characteristics are employed, which provides additional evidence on the robustness of the novel timing strategy we propose in this paper.

\subsection{Alternative Construction of Managed Factors}

We investigate the merits associated with momentum-based factor timing when the managed factors are constructed differently than in Section 2.2. When we construct the

\footnotetext{
45 The data can be accessed via http://mba.tuck.dartmouth.edu/pages/faculty/ken.french/ftp/ F-F_Research_Data_5_Factors_2x3_CSV.zip http://mba.tuck.dartmouth.edu/pages/faculty/k en.french/ftp/F-F_Momentum_Factor_CSV.zip, and http://mba.tuck.dartmouth.edu/pages/fac ulty/ken.french/ftp/25_Portfolios_ME_VAR_5x5_CSV.zip. Orthogonal HML, WML, CMA, RMW, and SMB are provided in the files. In contrast, we compute SMB-orthogonal SMV ourselves as the average excess return of two low-variance portfolios constructed from the smallest and the largest stocks minus the average excess return of the two high-variance portfolios constructed from the smallest and largest equities.

${ }^{46}$ Considering SMB as an example, the usual sort criterion is market capitalization (see e.g. Fama and French (1992, 1993)).

${ }^{47}$ Details on the calculation of the five alternative stock characteristics are provided in Appendices $A$ and $B$.
} 
managed factors, we calculate a timing signal given by (2). Remember that, in this context, we compute the $z$-score of the previous month's excess return of the plain factor and that all available past excess return data in the sample is considered to estimate the mean and standard deviation employed in the standardization in (2). We now investigate if our strategy remains profitable when the mean and standard deviation employed in the normalization are estimated from more recent excess returns rather than from all past data in the sample. In particular, we now employ weighted means and standard deviations of the past excess returns of the plain factors in (2), where we make use of an exponential weighting scheme with a half life of 12 months. Panel A of Table 14 documents that the significance of the positive mean alphas and increases in Sharpe ratios induced by timing remains unaffected by this variation. Thus, the timing strategy proposed in this paper produces large alphas and gains in Sharpe ratios, no matter whether the long- or short-term history of excess returns is employed in the calculation of the timing signal.

Then, inspired by Moreira and Muir (2017), we replace the timing variable $\pi_{t}$ employed in (2) with the latest residual of an out-of-sample AR(1) regression of the monthly excess returns of the plain factor. Employing the innovation in the excess return over the previous month rather than the realized excess return itself as the timing variable also yields significantly positive mean alphas and increases in Sharpe ratios, as shown in Panel B of Table 14.

We consider two further alternatives of constructing our managed factors. The first alternative is purely non-parametric. In particular, we use the quantile from the empirical distribution of the timing variable $\pi_{t}$. At each rebalancing date, the timing signal is computed as the quantile from the complete history in the sample up to the given point in time. For example, consider a history of 50 observations of $\pi_{t}$, and the latest observation is the second-largest among those 50. Then the timing signal would take on the value 
$\Pi_{t}=0.98{ }^{48}$ Naturally, the timing signal is again bounded between zero and one, just like in the case of the method we employ in the context of our main analyses. The difference is that the quantile as a pure rank statistic is insensitive to potential outliers and can thus be considered more robust by definition.

The associated performance analysis can be found in Panel $\mathrm{C}$ of Table 14, descriptive statistics on the exposures of managed factors with respect to plain factors are shown in Panel A of Table 15. The main message here is that our results do not appear to be sensitive to our choice of converting the timing variable into the timing signals by computing $z$-scores and mapping those into the unit interval via the standard normal distribution. A comparison with Panels $\mathrm{C}$ and $\mathrm{D}$ in Table 1 shows that both the changes in performance relative to the plain factor and the exposures are very similar for our benchmark case and this alternative approach.

The second variation is to reduce leverage via shrinking the respective timing variable towards the middle of the unit interval by applying the transformation $\widehat{\Pi}_{t}=0.5\left(\Pi_{t}+0.5\right)$. The performance analysis for this approach is presented in Panel D of Table 14, and the corresponding descriptive statistics regarding exposures can be found in Panel B of Table 15 .

The picture here is quite clear. Since the main purpose of this transformation is to curb potentially high leverage (i.e., to make sure that the exposure to the plain factors does not get extreme), the main interest is in the ninth decile and the maximum of the exposure, compared to the benchmark case. Indeed, these higher quantiles of the exposures are now substantially smaller than in the benchmark case, i.e., the transformation achieves its goal with respect to exposures. Regarding the performance, one can see that the strategies still work, since we obtain significant improvements with respect to average excess returns and Sharpe ratios in exactly the same cases as with the benchmark

\footnotetext{
${ }^{48}$ These quantiles are equal to those that would be assigned after centering and standardizing the returns in a given window, i.e., after computing $z$-scores, since we would always subtract the same mean and divide by the same standard deviation.
} 
specification. Quantitatively, however, curbing the exposures comes at the cost of less pronounced increases in average returns and Sharpe ratios.

\subsection{Performance Metrics}

We assess the timing-induced performance improvements by regressing the excess returns of the managed factors on the excess returns of the respective plain factors. Panel A of Table 16 shows the results of these time series regressions. For five factors, we find positive intercepts with $p$-values less than $1 \%$, which verifies our main result.

In Section 3.2, we find that momentum-based timing picks up a different empirical phenomenon than other well-known timing strategies. We verify this finding by regressing the monthly excess returns of momentum-managed factors on monthly excess returns of variance-, valuation-, sentiment-, and dispersion-managed factors. The regression results in Panel B of Table 16 reveal that the intercepts remain significant in five cases. Thus, our momentum-managed factors are largely distinct from other well-known timing strategies.

Goetzmann et al. (2007) explain how widely-used performance metrics (like Sharpe ratios) might be manipulated in order to report an impressive performance. Against this background, the authors propose their so-called manipulation-proof performance measure (MPPM) ${ }^{49}$ In what follows, we calculate MPPMs for the managed and plain factors whereas we set the risk aversion parameter equal to three as in Goetzmann et al.

49 The MPPM is given by

$$
\Theta=\frac{1}{(1-\rho) \Delta t} \ln \left(\frac{1}{T} \sum_{t}\left(\frac{1+r_{t}^{s}}{1+r_{t}^{f}}\right)^{1-\rho}\right)
$$


(2007) and Moreira and Muir (2017).50 The differences in the MPPMs of the managed and correspondent plain factors are shown in Panel $\mathrm{C}$ of Table 16 . For example, finding MPPMs of 662 bps p.a. and 104 bps p.a. for managed and plain SMB, respectively, we report that managed SMB yields an additional risk-adjusted return of 558 bps per year relative to plain SMB. The results show that differences between MPPMs of managed and plain factors are positive for six factors, which provides additional support for our claim that managed factors are superior to their plain counterparts.

\subsection{International Evidence}

We document that momentum-based factor timing yields added value in other developed equity markets than the US. On his homepage, Kenneth R. French provides factor excess returns for the stock universes Asia-Pacific ex Japan, Europe, global, global ex US, Japan, and North America 51 Rebalancing starts on Nov. 30, 1990, and the factors are doublesorted. For our robustness check, we use MKT, SMB-orthogonal HML, WML, CMA, and RMW, as well as HML-, CMA-, and RMW-orthogonal SMB. For the six regions under study, Table 17 shows that momentum-based factor timing yields significant increases in

where $r_{t}^{s}$ denotes the return of the strategy of interest, $r_{t}^{f}$ is the return of the risk-free asset, $T$ is the number of observations, $\Delta t$ is the time between successive observations, and $\rho$ should be chosen to make holding the risk-free asset optimal for an uniformed manager. The MPPM looks like the average of a power utility function calculated over the return history and $\rho$ may be thought of as an investor's degree of relative risk aversion, although the derivation of the MPPM does not require an assumption about utility. Further, the MPPM can be interpreted as an estimate of the return premium of the portfolio after adjusting for risk. For example, consider a strategy with an MPPM of 50 bps annually. This means that the strategy has the same MPPM as the risk-free asset with an additional return of 50 bps per year. In other words, we understand the MPPM as the annualized certainty equivalent of the excess returns of a portfolio.

${ }^{50}$ Goetzmann et al. (2007) (p. 1533) find: "The range of relative risk aversions in the market might be much wider than 2 to 4; however, this range is meant to capture the range of risk aversions that would be relevant for the construction of mutual funds or other well-diversified portfolios. Relative risk aversions of 2 to 4 correspond to portfolios that would range from leveraged positions of 1.5 down to 0.75 . This should encompass most portfolios that would be ranked." Our conclusions are robust to a variation of the relative risk aversion within the range from two to four and beyond.

${ }^{51}$ For our global sample, we consider http://mba.tuck.dartmouth. edu/pages/faculty/ken.french/ft p/Global_5_Factors_CSV.zip and http://mba.tuck.dartmouth.edu/pages/faculty/ken.french/ ftp/Global_Mom_Factor_CSV.zip. For the other five samples, data can be accessed via the same links whereas "Global” needs to be replaced by "Global_ex_US”, "Europe”, “Japan”, "Asia_Pacific_ex_Japan”, and "North_America", respectively. For SMV, international excess returns are not available. 
mean alphas and Sharpe ratios. Results are somewhat weaker for the narrower samples Asia-Pacific ex Japan, Japan, and North America (each comprising in-between one and four countries) and stronger for Europe, global, and global ex US (each containing 16 to 23 countries). In contract to our benchmark strategy (with results in Table 1), we find significant increases in mean alphas and Sharpe ratio for managed WML and CMA in the three most representative regions.

\section{Conclusion}

We identify a new timing strategy which exploits the predictive power of the excess returns of equity factors over the previous month. The positive mean alphas and increases in Sharpe ratios induced by momentum-based timing are substantial and pervasive across factors, survive transaction costs, exist in multi-factor portfolios, and withstand plenty of robustness checks. Momentum-managed factors are not spanned by timing strategies already known from the literature. We also find that our strategies outperform alternative specifications of time series factor momentum strategies.

The managed factors established in this paper are an even greater puzzle than the plain factors, which presents a new challenge to any theory seeking to explain anomalies in equity markets. This is also highlighted by the fact that it is hard to link the outperformance of managed relative to plain factors to economic variables. 


\section{References}

Amenc, Noël, Guillaume Coqueret, and Lionel Martellini, 2015, Active allocation to smart factor indices, Working Paper, EDHEC-Risk Institute.

Ang, Andrew, Robert J. Hodrick, Yuhang Xing, and Xiaoyan Zhang, 2006, The cross-section of volatility and expected returns, Journal of Finance 61, 259-299.

Ang, Andrew, Robert J. Hodrick, Yuhang Xing, and Xiaoyan Zhang, 2009, High idiosyncratic volatility and low returns: International and further U.S. evidence, Journal of Financial Economics 91, 1-23.

Angelidis, Timotheos, Athanasios Sakkas, and Nikolaos Tessaromatis, 2015, Stock market dispersion, the business cycle and expected factor returns, Journal of Banking \& Finance $59,265-279$.

Arnott, Rob, Mark Clements, Vitali Kalesnik, and Juhani Linnainmaa, 2018, Factor momentum, Working Paper, SSRN.

Asness, Clifford S. and Andrea Frazzini, 2013, The devil in HML's details, Journal of Portfolio Management 39, 49-68.

Asness, Clifford S., Tobias J. Moskowitz, and Lasse H. Pedersen, 2013, Value and momentum everywhere, Journal of Finance 68, 929-986.

Asness, Clifford S., Swati Chandra, Antti Ilmanen, and Ronen Israel, 2017, Contrarian factor timing is deceptively difficult, Journal of Portfolio Management 43, 72-87.

Avramov, Doron, Si Cheng, Amnon Schreiber, and Koby Shemer, 2017, Scaling up market anomalies, The Journal of Investing 26, 89-105.

Baker, Malcolm, Brendan Bradley, and Jeffrey Wurgler, 2011, Benchmarks as limits to arbitrage: Understanding the low-volatility anomaly, Financial Analysts Journal 67, $40-54$. 
Baker, Malcolm and Jeffrey Wurgler, 2006, Investor sentiment and the cross-section of stock returns, Journal of Finance 61, 1645-1680.

Baker, Nardin L. and Robert A. Haugen, 2012, Low risk stocks outperform within all observable markets of the world, Working Paper, SSRN.

Baltas, Akindynos-Nikolaos and Robert Kosowski, 2013, Momentum strategies in futures markets and trend-following funds, Working Paper, SSRN.

Banz, Rolf W., 1981, The relationship between returns and market value of common stocks, Journal of Financial Economics 9, 3-18.

Barberis, Nicholas and Andrei Shleifer, 2003, Style investing, Journal of Financial Economics 68, 161-199.

Barroso, Pedro and Pedro Santa-Clara, 2015a, Beyond the carry trade: Optimal currency portfolios, Journal of Financial and Quantitative Analysis 50, 1037-1056.

Barroso, Pedro and Pedro Santa-Clara, 2015b, Momentum has its moments, Journal of Financial Economics 116, 111-120.

Berkowitz, Stephen A., Dennis E. Logue, and Eugene A. Noser, Jr., 1988, The total cost of transactions on the NYSE, Journal of Finance 43, 97-112.

Blitz, David C. and Pim van Vliet, 2007, The volatility effect: Lower risk without lower return, Journal of Portfolio Management 34, 102-113.

Carhart, Mark M., 1997, On persistence in mutual fund performance, Journal of Finance $52,57-82$.

Chan, Louis K. C., Hsiu-Lang Chen, and Josef Lakonishok, 2002, On mutual fund investment styles, Review of Financial Studies 15, 1407-1437.

Daniel, Kent and Tobias J. Moskowitz, 2016, Momentum crashes, Journal of Financial Economics 122, 221-247. 
Davis, James L., Eugene F. Fama, and Kenneth R. French, 2000, Characteristics, covariances, and average returns: 1929 to 1997, Journal of Finance 55, 289-406.

Della Corte, Pasquale, Tarun Ramadorai, and Lucio Sarno, 2016, Volatility risk premia and exchange rate predictability, Journal of Financial Economics 120, 21-40.

Ehsani, Sina and Juhani T. Linnainmaa, 2019, Factor momentum and the momentum factor, Working Paper, SSRN.

Fama, Eugene F. and Kenneth R. French, 1988, Dividend yields and expected stock returns, Journal of Financial Economics 22, 3-25.

Fama, Eugene F. and Kenneth R. French, 1992, The cross-section of expected stock returns, Journal of Finance 47, 427-465.

Fama, Eugene F. and Kenneth R. French, 1993, Common risk factors in the returns on stocks and bonds, Journal of Financial Economics 33, 3-56.

Fama, Eugene F. and Kenneth R. French, 2015, A five-factor asset pricing model, Journal of Financial Economics 116, 1-22.

Fama, Eugene F. and James D. MacBeth, 1973, Risk, return, and equilibrium: Empirical tests, Journal of Political Economy 81, 607-636.

Frazzini, Andrea, Ronen Israel, and Tobias J. Moskowitz, 2015, Trading costs of asset pricing anomalies, Working Paper, SSRN.

Frazzini, Andrea, David Kabiller, and Lasse H. Pedersen, 2013, Buffett's alpha, Working Paper, National Bureau of Economic Research.

Frazzini, Andrea and Lasse H. Pedersen, 2014, Betting against beta, Journal of Financial Economics 111, 1-25.

French, Kenneth R., 2008, Presidential address: The cost of active investing, Journal of Finance 63, 1537-1573. 
Fung, William and David A. Hsieh, 2001, The risk in hedge fund strategies: Theory and evidence from trend followers, Review of Financial Studies 14, 313-341.

Fung, William and David A. Hsieh, 2004, Hedge fund benchmarks: A risk-based approach, Financial Analysts Journal 60, 65-80.

Goetzmann, William, Jonathan Ingersoll, Matthew Spiegel, and Ivo Welch, 2007, Portfolio performance manipulation and manipulation-proof performance measures, Review of Financial Studies 20, 1503-1546.

Graham, Benjamin and David L. Dodd, 1934, Security analysis: Principles and technique, McGraw-Hill Book Company.

Grinblatt, Mark and Sheridan Titman, 1989, Mutual fund performance: An analysis of quarterly portfolio holdings, Journal of Business 62, 393-416.

Grinblatt, Mark and Sheridan Titman, 1993, Performance measurement without benchmarks: An examination of mutual fund returns, Journal of Business 66, 47-68.

Grundy, Bruce D. and J. Spencer Martin, 2001, Understanding the nature of the risks and the source of the rewards to momentum investing, Review of Financial Studies 14, $29-78$.

Gupta, Tarun and Bryan Kelly, 2019, Factor Momentum Everywhere, Journal of Portfolio Management 45, 13-36.

Hou, Kewei, Chen Xue, and Lu Zhang, 2015, Digesting anomalies: An investment approach, Review of Financial Studies 28, 650-705.

Hutchinson, Mark C. and John O'Brien, 2014, Is this time different? Trend-following and financial crises, Journal of Alternative Investments 17, 82-102.

Jacobs, Heiko, Tobias Regele, and Martin Weber, 2015, Expected skewness and momentum, Working Paper, SSRN. 
Jegadeesh, Narasimhan, 1990, Evidence of predictable behavior of security returns, Journal of Finance 45, 881-898.

Jegadeesh, Narasimhan and Sheridan Titman, 1993, Returns to buying winners and selling losers: Implications for stock market efficiency, Journal of Finance 48, 65-91.

Jegadeesh, Narasimhan and Sheridan Titman, 1995, Overreaction, delayed reaction, and contrarian profits, Review of Financial Studies 8, 973-993.

Jordan, Bradford D. and Timothy B. Riley, 2016, Skill and persistence in mutual fund returns: Evidence from a six-factor model, Working Paper, SSRN.

Ledoit, Oliver and Michael Wolf, 2008, Robust performance hypothesis testing with the Sharpe ratio, Journal of Empirical Finance 15, 850-859.

Lewellen, Jonathan, 2002, Momentum and autocorrelation in stock returns, Review of Financial Studies 15, 533-564.

Lo, Andrew W. and A. Craig MacKinlay, 1990, When are contrarian profits due to stock market overreaction?, Review of Financial Studies 3, 175-205.

Menkhoff, Lukas, Lucio Sarno, Maik Schmeling, and Andreas Schrimpf, 2012, Currency momentum strategies, Journal of Financial Economics 106, 660-684.

Moreira, Alan and Tyler Muir, 2017, Volatility-managed portfolios, Journal of Finance 72, $1611-1644$.

Moskowitz, Tobias J. and Mark Grinblatt, 1999, Do industries explain momentum?, Journal of Finance 54, 1249-1290.

Moskowitz, Tobias J., Yao H. Ooi, and Lasse H. Pedersen, 2012, Time series momentum, Journal of Financial Economics 104, 228-250.

Newey, Whitney K. and Kenneth D. West, 1987, A simple, positive semi-definite, heteroskedasticity and autocorrelation consistent covariance matrix, Econometrica 55, 703-708. 
Newey, Whitney K. and Kenneth D. West, 1994, Automatic lag selection in covariance matrix estimation, Review of Economic Studies 61, 631-653.

Peláez, Rolando F., 2015, Market-timing the business cycle, Review of Financial Economics $26,55-64$.

Plyakha, Yuliya, Raman Uppal, and Grigory Vilkov, 2014, Equal or value weighting? Implications for asset-pricing tests, Working Paper, SSRN.

Politis, Dimitris N. and Joseph P. Romano, 1994, The stationary bootstrap, Journal of the American Statistical Association 89, 1303-1313.

Sharpe, William F., 1966, Mutual fund performance, Journal of Business 39, 119-138.

Sharpe, William F., 1994, The Sharpe ratio, Journal of Portfolio Management 21, 49-58.

Stambaugh, Robert F, Jianfeng Yu, and Yu Yuan, 2012, The short of it: Investor sentiment and anomalies, Journal of Financial Economics 104, 288-302.

Stivers, Chris and Licheng Sun, 2010, Cross-sectional return dispersion and time variation in value and momentum premiums, Journal of Financial and Quantitative Analysis 45, $987-1014$.

Teo, Melvyn and Sung-Jun Woo, 2004, Style effects in the cross-section of stock returns, Journal of Financial Economics 74, 367-398.

Tse, Yiuman, 2015, Momentum strategies with stock index exchange-traded funds, North American Journal of Economics and Finance 33, 134-148. 


\section{A Stock Characteristics Based on CRSP Data}

Dividend Yield Following Kenneth R. French's homepage, 52 dividend yield is calculated as total dividends paid over the year that precedes the rebalancing date, divided by price at rebalancing date. We rewrite this expression and calculate the dividend yield using the monthly with-dividend returns (RET) 53 and without-dividend returns (RETX) as in Fama and French (1988). We require that we have return data for seven out of 12 months available and exclude stocks with zero dividends which, both, follows Kenneth R. French's homepage referred to above.

Five-Year Beta We calculate betas via regressing stock returns (RET) minus the riskfree rate, that is taken from Kenneth R. French's homepage referred to above, on MKT which is calculated as described in Section 2.1. Following Baker, Bradley, and Wurgler (2011), we use a rolling window of five years and monthly return observations. We exclude stocks that have less than $50 \%$ of observations of excess returns available.

Five-Year Volatility We estimate the volatility of stock returns (RET). Motivated by the findings of Baker, Bradley, and Wurgler (2011), we use a rolling window of five years and monthly return observations in order to estimate the volatilities. We require that at least $50 \%$ of the return observations are available.

Momentum Following the broad literature pioneered by Jegadeesh and Titman (1993), we consider a momentum factor that is calculated as the geometric average monthly return $(\mathrm{RET})$ in the period from one year prior to the date of rebalancing to one month before

\footnotetext{
${ }^{52}$ In particular, we refer to http://mba.tuck.dartmouth.edu/pages/faculty/ken.french/Data_Libra ry/det_port_form_dp.html.

${ }^{53}$ In Appendices $\mathrm{A}$ and $\mathrm{B}$, the capitalized abbreviations in brackets refer to the respective items in the CRSP and Compustat databases.
} 
rebalancing. We require that at least eight out of 11 return observations are available which follows Daniel and Moskowitz (2016).

One-Month Volatility As in Ang et al. (2006), we use daily stock returns (RET) and employ a rolling window of one month. We require that at least $50 \%$ of the return observations are available.

Size For each security (PERMNO), we multiply the number of shares outstanding (SHROUT) by price (PRC). We sum the resulting market capitalizations on a company level (PERMCO).

\section{B Stock Characteristics Based on Compustat Data}

Framework We use consolidated (CONSOL equal to C) and non-restated (DATAFMT equal to STD) annual financial statement data from Compustat. We exclude observations with missing missing currency codes (CURCD). In order to assign CRSP identifiers to our records in the Compustat database, we employ the linking table from the CRSP/Compustat merged database. The linking table provides the unique CRSP identifier (LPERMNO), the unique Compustat identifier (GVKEY), the first effective date of the link (LINKDT), the last effective date of the link (LINKENDDT), as well as the link type (LINKTYPE). We make use of the link type via excluding links with missing prices (which are used by CRSP/Compustat in order to verify the link), links to securities not being traded at NYSE, AMEX or NASDAQ, as well as duplicate links (LINKTYPE equal to LN, LX, LD). Next, we consider the effective link date range via linking securities from CRSP to companies from Compustat whenever the end date of the respective financial year is within the effective link date range. Having assigned the unique CRSP identifier to the records in the Compustat database, we, next, lag all Compustat data by six months in order to ensure 
that there is no look-ahead bias which follows e.g. Fama and French $([1992,1993)$ and Asness and Frazzini (2013). We are now ready to calculate the Compustat-based stock characteristics of interest at an annual frequency and we carry them forward until the next company-individual lagged annual statements become available, but up to 11 months at most.

Book Equity Book equity is calculated as in Davis, Fama, and French (2000) and given by the stockholders' book equity, minus the book value of preferred stock, and plus deferred taxes and investment tax credit. Stockholders' equity is the value reported by Compustat (SEQ), if it is available. If not, we measure stockholders' equity as common equity (CEQ) plus the par value of preferred stock (PSTK) or total assets (AT) minus total liabilities (LT), in that order. Depending on availability, we use redemption value (PSTKRV), liquidation value (PSTKL), or par value (PSTK), in this order, for the book value of preferred stock. Deferred taxes and investment tax credit (TXDITC) is set to zero if missing.

Market Equity Market equity is price $\left(\mathrm{PRCC}_{F}\right)$ multiplied by number of common shares outstanding (CSHO). If any of these two items is not available, we use market value as reported (MKVALT).

Book-to-Market Equity We calculate the ratio of book equity as described above and market equity as likewise described above. We exclude stocks that have a negative book equity which follows Kenneth R. French's homepage 54

Cash Flow Yield Cash flow yield is defined as cash flow divided by market equity that is calculated as described above. We follow Kenneth R. French's homepage and define cash flow as income before extraordinary items (IB), plus deferred taxes (TXDB)

\footnotetext{
${ }^{54}$ The reader is referred to http://mba.tuck.dartmouth.edu/pages/faculty/ken.french/Data_Libra ry/det_form_btm.html
} 
if available, and plus equity share of depreciation and amortization (DP) 55 The equity share is calculated as a ratio with market equity in the numerator and the denominator is given by the book value of total assets (AT), minus book equity which is computed as described above, and plus market equity calculated as outlined above. We exclude stocks with negative cash flow which follows, again, Kenneth R. French's homepage mentioned before.

Earnings Yield Our calculation of earnings yield follows Kenneth R. French's homepage. ${ }^{56}$ Earnings yield is defined as income before extraordinary items (IB) divided by market equity calculated as described above. We exclude stocks with negative earnings.

Investment Following Fama and French (2015), investment is defined as change in total assets (AT) from the next to last fiscal year end to the last fiscal year end, divided by total assets of the next to last fiscal year end. We require that there is a time span of six to 18 months between last and next to last fiscal year end. We also require that assets at last and next to last fiscal year end are reported in the same currency.

Operating Profitability Adopting the approach of Fama and French (2015), we define operating profitability as annual revenues (REVT), minus costs of goods sold (COGS), minus interest expenses (XINT), minus selling, general, and administrative expenses (XSGA), all divided by book equity that is obtained as illustrated above. Following Kenneth R. French's homepage $\sqrt[57]{ }$ we only require that at least one of the three cost elements is available and exclude stocks with negative book equity.

\footnotetext{
${ }_{55}$ In more detail, we follow http://mba.tuck.dartmouth.edu/pages/faculty/ken.french/Data_Lib rary/det_port_form_cfp.html

${ }^{56}$ Our calculation is based on http://mba.tuck.dartmouth.edu/pages/faculty/ken.french/Data_L ibrary/det_port_form_ep.html.

${ }^{57}$ We refer to http://mba.tuck.dartmouth.edu/pages/faculty/ken.french/Data_Library/det_por t_form_op.html.
} 


\section{Economic Variables}

As the first economic variable, we consider a proxy for investor sentiment which is obtained as decribed in Section 3.2 . Furthermore, we consider equity factors, which are represented by our usual plain factors.

In addition to this, we employ seven hedge fund factors following Fung and Hsieh (2004). These factors have been used for asset pricing tests in various studies (see, e.g., Della Corte, Ramadorai, and Sarno (2016)). Three of the hedge fund factors are given by returns of portfolios. These are portfolios of lookback straddle options on bonds (bond trend), currency pairs (curr trend), and commodities (comm trend). Fung and Hsieh (2001, 2004) show that the portfolios of look back straddle options mimic the returns of trend-following funds. We take the trend-following factors from David A. Hsieh's homepage 58 The next two factors are given by the monthly changes of the yield of 10-year Treasury CMS (bond mkt) and of the yield differential between between Moody's BAA corporate bond index and 10-year Treasury CMS (credit spread). According to Fung and Hsieh (2004), these two factors mimic the returns of fixed-income hedge funds. The data for the factor construction of the two fixed-income factors is taken from the homepage of the Federal Reserve Bank of St. Louis 59 Moreover, the hedge fund factors include the monthly total return of S\&P 500 (mkt) as well as the difference of the monthly total returns of S\&P 500 and Russell 2000 (size). According to Fung and Hsieh (2004), these two factors explain the returns of merger-arbitrage and long-short equity funds. We obtain the data for their construction from S\&P and Russell via Datastream. The seven hedge fund factors are expressed in percent and we obtain monthly observations.

Finally, we check whether the excess returns of our timing strategy are related to US business cycle factors. The variables employed here follow Menkhoff et al. (2012): real personal consumption expenditures (cons), number of total nonfarm employees (emp), ISM

\footnotetext{
58 http://faculty.fuqua.duke.edu/\%7Edah7/DataLibrary/TF-Fac.xls

59 https://fred.stlouisfed.org/series/DGS10, https://fred.stlouisfed.org/series/DBAA
} 
manufacturing index (ism), consumer prices (cpi), money stock M2 (m2), real industry production (ip), real disposable personal income (inc), TED spread (ted), and term spread that is calculated from 10-year Treasury CMS and three-month Treasury CMS (term). The TED spread and the term spread are expressed as absolute monthly changes of percentage yields, while for the other macro variables we take monthly relative percentage changes. The data for the construction of the macro factors are taken from the Federal Reserve Bank of St. Louis 60

\footnotetext{
${ }^{60}$ For real personal consumption expenditures, we consider https://fred.stlouisfed.org/seri es/DPCERL1M225NBEA. For the other series, data can be accessed via the same link whereas "DPCERL1M225NBEA" needs to be replaced by "PAYEMS", "NAPM", "INDPRO", "CPIAUCSL", "M2SL", "DSPIC96", "TEDRATE", and "T10Y3MM", respectively.
} 

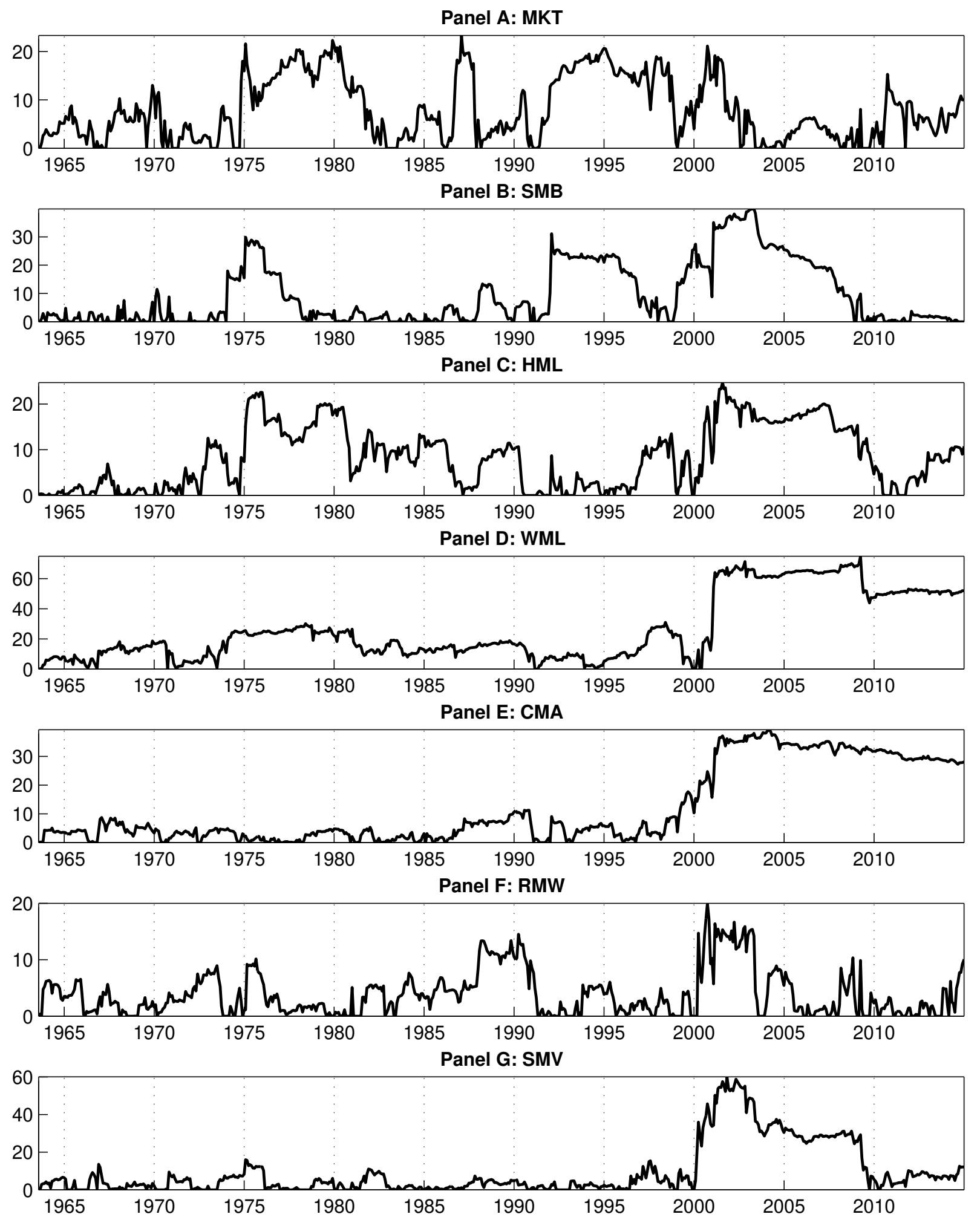

Figure 1: Drawdowns from the Peak over Time. For MKT, SMB, HML, WML, CMA, RMW, and SMV, we plot drawdowns from the peak computed as the percentage loss from the peak in the ratio $\prod_{t}\left(1+\widetilde{f}_{t}\right) /\left(1+f_{t}\right)$, i.e., in the ratio of the cumulative products of the one-month excess gross returns of the managed and respective plain factor. Rebalancing is performed monthly over the sample period from July 31, 1963 to Nov. 28, 2014 (617 observations). 


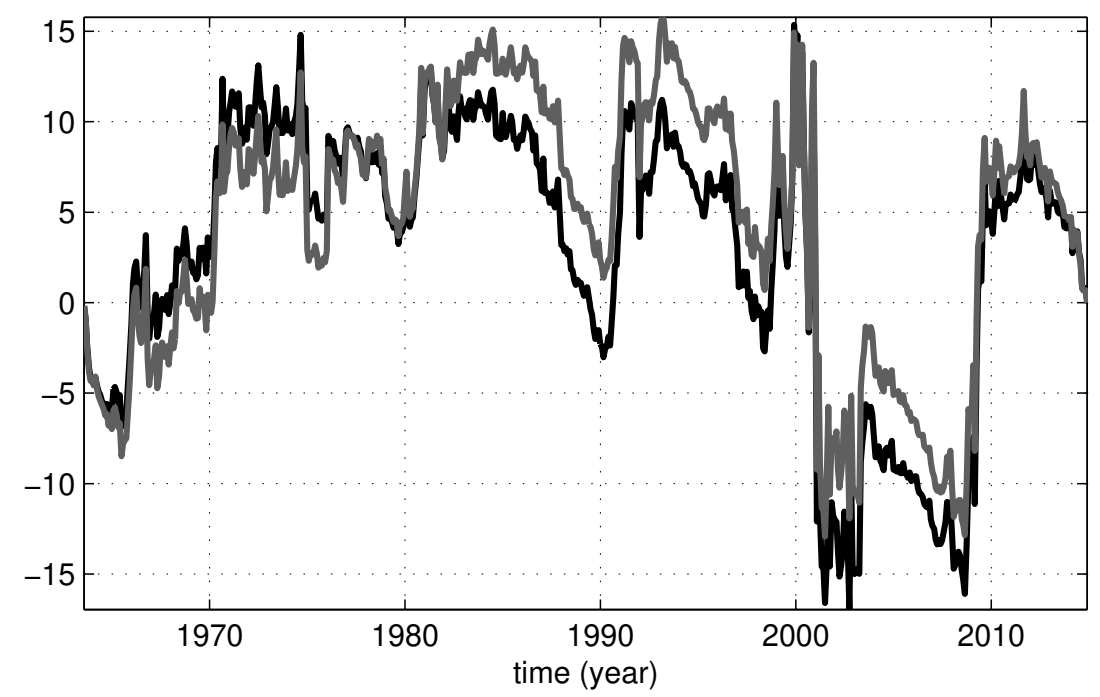

Figure 2: Cumulative Sum of First Principal Components of Alphas and Residuals. The figure shows the cumulative sums of the first principal components of the standardized alphas (defined in (4)) delivered by managed MKT, SMB, HML, WML, CMA, RMW, and SMV (black line) and of the residuals from time-series regressions of the one-month excess returns of managed MKT, SMB, HML, WML, CMA, RMW, and SMV, respectively, on the one-month excess returns of the corresponding plain factors and a constant (gray line). Rebalancing is performed monthly over the sample period from July 31, 1963 to Nov. 28, 2014 (617 observations). 


\begin{tabular}{|c|c|c|c|c|c|c|c|}
\hline & MKT & SMB & HML & WML & CMA & RMW & SMV \\
\hline & \multicolumn{7}{|c|}{$\begin{array}{c}\text { Panel A: } \\
\text { Plain Factors }\end{array}$} \\
\hline mean (\% p.a.) & 6.11 & 6.17 & 5.85 & 13.34 & 3.70 & 2.29 & 2.98 \\
\hline standard deviation (\% p.a.) & 15.45 & 19.37 & 13.46 & 22.86 & 10.52 & 14.41 & 25.68 \\
\hline Sharpe ratio (p.a.) & 0.40 & 0.32 & 0.43 & 0.58 & 0.35 & 0.16 & 0.12 \\
\hline skewness & -0.54 & 1.49 & 0.41 & -1.18 & 0.35 & 0.43 & -0.50 \\
\hline kurtosis & 4.94 & 9.84 & 4.60 & 10.09 & 5.58 & 7.20 & 7.51 \\
\hline \multirow[t]{2}{*}{ maximum 12-month drawdown (\%) } & 45.78 & 39.21 & 31.14 & 66.95 & 24.79 & 42.26 & 79.15 \\
\hline & \multicolumn{7}{|c|}{$\begin{array}{c}\text { Panel B: } \\
\text { Managed Factors }\end{array}$} \\
\hline mean (\% p.a.) & 8.52 & 11.74 & 8.08 & 13.10 & 3.91 & 6.63 & 8.51 \\
\hline standard deviation (\% p.a.) & 15.45 & 19.37 & 13.46 & 22.86 & 10.52 & 14.41 & 25.68 \\
\hline Sharpe ratio (p.a.) & 0.55 & 0.61 & 0.60 & 0.57 & 0.37 & 0.46 & 0.33 \\
\hline skewness & 0.02 & 1.56 & 0.80 & -2.35 & 0.48 & 1.98 & -0.23 \\
\hline kurtosis & 4.33 & 8.62 & 8.31 & 27.45 & 10.45 & 19.24 & 12.75 \\
\hline \multirow[t]{2}{*}{ maximum 12-month drawdown (\%) } & 33.59 & 26.49 & 21.96 & 76.04 & 23.49 & 21.27 & 69.64 \\
\hline & \multicolumn{7}{|c|}{$\begin{array}{c}\text { Panel C: } \\
\text { Managed Versus Plain Factors }\end{array}$} \\
\hline$\Delta$ mean (\% p.a.) & 2.41 & 5.57 & 2.23 & -0.24 & 0.21 & 4.33 & 5.52 \\
\hline$\tilde{p}$ & {$[0.01]$} & {$[0.00]$} & {$[0.01]$} & {$[0.56]$} & {$[0.37]$} & {$[0.00]$} & [0.00] \\
\hline$\widehat{p}$ & [0.03] & {$[0.00]$} & {$[0.02]$} & {$[0.56]$} & [0.39] & {$[0.00]$} & {$[0.00]$} \\
\hline$\Delta$ Sharpe ratio (p.a.) & 0.16 & 0.29 & 0.17 & -0.01 & 0.02 & 0.30 & 0.22 \\
\hline$\tilde{p}$ & [0.02] & {$[0.00]$} & {$[0.02]$} & {$[0.52]$} & [0.39] & {$[0.00]$} & {$[0.00]$} \\
\hline \multirow[t]{2}{*}{$\widehat{p}$} & {$[0.03]$} & {$[0.00]$} & [0.03] & {$[0.54]$} & [0.39] & {$[0.00]$} & {$[0.00]$} \\
\hline & \multicolumn{7}{|c|}{$\begin{array}{l}\text { Panel D: } \\
\text { Exposures }\end{array}$} \\
\hline minimum & 0.00 & 0.01 & 0.00 & 0.00 & 0.00 & 0.00 & 0.00 \\
\hline first decile & 0.18 & 0.25 & 0.16 & 0.12 & 0.20 & 0.11 & 0.18 \\
\hline median & 1.09 & 0.84 & 0.80 & 0.79 & 0.77 & 0.77 & 0.83 \\
\hline ninth decile & 1.82 & 1.70 & 1.50 & 1.36 & 1.36 & 1.45 & 1.39 \\
\hline maximum & 2.03 & 1.90 & 1.64 & 1.54 & 1.53 & 1.54 & 1.55 \\
\hline mean & 1.04 & 0.89 & 0.80 & 0.78 & 0.78 & 0.77 & 0.80 \\
\hline standard deviation & 0.59 & 0.50 & 0.48 & 0.43 & 0.43 & 0.48 & 0.43 \\
\hline skewness & -0.15 & 0.33 & 0.07 & -0.10 & -0.01 & 0.03 & -0.10 \\
\hline kurtosis & 1.84 & 2.20 & 1.91 & 2.04 & 1.94 & 1.72 & 1.99 \\
\hline autocorrelation & 0.05 & 0.25 & 0.17 & 0.11 & 0.09 & 0.21 & 0.19 \\
\hline
\end{tabular}

Table 1: Momentum-Managed Single-Factor Portfolios. We report statistics for managed and plain MKT, SMB, HML, WML, CMA, RMW, and SMV as indicated by columns. Rebalancing is performed monthly over the sample period from July 31, 1963 to Nov. 28, 2014 (617 observations). Panel A refers to excess returns of plain portfolios only and contains information on means, standard deviations, skewness, and kurtosis as indicated by rows. We also report Sharpe ratios and the maximum 12-month drawdowns which we obtain as the biggest loss in the product of the one-month excess gross returns over a period of one year. Panel B contains the same information for the managed portfolios. Panel C shows statistics based on managed and plain portfolios. Particularly, we report the average alpha defined in (4) (in the rows labeled $\Delta$ mean) together with $p$-values for the null that the average alpha is smaller than or equal to zero. Further, Panel C reports the difference of the Sharpe ratios of the managed and plain portfolios (as indicated by rows labeled $\Delta$ Sharpe ratio) together with $p$-values for the null that the Sharpe ratio of the managed portfolio is smaller than or equal to the Sharpe ratio of the plain portfolio. $\widetilde{p}$ refers to tests based on the stationary bootstrap suggested by Politis and Romano (1994) with a block length parameter of 12 and 10,000 samples. $\widehat{p}$ indicates that the tests on means are based on Newey and West (1987) and that the tests on Sharpe ratios are based on the HAC-approach of Ledoit and Wolf (2008). The lag length is computed as in Newey and West (1994). Shaded numbers indicate $p$-values smaller than $10 \%$. Panel D shows descriptive statistics for the exposure $\Pi_{t} c$ of the managed MKT, SMB, HML, WML, CMA, RMW, and SMV factors to the corresponding plain factors (with $\Pi_{t}$ as defined in (2), and $c$ as a constant for the purpose of ex-post position sizing). 


\begin{tabular}{crrrrrrr}
\hline & MKT & SMB & HML & WML & CMA & RMW & SMV \\
\cline { 2 - 8 } order 1 & 0.08 & 0.15 & 0.15 & 0.05 & 0.04 & 0.22 & 0.11 \\
$p$ & {$[0.03]$} & {$[0.00]$} & {$[0.00]$} & {$[0.09]$} & {$[0.16]$} & {$[0.00]$} & {$[0.00]$} \\
order 2 & -0.03 & 0.05 & 0.05 & -0.05 & 0.02 & 0.01 & 0.03 \\
$p$ & {$[0.78]$} & {$[0.10]$} & {$[0.13]$} & {$[0.91]$} & {$[0.28]$} & {$[0.40]$} & {$[0.22]$} \\
order 3 & 0.02 & -0.05 & 0.02 & 0.02 & 0.09 & -0.04 & -0.06 \\
$p$ & {$[0.28]$} & {$[0.88]$} & {$[0.30]$} & {$[0.30]$} & {$[0.01]$} & {$[0.81]$} & {$[0.94]$} \\
order 4 & 0.01 & 0.07 & 0.03 & 0.00 & -0.04 & -0.02 & -0.01 \\
$p$ & {$[0.39]$} & {$[0.03]$} & {$[0.26]$} & {$[0.46]$} & {$[0.82]$} & {$[0.65]$} & {$[0.58]$} \\
order 5 & 0.05 & 0.00 & 0.03 & -0.03 & 0.06 & -0.06 & -0.02 \\
$p$ & {$[0.10]$} & {$[0.50]$} & {$[0.23]$} & {$[0.78]$} & {$[0.05]$} & {$[0.93]$} & {$[0.64]$} \\
order 6 & -0.05 & 0.05 & 0.02 & 0.03 & 0.06 & -0.02 & 0.05 \\
$p$ & {$[0.89]$} & {$[0.12]$} & {$[0.32]$} & {$[0.21]$} & {$[0.07]$} & {$[0.68]$} & {$[0.10]$} \\
order 7 & -0.00 & 0.04 & -0.02 & -0.10 & 0.04 & -0.00 & 0.05 \\
$p$ & {$[0.54]$} & {$[0.17]$} & {$[0.72]$} & {$[0.99]$} & {$[0.14]$} & {$[0.52]$} & {$[0.11]$} \\
order 8 & -0.03 & 0.04 & 0.05 & -0.04 & -0.05 & 0.05 & -0.01 \\
$p$ & {$[0.78]$} & {$[0.16]$} & {$[0.10]$} & {$[0.84]$} & {$[0.91]$} & {$[0.13]$} & {$[0.60]$} \\
order 9 & -0.03 & -0.08 & 0.02 & -0.01 & 0.04 & -0.01 & -0.03 \\
$p$ & {$[0.75]$} & {$[0.98]$} & {$[0.29]$} & {$[0.57]$} & {$[0.17]$} & {$[0.58]$} & {$[0.80]$} \\
order 10 & 0.02 & 0.00 & 0.05 & -0.03 & 0.05 & 0.04 & 0.06 \\
$p$ & {$[0.29]$} & {$[0.48]$} & {$[0.11]$} & {$[0.78]$} & {$[0.09]$} & {$[0.15]$} & {$[0.09]$} \\
\hline$p$ & & & & & & &
\end{tabular}

Table 2: Autocorrelation of Excess Returns of Plain Factors. The table shows the estimated autocorrelation coefficients of excess returns for the plain factors MKT, SMB, HML, WML, CMA, RMW, and SMV for orders 1 to 10 . The numbers in square brackets are $p$-values for the null that the autocorrelation is less than or equal to zero (based on the Student's $t$ distribution). Rebalancing is performed monthly over the sample period from July 31, 1963 to Nov. 28, 2014 (617 observations). Shading indicates $p$-values less than $10 \%$. 


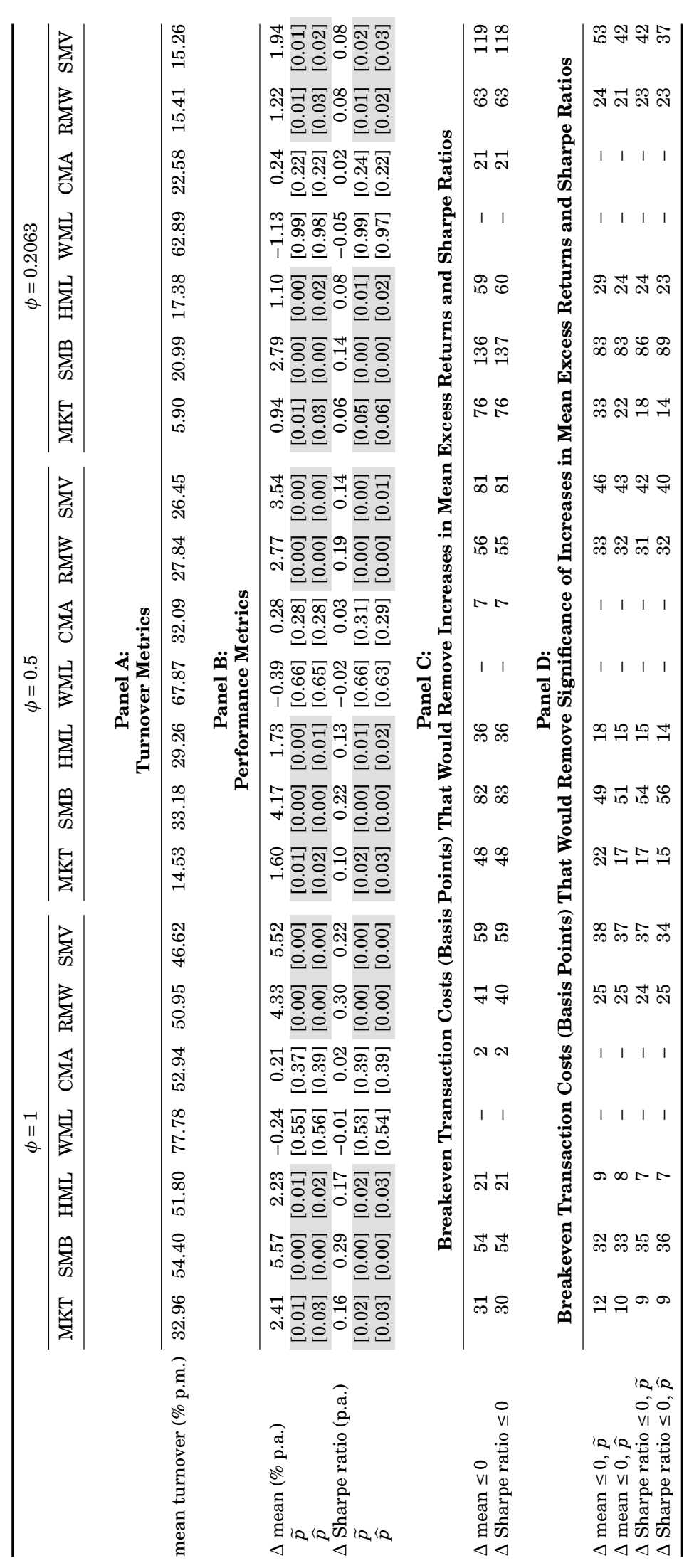

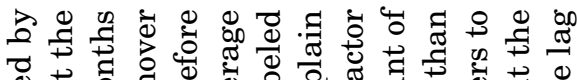

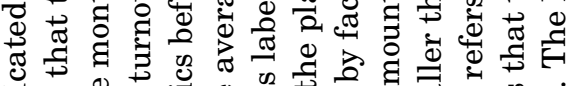

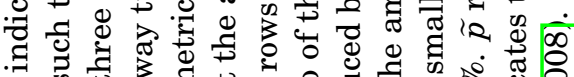
क क

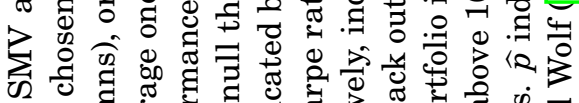
ส.

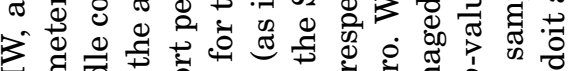

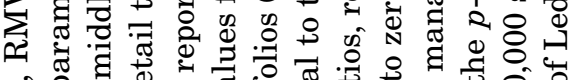
कू व

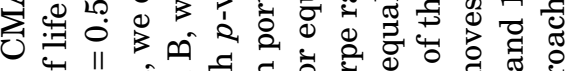

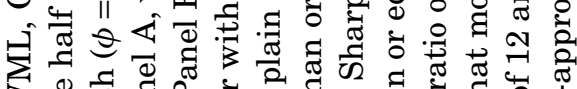

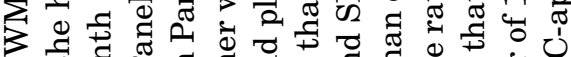

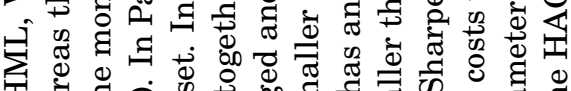

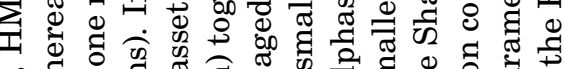

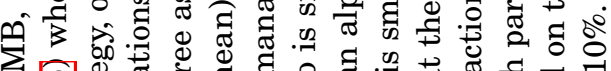

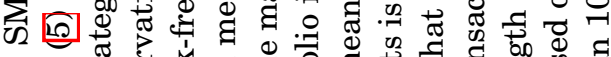

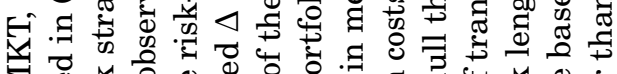

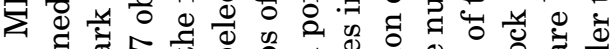

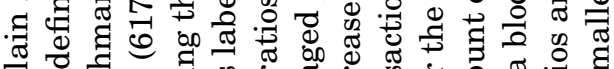
a - 궁 ฮึ के

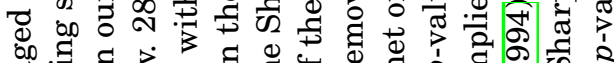

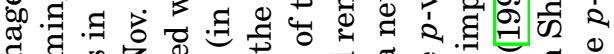

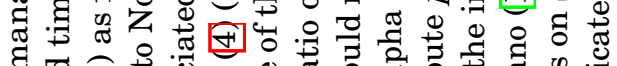
웡

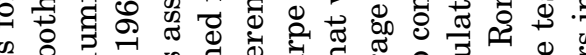

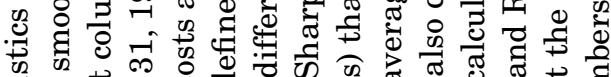

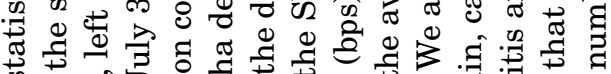

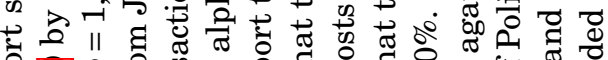

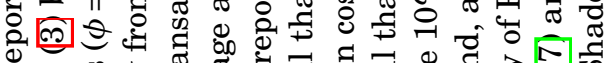

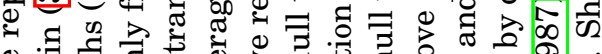

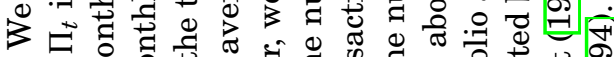

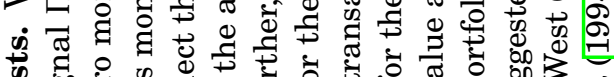
कि. 0 का कू

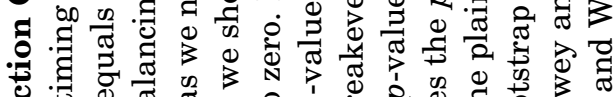

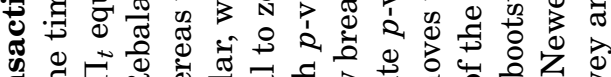

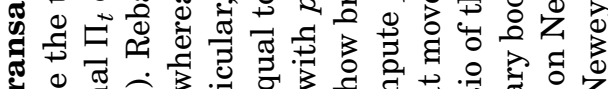
의

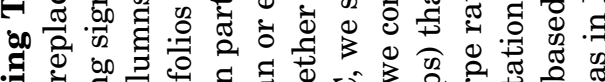

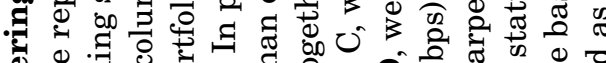

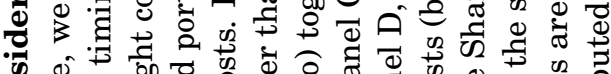
की

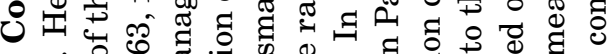
î. w.

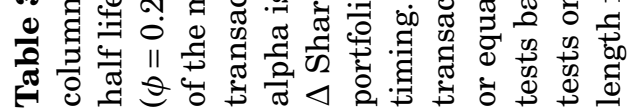




\begin{tabular}{|c|c|c|c|c|c|c|c|c|c|c|c|c|c|c|}
\hline & MKT & SMB & HML & WML & CMA & RMW & SMV & MKT & SMB & HML & WML & CMA & RMW & SMV \\
\hline & \multicolumn{7}{|c|}{$\begin{array}{l}\text { Panel A: } \\
\text { Momentum }\end{array}$} & \multicolumn{7}{|c|}{$\begin{array}{l}\text { Panel B: } \\
\text { Variance }\end{array}$} \\
\hline$\Delta$ mean (\% p.a.) & 2.59 & 5.45 & 2.19 & -0.53 & 0.29 & 4.59 & 5.11 & 1.50 & -3.07 & -0.44 & 9.37 & -0.62 & 1.14 & 3.34 \\
\hline$\tilde{p}$ & {$[0.01]$} & [0.00] & {$[0.01]$} & {$[0.62]$} & {$[0.34]$} & {$[0.00]$} & {$[0.00]$} & {$[0.06]$} & [0.94] & [0.61] & {$[0.00]$} & {$[0.72]$} & {$[0.21]$} & [0.12] \\
\hline$\widehat{p}$ & {$[0.02]$} & {$[0.00]$} & {$[0.02]$} & {$[0.62]$} & {$[0.35]$} & {$[0.00]$} & {$[0.00]$} & {$[0.07]$} & {$[0.96]$} & {$[0.62]$} & {$[0.00]$} & {$[0.73]$} & {$[0.23]$} & [0.09] \\
\hline$\Delta$ Sharpe ratio (p.a.) & 0.16 & 0.28 & 0.16 & -0.02 & 0.03 & 0.31 & 0.20 & 0.10 & -0.16 & -0.03 & 0.40 & -0.06 & 0.08 & 0.13 \\
\hline$\tilde{p}$ & {$[0.02]$} & {$[0.00]$} & {$[0.03]$} & {$[0.57]$} & {$[0.35]$} & {$[0.00]$} & {$[0.00]$} & {$[0.07]$} & {$[0.95]$} & [0.62] & {$[0.00]$} & {$[0.78]$} & {$[0.18]$} & {$[0.11]$} \\
\hline \multirow[t]{2}{*}{$\widehat{p}$} & {$[0.02]$} & {$[0.00]$} & {$[0.03]$} & {$[0.59]$} & {$[0.36]$} & {$[0.00]$} & {$[0.00]$} & {$[0.08]$} & [0.97] & {$[0.63]$} & {$[0.00]$} & {$[0.76]$} & {$[0.22]$} & [0.09] \\
\hline & \multicolumn{7}{|c|}{$\begin{array}{l}\text { Panel C: } \\
\text { Valuation }\end{array}$} & \multicolumn{7}{|c|}{$\begin{array}{c}\text { Panel D: } \\
\text { Investor Sentiment }\end{array}$} \\
\hline$\Delta$ mean $(\%$ p.a. $)$ & -0.30 & 3.43 & 1.22 & 1.18 & 1.50 & 0.24 & 3.60 & -1.36 & 1.19 & -0.09 & 0.16 & -0.72 & 1.24 & 3.35 \\
\hline$\widetilde{p}$ & {$[0.57]$} & {$[0.01]$} & {$[0.15]$} & {$[0.29]$} & {$[0.09]$} & {$[0.35]$} & {$[0.03]$} & {$[0.91]$} & {$[0.30]$} & {$[0.51]$} & {$[0.45]$} & {$[0.77]$} & {$[0.08]$} & {$[0.01]$} \\
\hline$\widehat{p}$ & {$[0.58]$} & {$[0.01]$} & {$[0.13]$} & {$[0.29]$} & {$[0.07]$} & {$[0.35]$} & {$[0.03]$} & {$[0.91]$} & {$[0.27]$} & {$[0.54]$} & {$[0.46]$} & {$[0.83]$} & {$[0.10]$} & {$[0.01]$} \\
\hline$\Delta$ Sharpe ratio (p.a.) & -0.02 & 0.17 & 0.09 & 0.05 & 0.14 & 0.02 & 0.14 & -0.09 & 0.06 & -0.01 & 0.01 & -0.07 & 0.08 & 0.13 \\
\hline$\tilde{p}$ & {$[0.56]$} & {$[0.01]$} & {$[0.13]$} & {$[0.33]$} & {$[0.03]$} & {$[0.35]$} & {$[0.03]$} & {$[0.90]$} & [0.27] & {$[0.55]$} & {$[0.45]$} & {$[0.81]$} & {$[0.06]$} & {$[0.02]$} \\
\hline \multirow[t]{2}{*}{$\widehat{p}$} & {$[0.57]$} & {$[0.01]$} & {$[0.13]$} & {$[0.32]$} & {$[0.04]$} & {$[0.35]$} & {$[0.04]$} & {$[0.90]$} & {$[0.25]$} & {$[0.54]$} & {$[0.47]$} & {$[0.85]$} & {$[0.09]$} & {$[0.01]$} \\
\hline & \multicolumn{7}{|c|}{$\begin{array}{l}\text { Panel E: } \\
\text { Return Dispersion }\end{array}$} & & & & & & & \\
\hline$\Delta$ mean (\% p.a.) & 1.91 & 1.08 & -0.09 & 7.48 & -0.06 & -1.47 & -1.53 & & & & & & & \\
\hline$\tilde{p}$ & [0.10] & {$[0.22]$} & {$[0.54]$} & {$[0.00]$} & [0.53] & {$[0.96]$} & {$[0.87]$} & & & & & & & \\
\hline$\widehat{p}$ & {$[0.11]$} & {$[0.18]$} & {$[0.54]$} & {$[0.00]$} & {$[0.54]$} & {$[0.95]$} & {$[0.88]$} & & & & & & & \\
\hline$\Delta$ Sharpe ratio (p.a.) & 0.12 & 0.05 & -0.01 & 0.32 & -0.01 & -0.10 & -0.06 & & & & & & & \\
\hline$\widetilde{p}$ & {$[0.10]$} & {$[0.20]$} & {$[0.53]$} & {$[0.01]$} & {$[0.52]$} & {$[0.96]$} & {$[0.86]$} & & & & & & & \\
\hline$\widehat{p}$ & {$[0.12]$} & {$[0.17]$} & {$[0.54]$} & {$[0.01]$} & {$[0.54]$} & {$[0.95]$} & {$[0.88]$} & & & & & & & \\
\hline
\end{tabular}

Table 4: Contrasting with Existing Managed Factors I. We report statistics for managed and plain MKT, SMB, HML, WML, CMA, RMW, and SMV as indicated by columns. Panel A refers to momentummanaged portfolios. In Panel B, the timing variable defined in (6) depends on last-month variance of the daily excess returns of the plain factor. In Panel C, the timing variable detailed in (7) is based on valuation spreads whereas in Panel D, we consider a timing variable that hinges on the the first principal component of five standardized sentiment proxies as described in (8). In Panel E, the timing variable given by (9) depends on return dispersion over the last three months. Rebalancing is performed monthly over the sample period from July 30, 1965 to Nov. 28, 2014 (593 observations). The panels report the average alpha defined in (4) (in the rows labeled $\Delta$ mean) together with $p$-values for the null that the average alpha is smaller than or equal to zero. Further, the panels show the difference of the Sharpe ratios of the managed and plain portfolios (as indicated by rows labeled $\Delta$ Sharpe ratio) together with $p$-values for the null that the Sharpe ratio of the managed portfolio is smaller than or equal to the Sharpe ratio of the plain portfolio. $\widetilde{p}$ refers to tests based on the stationary bootstrap suggested by of Politis and Romano (1994) with a block length parameter of 12 and 10,000 samples. $\widehat{p}$ indicates that the tests on means are based on Newey and West (1987) and that the tests on Sharpe ratios are based on the HAC-approach of Ledoit and Wolf (2008). The lag length is computed as in Newey and West (1994). Shaded numbers indicate $p$-values smaller than $10 \%$. 


\begin{tabular}{|c|c|c|c|c|c|c|c|c|c|c|c|c|c|c|}
\hline & MKT & SMB & HML & WML & CMA & RMW & SMV & MKT & SMB & HML & WML & CMA & RMW & SMV \\
\hline & \multicolumn{7}{|c|}{$\begin{array}{l}\text { Panel A: } \\
\text { Variance }\end{array}$} & \multicolumn{7}{|c|}{$\begin{array}{l}\text { Panel B: } \\
\text { Valuation }\end{array}$} \\
\hline$\Delta$ mean (\% p.a.) & 1.09 & 8.53 & 2.63 & -9.90 & 0.91 & 3.46 & 1.77 & 2.89 & 2.03 & 0.97 & -1.70 & -1.21 & 4.35 & 1.51 \\
\hline$\tilde{p}$ & {$[0.21]$} & {$[0.00]$} & {$[0.06]$} & [1.00] & {$[0.21]$} & {$[0.04]$} & {$[0.27]$} & {$[0.05]$} & {$[0.19]$} & {$[0.23]$} & {$[0.75]$} & [0.89] & {$[0.00]$} & {$[0.25]$} \\
\hline$\widehat{p}$ & {$[0.22]$} & {$[0.00]$} & {$[0.06]$} & [1.00] & {$[0.22]$} & {$[0.04]$} & {$[0.25]$} & {$[0.06]$} & {$[0.18]$} & {$[0.21]$} & {$[0.75]$} & {$[0.88]$} & {$[0.00]$} & {$[0.25]$} \\
\hline$\Delta$ Sharpe ratio (p.a.) & 0.07 & 0.43 & 0.19 & -0.43 & 0.09 & 0.24 & 0.07 & 0.18 & 0.10 & 0.07 & -0.07 & -0.11 & 0.30 & 0.06 \\
\hline$\tilde{p}$ & {$[0.17]$} & {$[0.00]$} & {$[0.05]$} & {$[1.00]$} & {$[0.20]$} & {$[0.01]$} & {$[0.25]$} & {$[0.06]$} & {$[0.13]$} & {$[0.22]$} & {$[0.75]$} & [0.88] & {$[0.00]$} & {$[0.24]$} \\
\hline \multirow[t]{2}{*}{$\widehat{p}$} & {$[0.20]$} & {$[0.00]$} & {$[0.05]$} & [1.00] & {$[0.21]$} & [0.02] & {$[0.25]$} & {$[0.06]$} & {$[0.10]$} & {$[0.19]$} & {$[0.76]$} & [0.89] & {$[0.00]$} & {$[0.26]$} \\
\hline & \multicolumn{7}{|c|}{$\begin{array}{c}\text { Panel C: } \\
\text { Investor Sentiment }\end{array}$} & \multicolumn{7}{|c|}{$\begin{array}{l}\text { Panel D: } \\
\text { Return Dispersion }\end{array}$} \\
\hline$\Delta$ mean (\% p.a.) & 3.95 & 4.26 & 2.29 & -0.69 & 1.00 & 3.36 & 1.76 & 0.68 & 4.38 & 2.28 & -8.01 & 0.35 & 6.06 & 6.64 \\
\hline$\widetilde{p}$ & {$[0.00]$} & {$[0.05]$} & {$[0.08]$} & {$[0.63]$} & {$[0.23]$} & {$[0.00]$} & {$[0.17]$} & {$[0.37]$} & {$[0.02]$} & {$[0.05]$} & {$[1.00]$} & {$[0.36]$} & {$[0.00]$} & {$[0.00]$} \\
\hline$\widehat{p}$ & {$[0.01]$} & {$[0.03]$} & {$[0.06]$} & {$[0.64]$} & {$[0.19]$} & {$[0.01]$} & {$[0.16]$} & {$[0.37]$} & {$[0.02]$} & {$[0.05]$} & {$[1.00]$} & {$[0.36]$} & {$[0.00]$} & {$[0.00]$} \\
\hline$\Delta$ Sharpe ratio (p.a.) & 0.25 & 0.22 & 0.17 & -0.03 & 0.09 & 0.23 & 0.07 & 0.04 & 0.22 & 0.17 & -0.34 & 0.03 & 0.41 & 0.25 \\
\hline$\tilde{p}$ & {$[0.01]$} & {$[0.03]$} & {$[0.04]$} & {$[0.67]$} & {$[0.21]$} & {$[0.00]$} & {$[0.16]$} & {$[0.34]$} & {$[0.01]$} & {$[0.03]$} & {$[0.99]$} & {$[0.36]$} & {$[0.00]$} & {$[0.00]$} \\
\hline$\widehat{p}$ & {$[0.01]$} & {$[0.01]$} & {$[0.05]$} & {$[0.65]$} & {$[0.17]$} & [0.01] & {$[0.17]$} & {$[0.36]$} & {$[0.00]$} & {$[0.04]$} & {$[0.98]$} & {$[0.35]$} & {$[0.00]$} & {$[0.00]$} \\
\hline
\end{tabular}

Table 5: Contrasting with Existing Managed Factors II. We report statistics for managed MKT, SMB, HML, WML, CMA, RMW, and SMV as indicated by columns. Panel A considers momentum- and variancemanaged portfolios. The timing variable for the variance-managed portfolios defined in (6) depends on last-month variance of the daily excess returns of the plain factor. Panel B employs momentum- and valuation-managed portfolios. The timing variable for the valuation-managed portfolios defined in (7) is based on valuation spreads. In Panel C, we make use of managed portfolios based on momentum and investor sentiment. The timing variable for investor sentiment given by (8) depends on the first principal component of five standardized sentiment proxies. Panel D considers momentum- and dispersion-managed portfolios. The timing variable for the dispersion-managed portfolios detailed in (9) relies on return dispersion over the last three months. Rebalancing is monthly from July 30, 1965 to Nov. 28, 2014 (593 observations). The panels show the difference of the mean excess returns of the momentum-managed and the variance-, valuation-, sentiment-, or dispersion-managed portfolios (in the rows labeled $\Delta$ mean), respectively, together with $p$-values for the null that the mean excess return of the momentum-managed portfolio is smaller than or equal to the mean excess return of the variance-, valuation-, sentiment, or dispersion-managed portfolio. Further, the panels show the same statistics for Sharpe ratios (as indicated by rows labeled $\Delta$ Sharpe ratio). $\widetilde{p}$ refers to tests based on the stationary bootstrap suggested by of Politis and Romano (1994) with a block length parameter of 12 and 10,000 samples. $\hat{p}$ indicates that the tests on means are based on Newey and West (1987) and that the tests on Sharpe ratios are based on the HAC-approach of Ledoit and Wolf (2008). The lag length is computed as in Newey and West (1994). Shaded numbers indicate $p$-values smaller than $10 \%$. 


\begin{tabular}{|c|c|c|c|c|c|c|c|c|c|c|}
\hline & FF3 & CAR & FF5 & HXZ & ALL & FF3 & CAR & FF5 & HXZ & ALL \\
\hline & \multicolumn{5}{|c|}{$\begin{array}{c}\text { Panel A: } \\
\text { Timing: Market Volatility }\end{array}$} & \multicolumn{5}{|c|}{$\begin{array}{c}\text { Panel B: } \\
\text { Timing: Minimum Variance }\end{array}$} \\
\hline$\Delta$ mean (\% p.a.) & 7.19 & 0.46 & 4.12 & 7.17 & 1.66 & 2.48 & 0.44 & 0.11 & 0.24 & -0.50 \\
\hline$\tilde{p}$ & {$[0.00]$} & {$[0.34]$} & {$[0.00]$} & {$[0.00]$} & {$[0.07]$} & {$[0.00]$} & {$[0.19]$} & {$[0.35]$} & {$[0.21]$} & [0.97] \\
\hline$\widehat{p}$ & {$[0.00]$} & {$[0.34]$} & {$[0.00]$} & {$[0.00]$} & {$[0.08]$} & {$[0.00]$} & {$[0.21]$} & {$[0.36]$} & {$[0.22]$} & {$[0.96]$} \\
\hline$\Delta$ Sharpe ratio (p.a.) & 0.46 & 0.03 & 0.27 & 0.46 & 0.11 & 0.27 & 0.06 & 0.02 & 0.05 & -0.11 \\
\hline$\widetilde{p}$ & {$[0.00]$} & {$[0.35]$} & {$[0.00]$} & {$[0.00]$} & [0.11] & {$[0.00]$} & {$[0.21]$} & {$[0.35]$} & {$[0.22]$} & [0.95] \\
\hline \multirow[t]{2}{*}{$\widehat{p}$} & {$[0.00]$} & {$[0.36]$} & {$[0.00]$} & {$[0.00]$} & {$[0.11]$} & {$[0.00]$} & {$[0.22]$} & {$[0.36]$} & {$[0.21]$} & [0.95] \\
\hline & \multicolumn{5}{|c|}{$\begin{array}{c}\text { Panel C: } \\
\text { Timing: Maximum Sharpe Ratio }\end{array}$} & \multicolumn{5}{|c|}{$\begin{array}{c}\text { Panel D: } \\
\text { Rotatation: } g_{t}^{i} \in(0.9,1.1)\end{array}$} \\
\hline$\Delta$ mean $(\%$ p.a. $)$ & 2.48 & -0.01 & 0.31 & 0.52 & -0.55 & 0.08 & 0.25 & 0.33 & 0.33 & 0.43 \\
\hline$\widetilde{p}$ & {$[0.00]$} & {$[0.50]$} & {$[0.16]$} & {$[0.05]$} & {$[0.96]$} & {$[0.08]$} & {$[0.01]$} & {$[0.00]$} & {$[0.00]$} & [0.00] \\
\hline$\widehat{p}$ & {$[0.00]$} & {$[0.51]$} & {$[0.17]$} & {$[0.05]$} & {$[0.95]$} & {$[0.09]$} & {$[0.00]$} & {$[0.00]$} & {$[0.00]$} & {$[0.00]$} \\
\hline$\Delta$ Sharpe ratio (p.a.) & 0.27 & -0.00 & 0.06 & 0.10 & -0.12 & 0.01 & 0.04 & 0.06 & 0.06 & 0.06 \\
\hline$\tilde{p}$ & {$[0.00]$} & {$[0.51]$} & {$[0.16]$} & {$[0.04]$} & [0.93] & {$[0.00]$} & {$[0.00]$} & {$[0.00]$} & {$[0.00]$} & [0.00] \\
\hline \multirow[t]{2}{*}{$\widehat{p}$} & {$[0.00]$} & {$[0.51]$} & {$[0.17]$} & {$[0.04]$} & {$[0.93]$} & {$[0.01]$} & {$[0.00]$} & {$[0.00]$} & {$[0.00]$} & {$[0.00]$} \\
\hline & \multicolumn{5}{|c|}{$\begin{array}{c}\text { Panel E: } \\
\text { Rotatation: } g_{t}^{i} \in(2 / 3,1+1 / 3)\end{array}$} & \multicolumn{5}{|c|}{$\begin{array}{c}\text { Panel F: } \\
\text { Rotatation: } g_{t}^{i} \in(0.5,1.5)\end{array}$} \\
\hline$\Delta$ mean (\% p.a.) & 0.27 & 0.82 & 1.07 & 1.06 & 1.38 & 0.40 & 1.26 & 1.60 & 1.58 & 2.08 \\
\hline$\tilde{p}$ & {$[0.08]$} & {$[0.00]$} & {$[0.00]$} & {$[0.00]$} & {$[0.00]$} & [0.09] & {$[0.00]$} & {$[0.00]$} & {$[0.00]$} & [0.00] \\
\hline$\widehat{p}$ & {$[0.10]$} & {$[0.00]$} & {$[0.00]$} & {$[0.00]$} & {$[0.00]$} & {$[0.10]$} & {$[0.00]$} & {$[0.00]$} & {$[0.00]$} & {$[0.00]$} \\
\hline$\Delta$ Sharpe ratio (p.a.) & 0.04 & 0.09 & 0.18 & 0.16 & 0.13 & 0.05 & 0.11 & 0.23 & 0.22 & 0.15 \\
\hline$\tilde{p}$ & [0.01] & {$[0.02]$} & {$[0.00]$} & {$[0.00]$} & {$[0.01]$} & {$[0.02]$} & {$[0.05]$} & {$[0.00]$} & {$[0.00]$} & [0.03] \\
\hline$\widehat{p}$ & {$[0.02]$} & {$[0.01]$} & {$[0.00]$} & {$[0.00]$} & {$[0.02]$} & {$[0.04]$} & {$[0.04]$} & {$[0.00]$} & {$[0.00]$} & {$[0.04]$} \\
\hline
\end{tabular}

Table 6: Momentum-Managed Multi-Factor Portfolios. We report statistics for momentum-managed and plain multi-factor portfolios. The available factors are the ones that are included in the models of Fama and French (1992, 1993) (FF3), Carhart (1997) (CAR), Fama and French (2015) (FF5), Hou, Xue, and Zhang (2015) (HXZ), or comprise the factors MKT, SMB, HML, CMA, RMW, WML, and SMV (ALL) as indicated by columns. In Panels A, B, and C, we employ the timing framework of Moreira and Muir (2017). The plain portfolio is a static frontier portfolio. Its excess returns are either equally volatile as the ones of the market portfolio as in Panel A, or exhibit minimum variance as in Panel B, or the plain portfolio has the maximum Sharpe ratio as in Panel C. The managed portfolio is obtained via scaling. Formally, (3) applies where $f_{t}$ is the excess return of the plain portfolio. In Panels $\mathrm{D}, \mathrm{E}$, and $\mathrm{F}$, we employ the rotation framework of Asness et al. (2017) and construct the plain portfolio as a static and equally weighted long-only portfolio of a set of single factors. In order to calculate the managed portfolios, we multiply the plain weights by a factor $g_{t}^{i}$ that depends on the timing signal $\Pi_{t}^{i}$ such that $g_{t}^{i} \in(0.9,1.1)$ in Panel $\mathrm{D}, g_{t}^{i} \in(2 / 3,1+1 / 3)$ in Panel E, and $g_{t}^{i} \in(0.5,1.5)$ in Panel F. Finally, we rescale the managed weights such that they sum up to 1. Rebalancing is performed monthly over the sample period from July 31, 1963 to Nov. 28, 2014 (617 observations). The panels report the average alpha defined in (4) (in the rows labeled $\Delta$ mean) together with $p$-values for the null that the average alpha is smaller than or equal to zero. Further, the panels show the difference of the Sharpe ratios of the managed and plain portfolios (as indicated by rows labeled $\Delta$ Sharpe ratio) together with $p$-values for the null that the Sharpe ratio of the managed portfolio is smaller than or equal to the Sharpe ratio of the plain portfolio. $\widetilde{p}$ refers to tests based on the stationary bootstrap suggested by Politis and Romano (1994) with a block length parameter of 12 and 10,000 samples. $\hat{p}$ indicates that the tests on means are based on Newey and West (1987) and that the tests on Sharpe ratios are based on the HAC-approach of Ledoit and Wolf (2008). The lag length is computed as in Newey and West (1994). Shaded numbers indicate $p$-values smaller than $10 \%$. 


\begin{tabular}{|c|c|c|c|c|c|c|c|c|c|c|c|c|}
\hline & SMB & HML & WML & CMA & RMW & SMV & SMB & HML & WML & CMA & RMW & SMV \\
\hline & \multicolumn{6}{|c|}{$\begin{array}{c}\text { Panel A: } \\
\text { Alphas }\end{array}$} & \multicolumn{6}{|c|}{$\begin{array}{l}\text { Panel B: } \\
\text { Residuals }\end{array}$} \\
\hline MKT & 0.15 & 0.22 & 0.16 & 0.20 & 0.14 & 0.06 & 0.10 & 0.20 & 0.32 & 0.24 & 0.12 & 0.38 \\
\hline$p$ & {$[0.00]$} & {$[0.00]$} & {$[0.00]$} & {$[0.00]$} & {$[0.00]$} & [0.08] & [0.01] & {$[0.00]$} & {$[0.00]$} & {$[0.00]$} & {$[0.00]$} & {$[0.00]$} \\
\hline SMB & & 0.30 & 0.04 & 0.25 & 0.20 & 0.07 & & 0.17 & 0.28 & 0.19 & 0.13 & 0.17 \\
\hline$p$ & & {$[0.00]$} & {$[0.14]$} & {$[0.00]$} & {$[0.00]$} & {$[0.04]$} & & {$[0.00]$} & {$[0.00]$} & {$[0.00]$} & {$[0.00]$} & {$[0.00]$} \\
\hline HML & & & 0.02 & 0.43 & 0.11 & 0.16 & & & 0.18 & 0.49 & 0.25 & 0.31 \\
\hline$p$ & & & {$[0.27]$} & {$[0.00]$} & {$[0.00]$} & {$[0.00]$} & & & {$[0.00]$} & {$[0.00]$} & {$[0.00]$} & {$[0.00]$} \\
\hline WML & & & & 0.24 & 0.30 & 0.25 & & & & 0.33 & 0.34 & 0.59 \\
\hline$p$ & & & & {$[0.00]$} & {$[0.00]$} & {$[0.00]$} & & & & [0.00] & [0.00] & {$[0.00]$} \\
\hline CMA & & & & & 0.17 & 0.20 & & & & & 0.14 & 0.43 \\
\hline$p$ & & & & & {$[0.00]$} & {$[0.00]$} & & & & & {$[0.00]$} & {$[0.00]$} \\
\hline RMW & & & & & & 0.41 & & & & & & 0.34 \\
\hline$p$ & & & & & & {$[0.00]$} & & & & & & {$[0.00]$} \\
\hline
\end{tabular}

Table 7: Correlations of Alphas and Residuals. Panel A details correlations between alphas (defined in (4)) delivered by managed MKT, SMB, HML, WML, CMA, RMW, and SMV. The respective factors are indicated by rows and columns. We also report $p$-values for the null that the correlation is smaller than or equal to zero. In Panel B, we repeat the analysis but, instead of alphas, we employ residuals that result from time series regressions of the one-month excess returns of managed MKT, SMB, HML, WML, CMA, RMW, and SMV, respectively, on the one-month excess returns of the corresponding plain factors and a constant. Rebalancing is performed monthly over the sample period from July 31, 1963 to Nov. 28, 2014 (617 observations). $p$-values are based on the Student's $t$ distribution. Shaded numbers indicate $p$-values smaller than $10 \%$. 


\begin{tabular}{|c|c|c|c|c|c|c|c|c|c|c|c|c|c|c|}
\hline & 1 & 2 & 3 & 4 & 5 & 6 & 7 & 1 & 2 & 3 & 4 & 5 & 6 & 7 \\
\hline & \multicolumn{7}{|c|}{$\begin{array}{c}\text { Panel A: } \\
\text { Alphas / Variance Explained }\end{array}$} & \multicolumn{7}{|c|}{$\begin{array}{c}\text { Panel B: } \\
\text { Residuals / Variance Explained }\end{array}$} \\
\hline & 0.36 & 0.16 & 0.13 & 0.13 & 0.10 & 0.06 & 0.06 & 0.39 & 0.14 & 0.13 & 0.13 & 0.10 & 0.06 & 0.05 \\
\hline & \multicolumn{7}{|c|}{$\begin{array}{c}\text { Panel C: } \\
\text { Alphas / Loadings }\end{array}$} & \multicolumn{7}{|c|}{$\begin{array}{c}\text { Panel D: } \\
\text { Residuals / Loadings }\end{array}$} \\
\hline MKT & 0.33 & 0.11 & 0.29 & 0.67 & -0.55 & -0.19 & 0.02 & 0.33 & -0.15 & 0.55 & 0.37 & -0.64 & -0.14 & 0.04 \\
\hline SMB & 0.22 & -0.21 & -0.91 & 0.13 & -0.22 & -0.04 & -0.14 & 0.25 & -0.05 & -0.75 & 0.55 & -0.20 & -0.02 & -0.16 \\
\hline HML & 0.36 & -0.57 & 0.21 & -0.23 & -0.27 & 0.60 & 0.10 & 0.36 & 0.63 & -0.07 & -0.23 & -0.27 & 0.55 & 0.19 \\
\hline WML & 0.44 & 0.42 & -0.16 & 0.15 & 0.36 & 0.31 & 0.60 & 0.45 & -0.42 & -0.01 & 0.09 & 0.37 & 0.17 & 0.67 \\
\hline CMA & 0.41 & -0.50 & 0.12 & -0.03 & 0.39 & -0.63 & 0.17 & 0.41 & 0.52 & 0.08 & 0.07 & 0.34 & -0.66 & 0.02 \\
\hline RMW & 0.32 & 0.38 & -0.01 & -0.67 & -0.44 & -0.31 & 0.10 & 0.31 & -0.31 & -0.28 & -0.70 & -0.34 & -0.34 & -0.04 \\
\hline SMV & 0.50 & 0.23 & 0.10 & -0.01 & 0.30 & 0.14 & -0.76 & 0.48 & -0.19 & 0.19 & -0.04 & 0.32 & 0.32 & -0.70 \\
\hline
\end{tabular}

Table 8: Principal Component Analysis of Alphas and Residuals. Panels A and C show the results of a principal component analysis of the standardized alphas (defined in (4)) delivered by managed MKT, SMB, HML, WML, CMA, RMW, and SMV. Panels B and D report the corresponding results for the residuals from time series regressions of the excess returns of the managed on the excess returns of the plain factors and a constant. Panels A and B report the variance explained by the principal components 1 to 7 . For the factors indicated by rows, Panel $\mathrm{C}$ and $\mathrm{D}$ report the loadings on the principal components indicated by columns. Rebalancing is performed monthly over the sample period from July 31, 1963 to Nov. 28, 2014 (617 observations). 


\begin{tabular}{rrrrr}
\hline & & \multicolumn{1}{c}{$\begin{array}{c}\text { Panel A: } \\
\text { Investor Sentiment }\end{array}$} \\
\cline { 2 - 4 } & & & & $R^{2}$ \\
\hline int & sent & & 0.00 \\
& 0.01 & -0.12 & & \\
$\widetilde{p}$ & {$[0.79]$} & {$[0.12]$} & & \\
$\widehat{p}$ & {$[0.85]$} & {$[0.16]$} &
\end{tabular}

Panel B:

Equity Factors

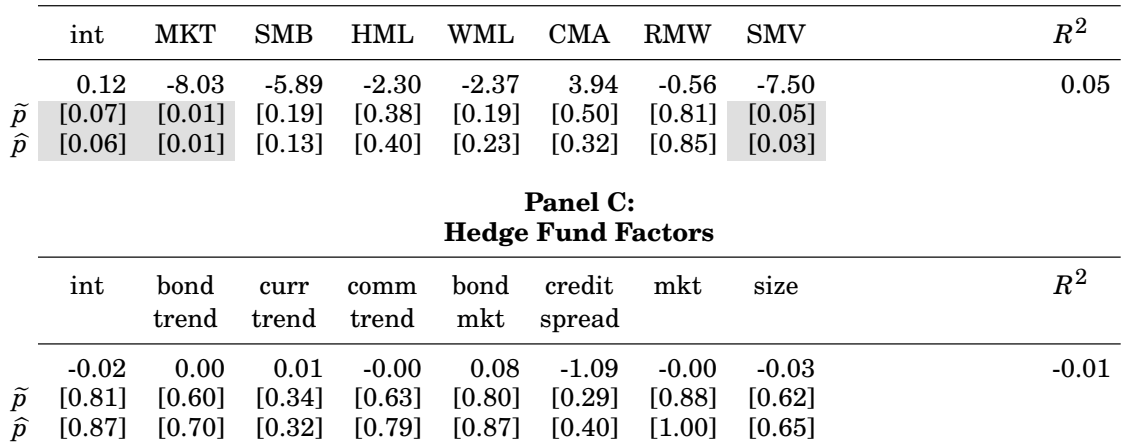

Panel D:

Macro Factors

\begin{tabular}{|c|c|c|c|c|c|c|c|c|c|c|c|}
\hline & int & cons & emp & ism & cpi & $\mathrm{m} 2$ & ip & inc & ted & term & $R^{2}$ \\
\hline & 0.14 & 0.06 & -1.42 & -0.03 & 0.03 & -0.16 & 0.10 & 0.04 & -0.57 & 0.32 & -0.00 \\
\hline$\widetilde{p}$ & [0.49] & {$[0.83]$} & [0.07] & [0.39] & {$[0.80]$} & [0.63] & [0.49] & [0.58] & [0.42] & [0.47] & \\
\hline$\widehat{p}$ & {$[0.28]$} & {$[0.75]$} & [0.02] & {$[0.34]$} & {$[0.91]$} & [0.61] & {$[0.56]$} & {$[0.59]$} & {$[0.30]$} & {$[0.50]$} & \\
\hline
\end{tabular}

Table 9: Linking the First Principal Component of Alphas to Economic Variables. The table shows the results of regressions of the first principal component of the standardized alphas (defined in (4)) delivered by the managed factors on different sets of right-hand side (rhs) variables. In Panel A, the rhs variable is investor sentiment (sent), obtained as an updated version of Equation (3) in Baker and Wurgler (2006). We obtain monthly observations over the sample period ranges from July 30, 1965 to Nov. 28, 2014 (593 observations). In Panel B, we use equity factors, i.e., the monthly excess returns of the plain factors, as explanatory variables. The sample period is from July 31, 1963 to Nov. 28, 2014 (617 observations). In Panel C, we employ hedge fund factors as regressors. These are given by the monthly percentage returns on portfolios of look back straddle options on bonds (bond trend), currency pairs (curr trend), and commodities (comm trend), as well as the monthly change in the percentage yield of 10-year Treasury CMS (bond mkt), and the monthly change in the percentage difference between the yields of Moody's BAA corporate bond and 10-year Treasury CMS (credit spread). Finally, we include the total return of S\&P 500 (mkt) and the difference between the total returns of S\&P 500 and the Russell 2000 (size). We obtain monthly observations over the sample period from Dec. 31, 1993 to Nov. 28, 2014 (252 observations). In Panel D, we consider several macro factors as regressors. These are the monthly percentage changes in real personal consumption expenditures (cons), the number of total nonfarm employees (emp), the ISM manufacturing index (ism), the consumer price index (cpi), the money stock M2 (m2), real industry production (ip), and real disposable personal income (inc). Furthermore, we use monthly changes in the percentage TED spread (ted) and the percentage term spread (term). The sample period is from Dec. 31, 1985 to Nov. 28, 2014 (348 observations). Further information on the economic variables is provided in Appendix C] We report the intercepts (int) and slope coefficients with their respective $p$-values for a two-sided test. $\widetilde{p}$ refers to tests based on the stationary bootstrap suggested by Politis and Romano (1994) with a block length parameter of 12 and 10,000 samples. $\widehat{p}$ indicates that the tests are based on Newey and West (1987). The lag length is computed as in Newey and West (1994). We also report the adjusted $R^{2}$. Shaded cells indicate $p$-values smaller than $10 \%$. 


\begin{tabular}{|c|c|c|c|c|c|c|c|}
\hline & MKT & $\mathrm{SMB}$ & HML & WML & CMA & RMW & SMV \\
\hline & \multicolumn{7}{|c|}{$\begin{array}{c}\text { Panel A: } \\
\text { Plain Factors }\end{array}$} \\
\hline mean (\% p.a.) & 6.11 & 6.17 & 5.85 & 13.34 & 3.70 & 2.29 & 2.98 \\
\hline standard deviation (\% p.a.) & 15.45 & 19.37 & 13.46 & 22.86 & 10.52 & 14.41 & 25.68 \\
\hline Sharpe ratio (p.a.) & 0.40 & 0.32 & 0.43 & 0.58 & 0.35 & 0.16 & 0.12 \\
\hline skewness & -0.54 & 1.49 & 0.41 & -1.18 & 0.35 & 0.43 & -0.50 \\
\hline kurtosis & 4.94 & 9.84 & 4.60 & 10.09 & 5.58 & 7.20 & 7.51 \\
\hline \multirow[t]{2}{*}{ maximum 12 -month drawdown $(\%)$} & 45.78 & 39.21 & 31.14 & 66.95 & 24.79 & 42.26 & 79.15 \\
\hline & \multicolumn{7}{|c|}{$\begin{array}{l}\text { Panel B: } \\
\text { TSFM Factors }\end{array}$} \\
\hline mean (\% p.a.) & 3.79 & 8.47 & 6.03 & 7.37 & 2.19 & 9.79 & 12.73 \\
\hline standard deviation (\% p.a.) & 16.16 & 22.74 & 14.13 & 29.79 & 12.33 & 17.58 & 27.82 \\
\hline Sharpe ratio (p.a.) & 0.23 & 0.37 & 0.43 & 0.25 & 0.18 & 0.56 & 0.46 \\
\hline skewness & 0.75 & -3.72 & 0.67 & 0.17 & -1.23 & 1.59 & 1.48 \\
\hline kurtosis & 14.48 & 46.74 & 8.39 & 21.33 & 23.90 & 24.74 & 24.96 \\
\hline \multirow[t]{2}{*}{ maximum 12 -month drawdown $(\%)$} & 34.07 & 73.83 & 37.27 & 87.17 & 47.17 & 19.13 & 44.54 \\
\hline & \multicolumn{7}{|c|}{$\begin{array}{c}\text { Panel C: } \\
\text { TSFM Versus Plain Factors }\end{array}$} \\
\hline$\Delta$ mean (\% p.a.) & -2.32 & 2.30 & 0.18 & -5.97 & -1.50 & 7.50 & 9.75 \\
\hline$\tilde{p}$ & {$[0.75]$} & {$[0.31]$} & {$[0.47]$} & [0.92] & {$[0.76]$} & {$[0.00]$} & [0.02] \\
\hline$\widehat{p}$ & {$[0.75]$} & {$[0.29]$} & {$[0.47]$} & {$[0.90]$} & {$[0.77]$} & {$[0.01]$} & {$[0.02]$} \\
\hline$\Delta$ Sharpe ratio (p.a.) & -0.16 & 0.05 & -0.01 & -0.34 & -0.17 & 0.40 & 0.34 \\
\hline$\widetilde{p}$ & {$[0.79]$} & [0.39] & {$[0.51]$} & [0.98] & {$[0.80]$} & {$[0.01]$} & [0.02] \\
\hline \multirow[t]{2}{*}{$\widehat{p}$} & {$[0.77]$} & {$[0.40]$} & {$[0.52]$} & {$[0.97]$} & {$[0.83]$} & {$[0.02]$} & [0.03] \\
\hline & \multicolumn{7}{|c|}{$\begin{array}{l}\text { Panel D: } \\
\text { Turnover Metrics }\end{array}$} \\
\hline mean turnover (\% p.m.) & 52.34 & 92.38 & 100.12 & 109.89 & 102.49 & 99.53 & 95.12 \\
\hline
\end{tabular}

Table 10: Summary Statistics on TSFM Factors. We report statistics for plain MKT, SMB, HML, WML, CMA, RMW, and SMV and the corresponding TSFM factors. Rebalancing is performed monthly over the sample period from July 31, 1963 to Nov. 28, 2014 (617 observations). Panel A refers to excess returns of plain portfolios only and contains information on means, standard deviations, skewness, and kurtosis as indicated by rows. We also report Sharpe ratios and the maximum 12-month drawdowns which we obtain as the biggest loss in the product of the one-month excess gross returns over a period of one year. Panel B contains the same information for the TSFM portfolios. Panel C shows statistics based on the TSFM factors and the plain portfolios. Particularly, we report the average alpha (defined in (4) of the TSFM factors relative the respective plain factors (in the rows labeled $\Delta$ mean) together with $p$-values for the null that the average alpha is smaller than or equal to zero. Further, Panel C reports the difference of the Sharpe ratios of the TSFM factors and the respective plain portfolios (as indicated by rows labeled $\Delta$ Sharpe ratio) together with $p$-values for the null that the Sharpe ratio of the TSFM portfolio is smaller than or equal to the Sharpe ratio of the plain portfolio. Panel D presents the average one-way turnover of the TSFM factors, where transaction costs associated with trading the risk-free asset are ignored. $\widetilde{p}$ refers to tests based on the stationary bootstrap suggested by Politis and Romano (1994) with a block length parameter of 12 and 10,000 samples. $\hat{p}$ indicates that the tests on means are based on Newey and West (1987) and that the tests on Sharpe ratios are based on the HAC-approach of Ledoit and Wolf (2008). The lag length is computed as in Newey and West (1994). Shaded numbers indicate $p$-values smaller than $10 \%$. 


\begin{tabular}{|c|c|c|c|c|c|c|c|}
\hline & MKT & SMB & HML & WML & CMA & RMW & SMV \\
\hline & \multicolumn{7}{|c|}{$\begin{array}{c}\text { Panel A: } \\
\text { TSFM Only }\end{array}$} \\
\hline int & 7.59 & 8.71 & 4.56 & 9.90 & 2.82 & 1.78 & 1.88 \\
\hline$\tilde{p}$ & {$[0.00]$} & [0.01] & {$[0.01]$} & {$[0.00]$} & [0.04] & [0.27] & {$[0.52]$} \\
\hline$\widehat{p}$ & {$[0.00]$} & {$[0.00]$} & {$[0.00]$} & {$[0.00]$} & {$[0.02]$} & {$[0.28]$} & {$[0.48]$} \\
\hline TSFM & 0.25 & 0.36 & 0.58 & 0.43 & 0.50 & 0.50 & 0.52 \\
\hline$\widetilde{p}$ & {$[0.00]$} & {$[0.00]$} & {$[0.00]$} & {$[0.00]$} & {$[0.00]$} & {$[0.00]$} & {$[0.00]$} \\
\hline$\widehat{p}$ & {$[0.00]$} & {$[0.00]$} & {$[0.00]$} & {$[0.00]$} & {$[0.00]$} & {$[0.00]$} & {$[0.00]$} \\
\hline \multirow[t]{2}{*}{$R^{2}$} & 0.07 & 0.17 & 0.37 & 0.32 & 0.34 & 0.36 & 0.32 \\
\hline & \multicolumn{7}{|c|}{$\begin{array}{c}\text { Panel B: } \\
\text { TSFM and Plain Factor }\end{array}$} \\
\hline int & 0.12 & 1.75 & 0.57 & -0.93 & 0.00 & 0.46 & 0.15 \\
\hline$\widetilde{p}$ & {$[0.71]$} & {$[0.00]$} & [0.07] & {$[0.10]$} & [0.97] & [0.12] & {$[0.79]$} \\
\hline$\widehat{p}$ & {$[0.70]$} & {$[0.00]$} & {$[0.07]$} & {$[0.10]$} & [0.98] & {$[0.10]$} & {$[0.81]$} \\
\hline PLAIN & 1.01 & 0.91 & 0.78 & 0.81 & 0.80 & 0.78 & 0.81 \\
\hline$\tilde{p}$ & {$[0.00]$} & {$[0.00]$} & {$[0.00]$} & {$[0.00]$} & {$[0.00]$} & {$[0.00]$} & {$[0.00]$} \\
\hline$\widehat{p}$ & {$[0.00]$} & {$[0.00]$} & {$[0.00]$} & {$[0.00]$} & {$[0.00]$} & {$[0.00]$} & {$[0.00]$} \\
\hline TSFM & 0.58 & 0.51 & 0.49 & 0.44 & 0.43 & 0.45 & 0.47 \\
\hline$\tilde{p}$ & {$[0.00]$} & [0.00] & {$[0.00]$} & {$[0.00]$} & [0.00] & {$[0.00]$} & {$[0.00]$} \\
\hline$\widehat{p}$ & {$[0.00]$} & {$[0.00]$} & {$[0.00]$} & {$[0.00]$} & {$[0.00]$} & {$[0.00]$} & {$[0.00]$} \\
\hline$R^{2}$ & 0.98 & 0.98 & 0.98 & 0.98 & 0.98 & 0.98 & 0.97 \\
\hline
\end{tabular}

Table 11: Regressions on TSFM Factors. The table shows the results of regressions of the one-month excess return of the managed MKT, SMB, HML, WML, CMA, RMW, and SMV factors (generated using our benchmark approach) on the one-month excess returns of the corresponding TSFM factor alone (Panel A) and on the one-month excess returns of the corresponding TSFM and plain factor (PLAIN) together (Panel B). We report the regression intercepts multiplied by 12 , expressed in percent, the slope coefficients, as well as the adjusted $R^{2}$. We further show $p$-values for a two-sided test on the coefficients of the regressions. $\widetilde{p}$ refers to tests based on the stationary bootstrap suggested by Politis and Romano (1994) with a block length of 12 and 10,000 bootstrap samples. $\widehat{p}$ denotes $p$-values based on Newey and West (1987). The lag length is computed as in Newey and West (1994). Shaded numbers indicate $p$-values less than $10 \%$. The sample period is from July 31, 1963 to Nov. 28, 2014 (617 observations). 


\begin{tabular}{|c|c|c|c|c|c|c|c|c|c|c|c|c|c|c|}
\hline & MKT & SMB & HML & WML & CMA & RMW & SMV & MKT & SMB & HML & WML & CMA & RMW & SMV \\
\hline & \multicolumn{7}{|c|}{$\begin{array}{c}\text { Panel A: } \\
\text { First Half of Sample }\end{array}$} & \multicolumn{7}{|c|}{$\begin{array}{c}\text { Panel B: } \\
\text { Second Half of Sample }\end{array}$} \\
\hline$\Delta$ mean $(\%$ p.a. $)$ & 2.57 & 7.92 & 1.73 & -0.37 & 0.96 & 1.68 & 6.40 & 2.26 & 3.21 & 2.73 & -0.11 & -0.54 & 7.00 & 4.64 \\
\hline$\widetilde{p}$ & {$[0.04]$} & {$[0.00]$} & {$[0.09]$} & [0.63] & {$[0.08]$} & {$[0.06]$} & {$[0.00]$} & [0.08] & {$[0.09]$} & [0.03] & {$[0.51]$} & {$[0.65]$} & {$[0.00]$} & [0.03] \\
\hline$\widehat{p}$ & {$[0.08]$} & {$[0.00]$} & {$[0.11]$} & {$[0.60]$} & {$[0.10]$} & {$[0.07]$} & {$[0.00]$} & {$[0.09]$} & {$[0.09]$} & {$[0.04]$} & {$[0.51]$} & {$[0.67]$} & {$[0.00]$} & {$[0.04]$} \\
\hline$\Delta$ Sharpe ratio (p.a.) & 0.18 & 0.35 & 0.09 & -0.02 & 0.09 & 0.20 & 0.31 & 0.12 & 0.20 & 0.22 & -0.00 & -0.04 & 0.38 & 0.15 \\
\hline$\tilde{p}$ & {$[0.04]$} & {$[0.00]$} & {$[0.21]$} & {$[0.55]$} & {$[0.10]$} & {$[0.04]$} & {$[0.00]$} & {$[0.17]$} & {$[0.04]$} & [0.03] & {$[0.49]$} & {$[0.63]$} & {$[0.00]$} & {$[0.04]$} \\
\hline \multirow[t]{2}{*}{$\widehat{p}$} & {$[0.07]$} & {$[0.00]$} & {$[0.21]$} & {$[0.58]$} & {$[0.12]$} & {$[0.04]$} & {$[0.00]$} & {$[0.16]$} & {$[0.04]$} & {$[0.04]$} & {$[0.51]$} & {$[0.65]$} & {$[0.00]$} & {$[0.06]$} \\
\hline & \multicolumn{7}{|c|}{$\begin{array}{c}\text { Panel C: } \\
\text { No Recessions }\end{array}$} & \multicolumn{7}{|c|}{$\begin{array}{l}\text { Panel D: } \\
\text { Recessions }\end{array}$} \\
\hline$\Delta$ mean $(\%$ p.a. $)$ & 0.24 & 5.76 & 2.57 & -1.28 & -0.34 & 4.02 & 5.12 & 16.41 & 4.32 & 0.02 & 6.46 & 3.75 & 6.35 & 8.10 \\
\hline$\tilde{p}$ & {$[0.40]$} & {$[0.00]$} & {$[0.01]$} & [0.79] & {$[0.67]$} & {$[0.00]$} & {$[0.00]$} & {$[0.00]$} & [0.17] & {$[0.48]$} & [0.12] & {$[0.01]$} & {$[0.05]$} & [0.03] \\
\hline$\widehat{p}$ & {$[0.42]$} & {$[0.00]$} & {$[0.01]$} & {$[0.79]$} & {$[0.69]$} & {$[0.00]$} & {$[0.00]$} & {$[0.00]$} & {$[0.22]$} & {$[0.50]$} & {$[0.19]$} & {$[0.06]$} & {$[0.07]$} & {$[0.04]$} \\
\hline$\Delta$ Sharpe ratio (p.a.) & -0.02 & 0.30 & 0.22 & -0.06 & -0.02 & 0.33 & 0.21 & 0.79 & 0.22 & -0.04 & 0.19 & 0.17 & 0.20 & 0.20 \\
\hline$\tilde{p}$ & {$[0.61]$} & {$[0.00]$} & {$[0.00]$} & {$[0.67]$} & {$[0.62]$} & {$[0.00]$} & {$[0.00]$} & {$[0.00]$} & {$[0.13]$} & {$[0.59]$} & {$[0.19]$} & [0.09] & {$[0.11]$} & {$[0.06]$} \\
\hline \multirow[t]{2}{*}{$\widehat{p}$} & {$[0.59]$} & {$[0.00]$} & {$[0.01]$} & {$[0.71]$} & {$[0.64]$} & {$[0.00]$} & {$[0.00]$} & {$[0.00]$} & {$[0.16]$} & {$[0.58]$} & {$[0.21]$} & {$[0.21]$} & {$[0.14]$} & {$[0.10]$} \\
\hline & \multicolumn{7}{|c|}{$\begin{array}{c}\text { Panel E: } \\
\text { Long Sample }\end{array}$} & & & & & & & \\
\hline$\Delta$ mean (\% p.a.) & 1.65 & 2.17 & 2.23 & 0.10 & 0.53 & 3.44 & 4.96 & & & & & & & \\
\hline$\tilde{p}$ & {$[0.08]$} & {$[0.05]$} & [0.01] & [0.49] & {$[0.21]$} & {$[0.00]$} & {$[0.00]$} & & & & & & & \\
\hline$\widehat{p}$ & {$[0.07]$} & {$[0.05]$} & {$[0.02]$} & {$[0.47]$} & {$[0.20]$} & {$[0.00]$} & {$[0.00]$} & & & & & & & \\
\hline$\Delta$ Sharpe ratio (p.a.) & 0.09 & 0.09 & 0.17 & 0.00 & 0.05 & 0.26 & 0.19 & & & & & & & \\
\hline$\widetilde{p}$ & {$[0.05]$} & {$[0.01]$} & {$[0.02]$} & {$[0.50]$} & {$[0.22]$} & {$[0.00]$} & {$[0.00]$} & & & & & & & \\
\hline$\widehat{p}$ & {$[0.06]$} & {$[0.02]$} & {$[0.03]$} & {$[0.48]$} & {$[0.21]$} & {$[0.00]$} & {$[0.00]$} & & & & & & & \\
\hline
\end{tabular}

Table 12: Varying the Sample Period. We report statistics for managed and plain MKT, SMB, HML, WML, CMA, RMW, and SMV as indicated by columns. Rebalancing is always monthly. In Panel A, the sample period is from July 31, 1963 to Mar. 31, 1989 (309 observations). In Panel B, the sample period is from Apr. 28, 1989 to Nov. 28, 2014 (308 observations). The sample in Panel C covers our main sample period from July 31, 1963 to Nov. 28, 2014, but excluding the months that are classified as recession period by NBER (534 observations). Panel D then shows the results for the NBER recession months within our main sample from July 31, 1963 to Nov. 28, 2014 (83 observations). In Panel E, the sample periods are from July 31, 1926 to Nov. 28, 2014 (1,061 observations) for MKT, from Jan. 30, 1926 to Nov. 28, 2014 (1,067 observations) for SMB, from July 31, 1963 to Nov. 28, 2014 (617 observations) for HML, from Oct. 30, 1926 to Nov. 28, 2014 (1,058 observations) for WML, from July 31, 1952 to Nov. 28, 2014 (749 observations) for CMA, from July 31, 1951 to Nov. 28, 2014 (761 observations) for RMW, and from July 31, 1928 to Nov. 28, 2014 (1,037 observations) for SMV. The panels report the average alpha defined in (4) (in the rows labeled $\Delta$ mean) together with $p$-values for the null that the average alpha is smaller than or equal to zero. Furthermore, the panels show the difference of the Sharpe ratios of the managed and plain portfolios (as indicated by rows labeled $\Delta$ Sharpe ratio) together with $p$-values for the null that the Sharpe ratio of the managed portfolio is smaller than or equal to the Sharpe ratio of the plain portfolio. $\widetilde{p}$ refers to tests based on the stationary bootstrap suggested by Politis and Romano (1994) with a block length parameter of 12 and 10,000 samples. $\hat{p}$ indicates that the tests on means are based on Newey and West (1987) and that the tests on Sharpe ratios are based on the HAC-approach of Ledoit and Wolf (2008). The lag length is computed as in Newey and West (1994). Shaded numbers indicate $p$-values smaller than $10 \%$. 


\begin{tabular}{|c|c|c|c|c|c|c|c|c|c|c|c|c|c|c|}
\hline & MKT & SMB & HML & WML & CMA & RMW & SMV & MKT & SMB & HML & WML & CMA & RMW & SMV \\
\hline & \multicolumn{7}{|c|}{$\begin{array}{c}\text { Panel A: } \\
\text { Price and Size Filter }\end{array}$} & \multicolumn{7}{|c|}{$\begin{array}{c}\text { Panel B: } \\
\text { NYSE Break Points }\end{array}$} \\
\hline$\Delta$ mean (\% p.a.) & 1.75 & 2.39 & 2.13 & 0.40 & 1.01 & 1.53 & 4.22 & 2.41 & 3.98 & 1.47 & -0.24 & 0.51 & 1.82 & 5.63 \\
\hline$\tilde{p}$ & {$[0.06]$} & {$[0.01]$} & {$[0.01]$} & {$[0.37]$} & {$[0.08]$} & {$[0.02]$} & {$[0.00]$} & {$[0.01]$} & {$[0.00]$} & {$[0.05]$} & {$[0.58]$} & {$[0.23]$} & {$[0.01]$} & {$[0.00]$} \\
\hline$\widehat{p}$ & {$[0.08]$} & {$[0.01]$} & {$[0.02]$} & {$[0.37]$} & [0.09] & {$[0.02]$} & {$[0.00]$} & {$[0.03]$} & {$[0.00]$} & {$[0.06]$} & {$[0.57]$} & {$[0.23]$} & {$[0.01]$} & {$[0.00]$} \\
\hline$\Delta$ Sharpe ratio (p.a.) & 0.12 & 0.24 & 0.17 & 0.02 & 0.09 & 0.14 & 0.20 & 0.16 & 0.27 & 0.12 & -0.01 & 0.05 & 0.17 & 0.26 \\
\hline$\tilde{p}$ & {$[0.08]$} & {$[0.01]$} & {$[0.02]$} & {$[0.38]$} & {$[0.12]$} & {$[0.03]$} & {$[0.00]$} & {$[0.02]$} & {$[0.00]$} & {$[0.07]$} & {$[0.56]$} & {$[0.25]$} & {$[0.01]$} & {$[0.00]$} \\
\hline \multirow[t]{2}{*}{$\widehat{p}$} & [0.09] & {$[0.01]$} & {$[0.04]$} & {$[0.38]$} & {$[0.13]$} & {$[0.03]$} & {$[0.00]$} & [0.03] & {$[0.00]$} & {$[0.08]$} & {$[0.55]$} & {$[0.25]$} & {$[0.01]$} & {$[0.00]$} \\
\hline & \multicolumn{7}{|c|}{$\begin{array}{c}\text { Panel C: } \\
\text { Equal Weighting }\end{array}$} & & \multicolumn{6}{|c|}{$\begin{array}{c}\text { Panel D: } \\
\text { Double-Sorted Factors }\end{array}$} \\
\hline$\Delta$ mean (\% p.a.) & 8.68 & 4.09 & 0.42 & -1.66 & -0.98 & 2.33 & 8.91 & & 1.59 & 1.78 & 0.16 & 0.68 & 2.05 & 3.18 \\
\hline$\tilde{p}$ & {$[0.00]$} & {$[0.01]$} & [0.33] & {$[0.81]$} & {$[0.91]$} & {$[0.02]$} & {$[0.00]$} & & {$[0.02]$} & {$[0.01]$} & {$[0.46]$} & {$[0.06]$} & {$[0.00]$} & {$[0.02]$} \\
\hline$\widehat{p}$ & {$[0.00]$} & {$[0.01]$} & {$[0.34]$} & {$[0.82]$} & {$[0.87]$} & {$[0.05]$} & {$[0.00]$} & & {$[0.02]$} & {$[0.02]$} & {$[0.45]$} & {$[0.09]$} & {$[0.00]$} & {$[0.03]$} \\
\hline$\Delta$ Sharpe ratio (p.a.) & 0.42 & 0.21 & 0.03 & -0.08 & -0.09 & 0.16 & 0.34 & & 0.15 & 0.18 & 0.01 & 0.10 & 0.28 & 0.16 \\
\hline$\tilde{p}$ & {$[0.00]$} & {$[0.00]$} & [0.37] & {$[0.70]$} & {$[0.84]$} & {$[0.04]$} & {$[0.00]$} & & {$[0.04]$} & [0.03] & {$[0.49]$} & {$[0.09]$} & {$[0.00]$} & {$[0.04]$} \\
\hline \multirow[t]{3}{*}{$\widehat{p}$} & {$[0.00]$} & {$[0.00]$} & {$[0.38]$} & {$[0.75]$} & {$[0.90]$} & {$[0.07]$} & {$[0.00]$} & & {$[0.03]$} & {$[0.04]$} & {$[0.46]$} & {$[0.11]$} & {$[0.01]$} & {$[0.07]$} \\
\hline & EAY & CFY & DIY & OMV & FYB & & & & & & & & & \\
\hline & \multicolumn{5}{|c|}{$\begin{array}{l}\text { Panel E: } \\
\text { Stock Characteristics }\end{array}$} & & & & & & & & & \\
\hline$\Delta$ mean (\% p.a.) & 0.85 & 1.48 & 2.63 & 3.60 & 4.40 & & & & & & & & & \\
\hline$\widetilde{p}$ & {$[0.18]$} & {$[0.05]$} & {$[0.00]$} & {$[0.02]$} & {$[0.00]$} & & & & & & & & & \\
\hline$\widehat{p}$ & {$[0.19]$} & {$[0.06]$} & {$[0.01]$} & {$[0.03]$} & {$[0.00]$} & & & & & & & & & \\
\hline$\Delta$ Sharpe ratio (p.a.) & 0.07 & 0.11 & 0.18 & 0.14 & 0.20 & & & & & & & & & \\
\hline$\tilde{p}$ & {$[0.21]$} & {$[0.07]$} & [0.01] & {$[0.05]$} & {$[0.00]$} & & & & & & & & & \\
\hline$\widehat{p}$ & {$[0.22]$} & [0.08] & {$[0.01]$} & {$[0.06]$} & {$[0.01]$} & & & & & & & & & \\
\hline
\end{tabular}

Table 13: Constructing Plain Portfolios in Different Ways. We report statistics for managed and plain MKT, SMB, HML, WML, CMA, RMW, and SMV as indicated by columns. In Panel A, we filter out stocks with prices less than USD 1 in a first step. In a second step, we filter out the smallest stocks up to the point where we drop 10\% of the market equity that remains after the first step. In Panel B, break points are calculated based on stocks traded at NYSE only. In Panel C, the factors are equally weighted. In Panel D, we employ double-sorted factors. We consider SMB-orthogonal HML, WML, CMA, RMW, and SMV as well as HML-, CMA-, and RMW-orthogonal SMB. In Panel E, we form portfolios based on earnings yield (EAY), cash flow yield (CFY), dividend yield (DIY), one-month volatility (OMV), and five-year beta (FYB). Rebalancing is performed monthly over the sample period from July 31, 1963 to Nov. 28, 2014 (617 observations). The panels report the average alpha defined in (4) (in the rows labeled $\Delta$ mean) together with $p$-values for the null that the average alpha is smaller than or equal to zero. Further, the panels show the difference of the Sharpe ratios of the managed and plain portfolios (as indicated by rows labeled $\Delta$ Sharpe ratio) together with $p$-values for the null that the Sharpe ratio of the managed portfolio is smaller than or equal to the Sharpe ratio of the plain portfolio. $\widetilde{p}$ refers to tests based on the stationary bootstrap suggested by Politis and Romano (1994) with a block length parameter of 12 and 10,000 samples. $\widehat{p}$ indicates that the tests on means are based on Newey and West (1987) and that the tests on Sharpe ratios are based on the HAC-approach of Ledoit and Wolf (2008). The lag length is computed as in Newey and West (1994). Shaded numbers indicate $p$-values smaller than $10 \%$. 


\begin{tabular}{|c|c|c|c|c|c|c|c|}
\hline \multirow[b]{3}{*}{$A$ man $(O / n)$} & MKT & SMB & HML & WML & CMA & RMW & SMV \\
\hline & \multicolumn{7}{|c|}{$\begin{array}{l}\text { Panel A: } \\
\text { is and Standard Deviations }\end{array}$} \\
\hline & 2.24 & 4.48 & 1.78 & 0.93 & 0.18 & 4.00 & 5.57 \\
\hline$\tilde{p}$ & {$[0.02]$} & {$[0.00]$} & [0.03] & {$[0.27]$} & {$[0.38]$} & {$[0.00]$} & {$[0.00]$} \\
\hline$\widehat{p}$ & {$[0.03]$} & [0.00] & [0.03] & {$[0.28]$} & {$[0.40]$} & {$[0.00]$} & {$[0.00]$} \\
\hline$\Delta$ Sharpe ratio (p.a.) & 0.14 & 0.23 & 0.13 & 0.04 & 0.02 & 0.28 & 0.22 \\
\hline$\widetilde{p}$ & [0.03] & {$[0.00]$} & {$[0.04]$} & {$[0.31]$} & [0.39] & {$[0.00]$} & {$[0.00]$} \\
\hline \multirow[t]{2}{*}{$\widehat{p}$} & {$[0.04]$} & {$[0.00]$} & {$[0.04]$} & {$[0.33]$} & {$[0.40]$} & {$[0.00]$} & {$[0.00]$} \\
\hline & \multicolumn{7}{|c|}{$\begin{array}{l}\text { Panel B: } \\
\text { AR(1) Residuals }\end{array}$} \\
\hline$\Delta$ mean $(\%$ p.a. $)$ & 2.30 & 4.63 & 2.17 & -0.35 & 0.28 & 4.21 & 4.77 \\
\hline$\widetilde{p}$ & {$[0.02]$} & [0.00] & [0.01] & {$[0.58]$} & [0.34] & {$[0.00]$} & {$[0.00]$} \\
\hline$\widehat{p}$ & {$[0.03]$} & {$[0.00]$} & {$[0.02]$} & {$[0.58]$} & {$[0.35]$} & {$[0.00]$} & {$[0.00]$} \\
\hline$\Delta$ Sharpe ratio (p.a.) & 0.15 & 0.24 & 0.16 & -0.02 & 0.03 & 0.29 & 0.19 \\
\hline$\tilde{p}$ & [0.03] & {$[0.00]$} & [0.03] & {$[0.54]$} & {$[0.36]$} & {$[0.00]$} & [0.00] \\
\hline \multirow[t]{2}{*}{$\widehat{p}$} & {$[0.04]$} & {$[0.00]$} & {$[0.03]$} & {$[0.56]$} & {$[0.35]$} & {$[0.00]$} & [0.01] \\
\hline & \multicolumn{7}{|c|}{$\begin{array}{c}\text { Panel C: } \\
\text { Quantile of the Distribution of } \pi_{t}\end{array}$} \\
\hline$\Delta$ mean $(\%$ p.a. $)$ & 2.46 & 5.63 & 2.30 & -0.43 & 0.24 & 4.49 & 5.75 \\
\hline$\widetilde{p}$ & {$[0.01]$} & {$[0.00]$} & {$[0.01]$} & {$[0.60]$} & {$[0.36]$} & {$[0.00]$} & {$[0.00]$} \\
\hline$\widehat{p}$ & [0.03] & {$[0.00]$} & {$[0.02]$} & {$[0.60]$} & {$[0.37]$} & {$[0.00]$} & {$[0.00]$} \\
\hline$\Delta$ Sharpe ratio (p.a.) & 0.16 & 0.29 & 0.17 & -0.02 & 0.02 & 0.31 & 0.22 \\
\hline$\widetilde{p}$ & {$[0.02]$} & {$[0.00]$} & [0.02] & {$[0.56]$} & {$[0.38]$} & {$[0.00]$} & {$[0.00]$} \\
\hline \multirow[t]{2}{*}{$\widehat{p}$} & {$[0.03]$} & {$[0.00]$} & {$[0.02]$} & {$[0.57]$} & {$[0.37]$} & {$[0.00]$} & [0.00] \\
\hline & \multicolumn{7}{|c|}{$\begin{array}{c}\text { Panel D: } \\
\text { Deleveraged Benchmark Strategy }\end{array}$} \\
\hline$\Delta$ mean $(\%$ p.a. $)$ & 1.58 & 3.36 & 1.51 & 0.53 & 0.26 & 2.66 & 3.35 \\
\hline$\widetilde{p}$ & {$[0.00]$} & {$[0.00]$} & {$[0.00]$} & {$[0.28]$} & {$[0.25]$} & {$[0.00]$} & [0.00] \\
\hline$\widehat{p}$ & {$[0.01]$} & {$[0.00]$} & {$[0.00]$} & {$[0.29]$} & {$[0.26]$} & {$[0.00]$} & {$[0.00]$} \\
\hline$\Delta$ Sharpe ratio (p.a.) & 0.10 & 0.17 & 0.11 & 0.02 & 0.03 & 0.18 & 0.13 \\
\hline$\tilde{p}$ & {$[0.01]$} & {$[0.00]$} & {$[0.00]$} & {$[0.34]$} & [0.28] & {$[0.00]$} & {$[0.00]$} \\
\hline$\widehat{p}$ & {$[0.01]$} & {$[0.00]$} & {$[0.01]$} & {$[0.35]$} & {$[0.26]$} & {$[0.00]$} & {$[0.00]$} \\
\hline
\end{tabular}

Table 14: Constructing Managed Portfolios in Different Ways. We report statistics for managed and plain MKT, SMB, HML, WML, CMA, RMW, and SMV when the managed factors are constructed using an alternative timing signal. In Panel A, we employ the timing signal described by (2), however, we now employ weighted means and standard deviations when we calculate the $z$-score of the last-month excess return. We put more weight on the recent observations and employ an exponential weighting scheme with a half life of 12 months. In Panel B, we replace the timing variable $\pi_{t}$ (defined in (1)) with the latest residual of an out-of-sample AR(1) regression of the monthly excess returns of the plain factor. Panel C shows the results when the quantile from the empirical distribution of the timing variable $\pi_{t}$ is used as the timing signal. At each rebalancing date, the quantile is calculated from the complete history in the sample up to the given point in time. Panel D shows the results for the case when the original timing signal $\Pi_{t}$ is transformed to the new signal $\widehat{\Pi}_{t}$ with $\widehat{\Pi}_{t}=0.5\left(\Pi_{t}+0.5\right.$ ) (which shrinks the original timing signal towards 0.5). Rebalancing is performed monthly over the sample period from July 31, 1963 to Nov. 28, 2014 (617 observations). The panels report the average alpha defined in (4) (in the rows labeled $\Delta$ mean) together with $p$-values for the null that the average alpha is smaller than or equal to zero. Further, the panels show the difference of the Sharpe ratios of the managed and plain portfolios (as indicated by rows labeled $\Delta$ Sharpe ratio) together with $p$-values for the null that the Sharpe ratio of the managed portfolio is smaller than or equal to the Sharpe ratio of the plain portfolio. $\widetilde{p}$ refers to tests based on the stationary bootstrap suggested by Politis and Romano (1994) with a block length parameter of 12 and 10,000 samples. $\widehat{p}$ indicates that the tests on means are based on Newey and West (1987) and that the tests on Sharpe ratios are based on the HAC-approach of Ledoit and Wolf (2008). The lag length is computed as in Newey and West (1994). Shaded numbers indicate $p$-values smaller than $10 \%$. 


\begin{tabular}{|c|c|c|c|c|c|c|c|}
\hline \multirow[b]{3}{*}{ minimum } & MKT & SMB & HML & WML & CMA & RMW & SMV \\
\hline & \multicolumn{7}{|c|}{$\begin{array}{l}\text { Panel A: } \\
\text { the Distribution of } \pi_{t}\end{array}$} \\
\hline & 0.01 & 0.01 & 0.01 & 0.00 & 0.00 & 0.00 & 0.00 \\
\hline first decile & 0.19 & 0.18 & 0.15 & 0.12 & 0.18 & 0.09 & 0.16 \\
\hline median & 1.06 & 0.86 & 0.81 & 0.76 & 0.79 & 0.75 & 0.80 \\
\hline ninth decile & 1.90 & 1.65 & 1.49 & 1.41 & 1.39 & 1.45 & 1.43 \\
\hline maximum & 2.03 & 1.82 & 1.61 & 1.52 & 1.51 & 1.53 & 1.53 \\
\hline mean & 1.04 & 0.89 & 0.81 & 0.76 & 0.78 & 0.77 & 0.79 \\
\hline lard deviation & 0.61 & 0.52 & 0.49 & 0.46 & 0.44 & 0 . & 0.45 \\
\hline ske & -0.05 & 0.08 & 0.02 & 0.03 & -0.01 & 0.02 & 0.00 \\
\hline kurt & 1.74 & 1.88 & 1.75 & 1.74 & 1.81 & 1.61 & 1.80 \\
\hline \multirow[t]{2}{*}{ autocorrelation } & 0.05 & 0.26 & 0.17 & 0.12 & 0.09 & 0.21 & 0.20 \\
\hline & \multicolumn{7}{|c|}{$\begin{array}{l}\text { Panel B: } \\
\text { d Benchmark Strategy }\end{array}$} \\
\hline $\min$ & 0.53 & 0.52 & 0.46 & 0.46 & 0.45 & 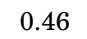 & 0.45 \\
\hline firs & 0.62 & 0.65 & 0.56 & 0.53 & 0.57 & 0.52 & 0.56 \\
\hline med & 1.10 & 0.97 & 0.93 & 0.93 & 0.90 & 0.91 & 0.94 \\
\hline ninth decile & 1.48 & 1.43 & 1.33 & 1.27 & 1.25 & 1.31 & 1.27 \\
\hline maximum & 1.59 & 1.54 & 1.41 & 1.37 & 1.35 & 1.37 & 1.36 \\
\hline mean & 1.08 & 1.00 & 0.93 & 0.92 & 0.91 & 0.91 & 0.92 \\
\hline standard deviation & 0.31 & 0.27 & 0.27 & 0.26 & 0.25 & 0.28 & 0.25 \\
\hline skewness & -0.15 & 0.33 & 0.07 & -0.10 & -0.01 & 0.03 & -0.10 \\
\hline kurt & 1.84 & 2.20 & 1.91 & 2.04 & 1.94 & 1.72 & 1.99 \\
\hline autocorrelation & 0.05 & 0.25 & 0.17 & 0.11 & 0.09 & 0.21 & 0.19 \\
\hline
\end{tabular}

Table 15: Summary Statistics on Exposures. For the exposure $\Pi_{t} c$ of the managed MKT, SMB, HML, WML, CMA, RMW, and SMV factors to the corresponding plain factors (with $\Pi_{t}$ defined in (2)), and $c$ is a constant for the purpose of ex-post position sizing), the table reports various rank statistics along with means, standard deviations, skewness, kurtosis, and first-order autocorrelation. Rebalancing is performed monthly over the sample period from July 31, 1963 to Nov. 28, 2014 (617 observations). Panel A reports the statistics for a strategy that uses the quantile from the empirical distribution of the timing variable $\pi_{t}$ (defined in (1) as the timing signal. At each rebalancing date, the quantile is calculated from the complete history in the sample up to the given point in time. Panel B shows descriptive statistics for the exposures of the managed to the plain factors when the original timing signal $\Pi_{t}$ is transformed to the new signal $\widehat{\Pi}_{t}$ with $\widehat{\Pi}_{t}=0.5\left(\Pi_{t}+0.5\right)$ (which shrinks the original timing signal towards 0.5$)$. 


\begin{tabular}{|c|c|c|c|c|c|c|c|}
\hline & MKT & SMB & HML & WML & CMA & RMW & SMV \\
\hline & \multicolumn{7}{|c|}{$\begin{array}{l}\text { Panel A: } \\
\text { ons on Plain Factors }\end{array}$} \\
\hline int & 3.59 & 6.84 & 3.12 & 2.31 & 0.75 & 4.73 & 5.97 \\
\hline$\widetilde{p}$ & {$[0.00]$} & {$[0.00]$} & {$[0.00]$} & {$[0.30]$} & {$[0.30]$} & [0.00] & {$[0.00]$} \\
\hline$\widehat{p}$ & {$[0.01]$} & {$[0.00]$} & {$[0.00]$} & {$[0.31]$} & {$[0.26]$} & [0.00] & {$[0.00]$} \\
\hline PLAIN & 0.81 & 0.79 & 0.85 & 0.81 & 0.85 & 0.83 & 0.85 \\
\hline$\widetilde{p}$ & {$[0.00]$} & {$[0.00]$} & {$[0.00]$} & {$[0.00]$} & {$[0.00]$} & [0.00] & {$[0.00]$} \\
\hline$\widehat{p}$ & {$[0.00]$} & {$[0.00]$} & {$[0.00]$} & {$[0.00]$} & {$[0.00]$} & {$[0.00]$} & {$[0.00]$} \\
\hline \multirow[t]{2}{*}{$R^{2}$} & 0.65 & 0.63 & 0.72 & 0.65 & 0.73 & 0.68 & 0.72 \\
\hline & \multicolumn{7}{|c|}{$\begin{array}{c}\text { Panel B: } \\
\text { Regressions on Other Managed Factors }\end{array}$} \\
\hline int & 3.05 & 6.74 & 2.09 & -1.70 & 0.48 & 5.29 & 3.23 \\
\hline$\tilde{p}$ & {$[0.00]$} & {$[0.00]$} & [0.04] & {$[0.38]$} & {$[0.56]$} & [0.00] & {$[0.05]$} \\
\hline$\widehat{p}$ & {$[0.02]$} & {$[0.00]$} & {$[0.02]$} & {$[0.37]$} & [0.48] & {$[0$.} & {$[0.02]$} \\
\hline VAR & 0.61 & 0.32 & 0.04 & 0.29 & 0.17 & 0.14 & 0.17 \\
\hline$\tilde{p}$ & {$[0.00]$} & {$[0.00]$} & [0.47] & {$[0.00]$} & {$[0.00]$} & [0.08] & {$[0.05]$} \\
\hline$\widehat{p}$ & {$[0.00]$} & {$[0.00]$} & [0.37] & {$[0.00]$} & {$[0.00]$} & [0.05] & {$[0.01]$} \\
\hline VAL & 0.11 & -0.07 & 0.44 & 0.15 & 0.19 & 0.31 & -0.12 \\
\hline$\tilde{p}$ & {$[0.06]$} & [0.84] & {$[0.00]$} & {$[0.30]$} & [0.04] & [0.03] & {$[0.38]$} \\
\hline$\widehat{p}$ & {$[0.14]$} & {$[0.68]$} & {$[0.00]$} & {$[0.13]$} & {$[0.01]$} & {$[0.01]$} & {$[0.23]$} \\
\hline SENT & 0.23 & 0.36 & 0.27 & 0.45 & 0.13 & -0.00 & 0.69 \\
\hline$\tilde{p}$ & {$[0.00]$} & {$[0.16]$} & {$[0.00]$} & {$[0.00]$} & [0.22] & [0.85] & {$[0.00]$} \\
\hline$\widehat{p}$ & {$[0.00]$} & [0.04] & {$[0.01]$} & {$[0.00]$} & [0.31] & [0.98] & {$[0.00]$} \\
\hline DISP & -0.09 & 0.27 & 0.17 & -0.01 & 0.45 & 0.43 & 0.16 \\
\hline$\tilde{p}$ & [0.17] & [0.02] & [0.09] & [0.95] & {$[0.00]$} & [0.17] & {$[0.28]$} \\
\hline$\widehat{p}$ & {$[0.20]$} & {$[0.01]$} & [0.12] & {$[0.91]$} & {$[0.00]$} & [0.05] & {$[0.22]$} \\
\hline \multirow[t]{2}{*}{$R^{2}$} & 0.68 & 0.62 & 0.72 & 0.65 & 0.71 & 0.66 & 0.74 \\
\hline & \multicolumn{7}{|c|}{ Panel C } \\
\hline$\triangle \mathrm{MPPM}$ & 253 & 558 & 225 & -539 & 21 & 450 & 506 \\
\hline
\end{tabular}

Table 16: Varying the Performance Metric. We report statistics for managed and plain MKT, SMB, HML, WML, CMA, RMW, and SMV as indicated by columns. Rebalancing is performed monthly over the sample period from July 31, 1963 to Nov. 28, 2014 (617 observations) in Panels A and C and from July 30, 1965 to Nov. 28, 2014 (593 observations) in Panel B. In Panels A and B, we report results for time series regressions. The left-hand side variable is the one-month excess return of managed MKT, SMB, HML, WML, CMA, RMW, and SMV, respectively. In Panel A, we employ the one-month excess return of the corresponding plain factor (PLAIN) as the right-hand side variable. In Panel B, we use the respective one-month excess returns of well-known timing strategies as regressors. We consider factor management based on variance (VAR), valuation (VAL), investor sentiment (SENT), and dispersion (DISP) with timing variables defined in (6), (7), (8), and (9), respectively. We report the regression intercepts multiplied by 12, expressed in percent. Panels A and B also contain information on the slope coefficients as well as the adjusted $R$-Squared denoted by $R^{2}$. Further, we show $p$-values for a two-sided test on the coefficients of the regressions. $\widetilde{p}$ refers to tests based on the stationary bootstrap suggested by Politis and Romano (1994) with a block length parameter of 12 and 10,000 samples. $\widehat{p}$ indicates that the tests are based on Newey and West (1987). The lag length is computed as in Newey and West (1994). Shaded numbers indicate $p$-values smaller than $10 \%$. In Panel $\mathrm{C}$, we calculate the manipulation-proof performance measure of Goetzmann et al. (2007) for an investor's degree of risk aversion as high as three. We report the differences of the manipulation-proof performance measures for the managed and the corresponding plain factors. 


\begin{tabular}{|c|c|c|c|c|c|c|c|c|c|c|c|c|}
\hline & MKT & SMB & HML & WML & CMA & RMW & MKT & SMB & HML & WML & CMA & RMW \\
\hline & \multicolumn{6}{|c|}{$\begin{array}{c}\text { Panel A: } \\
\text { Asia-Pacific Ex Japan }\end{array}$} & \multicolumn{6}{|c|}{$\begin{array}{l}\text { Panel B: } \\
\text { Europe }\end{array}$} \\
\hline$\Delta$ mean (\% p.a.) & 3.64 & 2.96 & -0.69 & 4.03 & 0.14 & 1.63 & 3.11 & 0.06 & 3.26 & 4.41 & 2.28 & 0.76 \\
\hline$\widetilde{p}$ & {$[0.08]$} & {$[0.00]$} & {$[0.76]$} & [0.02] & {$[0.49]$} & {$[0.02]$} & [0.09] & {$[0.46]$} & {$[0.00]$} & {$[0.00]$} & {$[0.00]$} & [0.09] \\
\hline$\widehat{p}$ & {$[0.09]$} & {$[0.00]$} & {$[0.76]$} & {$[0.05]$} & {$[0.45]$} & {$[0.02]$} & {$[0.08]$} & {$[0.47]$} & {$[0.01]$} & {$[0.01]$} & {$[0.01]$} & {$[0.08]$} \\
\hline$\Delta$ Sharpe ratio (p.a.) & 0.17 & 0.29 & -0.06 & 0.26 & 0.02 & 0.17 & 0.18 & 0.01 & 0.39 & 0.31 & 0.35 & 0.15 \\
\hline$\tilde{p}$ & {$[0.08]$} & {$[0.00]$} & {$[0.80]$} & [0.12] & [0.49] & {$[0.04]$} & [0.12] & [0.47] & [0.02] & [0.04] & [0.01] & [0.07] \\
\hline \multirow[t]{2}{*}{$\widehat{p}$} & {$[0.11]$} & {$[0.00]$} & {$[0.76]$} & {$[0.16]$} & {$[0.45]$} & {$[0.03]$} & [0.10] & {$[0.47]$} & {$[0.02]$} & {$[0.03]$} & [0.01] & [0.06] \\
\hline & \multicolumn{6}{|c|}{$\begin{array}{c}\text { Panel C: } \\
\text { Global }\end{array}$} & \multicolumn{6}{|c|}{$\begin{array}{c}\text { Panel D: } \\
\text { Global Ex US }\end{array}$} \\
\hline$\Delta$ mean (\% p.a.) & 2.28 & 0.18 & 2.42 & 3.22 & 1.34 & 0.54 & 3.21 & 0.24 & 2.64 & 3.90 & 2.60 & 0.59 \\
\hline$\tilde{p}$ & {$[0.12]$} & {$[0.38]$} & {$[0.00]$} & {$[0.03]$} & {$[0.04]$} & {$[0.10]$} & {$[0.05]$} & [0.35] & {$[0.01]$} & {$[0.01]$} & [0.02] & [0.05] \\
\hline$\widehat{p}$ & {$[0.11]$} & [0.39] & {$[0.01]$} & {$[0.05]$} & {$[0.06]$} & {$[0.11]$} & {$[0.05]$} & [0.36] & {$[0.01]$} & {$[0.02]$} & {$[0.02]$} & [0.05] \\
\hline$\Delta$ Sharpe ratio (p.a.) & 0.15 & 0.03 & 0.30 & 0.23 & 0.20 & 0.11 & 0.20 & 0.03 & 0.35 & 0.31 & 0.40 & 0.13 \\
\hline$\tilde{p}$ & [0.17] & [0.37] & [0.03] & {$[0.06]$} & {$[0.06]$} & [0.14] & {$[0.08]$} & [0.37] & [0.03] & [0.03] & [0.03] & [0.05] \\
\hline \multirow[t]{2}{*}{$\widehat{p}$} & {$[0.13]$} & {$[0.39]$} & {$[0.06]$} & {$[0.07]$} & {$[0.09]$} & {$[0.18]$} & {$[0.06]$} & {$[0.37]$} & {$[0.05]$} & {$[0.04]$} & [0.02] & [0.07] \\
\hline & \multicolumn{6}{|c|}{$\begin{array}{l}\text { Panel E: } \\
\text { Japan }\end{array}$} & \multicolumn{6}{|c|}{$\begin{array}{c}\text { Panel F: } \\
\text { North America }\end{array}$} \\
\hline$\Delta$ mean (\% p.a.) & 4.76 & 0.94 & 1.46 & 2.02 & 1.44 & 0.29 & 1.37 & -0.26 & 1.77 & 1.48 & -0.11 & 1.54 \\
\hline$\tilde{p}$ & {$[0.00]$} & {$[0.15]$} & {$[0.07]$} & {$[0.10]$} & {$[0.13]$} & {$[0.31]$} & {$[0.26]$} & [0.62] & {$[0.08]$} & {$[0.21]$} & [0.54] & [0.04] \\
\hline$\widehat{p}$ & {$[0.01]$} & {$[0.19]$} & {$[0.10]$} & {$[0.13]$} & {$[0.14]$} & {$[0.32]$} & {$[0.24]$} & {$[0.60]$} & {$[0.10]$} & {$[0.23]$} & {$[0.55]$} & [0.07] \\
\hline$\Delta$ Sharpe ratio (p.a.) & 0.24 & 0.08 & 0.15 & 0.13 & 0.17 & 0.04 & 0.09 & -0.03 & 0.15 & 0.09 & -0.01 & 0.18 \\
\hline$\tilde{p}$ & {$[0.00]$} & {$[0.17]$} & {$[0.11]$} & {$[0.11]$} & {$[0.16]$} & {$[0.34]$} & [0.29] & [0.56] & {$[0.12]$} & {$[0.25]$} & {$[0.52]$} & [0.11] \\
\hline$\widehat{p}$ & {$[0.00]$} & {$[0.20]$} & {$[0.14]$} & {$[0.14]$} & {$[0.15]$} & {$[0.33]$} & {$[0.26]$} & {$[0.60]$} & {$[0.15]$} & {$[0.25]$} & [0.55] & {$[0.15]$} \\
\hline
\end{tabular}

Table 17: International Evidence. We report statistics for managed and plain MKT, SMB-orthogonal HML, WML, CMA, and RMW, as well as HML-, CMA-, and RMW-orthogonal SMB as indicated by columns. The different panels refer to different equity universes within global developed markets. Rebalancing is performed monthly over the sample period from Nov. 30, 1990 to Nov. 28, 2014 (289 observations). The panels report the average alpha defined in (4) (in the rows labeled $\Delta$ mean) together with $p$-values for the null that the average alpha is smaller than or equal to zero. Further, the panels show the difference of the Sharpe ratios of the managed and plain portfolios (as indicated by rows labeled $\Delta$ Sharpe ratio) together with $p$-values for the null that the Sharpe ratio of the managed factor is smaller than or equal to the Sharpe ratio of the plain factor. $\widetilde{p}$ refers to tests based on the stationary bootstrap suggested by Politis and Romano (1994) with a block length parameter of 12 and 10,000 samples. $\widehat{p}$ indicates that the tests on means are based on Newey and West (1987) and that the tests on Sharpe ratios are based on the HAC-approach of Ledoit and Wolf (2008). The lag length is computed as in Newey and West (1994). Shaded numbers indicate $p$-values smaller than $10 \%$. 


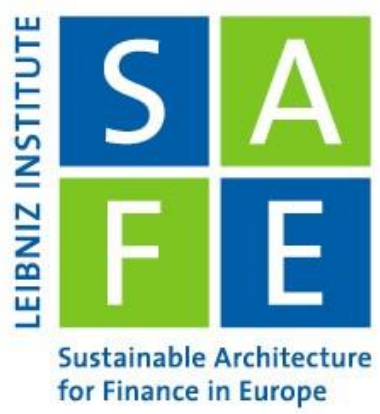

\section{Recent Issues}

No. 316 Christian Mücke, Loriana Pelizzon, Vincenzo Pezone, Anjan Thako

No. 315 Kevin Bauer, Moritz von Zahn, Oliver Hinz

No. 314 Farshid Abdi, Mila Getmansky Sherman, Emily Kormanyos, Loriana Pelizzon, Zorka Simon

No. 313 Kevin Bauer, Andrej Gill

No. 312 Can Gao lan Martin

No. 311 Wenhui Li, Christian Wilde

No. 310 Carmelo Latino, Loriana Pelizzon, Aleksandra Rzeźnik

No. 309 Tabea Bucher-Koenen, Andreas Hackethal, Johannes Koenen, Christine Laudenbach

No. 308 Thomas Pauls

No. 307 Ester Faia, Andreas Fuster, Vincenzo Pezone, Basit Zafar

No. 306 Aljoscha Janssen, Johannes Kasinger

No. 305 Sabine Bernard, Benjamin Loos, Martin Weber

No. 304 Monica Billio, Andrew W. Lo, Loriana Pelizzon, Mila Getmansky Sherman, Abalfazl Zareei

No. 303 Ankit Kalda, Benjamin Loos, Alessandro Previtero, Andreas Hackethal
The Carrot and the Stick: Bank Bailouts and the Disciplining Role of Board Appointments

Expl(Al)ned: The Impact of Explainable Artificial Intelligence on Cognitive Processes

A Modern Take on Market Efficiency: The Impact of Trump's Tweets on Financial Markets

Mirror, Mirror on the Wall: Machine Predictions and Self-Fulfilling Prophecies

Volatility, Valuation Ratios, and Bubbles: An Empirical Measure of Market Sentiment

Separating the Effects of Beliefs and Attitudes on Pricing under Ambiguity

The Power of ESG Ratings on Stock Markets

Gender Differences in Financial Advice

The Impact of Temporal Framing on the Marginal Propensity to Consume

Biases in Information Selection and Processing: Survey Evidence from the Pandemic

Obfuscation and Rational Inattention in Digitalized Markets

The Disposition Effect in Boom and Bust Markets

Global Realignment in Financial Market Dynamics: Evidence from ETF Networks

Smart (Phone) Investing? A Within Investor-Time Analysis of New Technologies and Trading Behavior 